Aus der Klinik für Nephrologie und Rheumatologie

(Prof. Dr. med. G. A. Müller)

der Medizinischen Fakultät der Universität Göttingen

\title{
Die Rolle der endothelialen Progenitorzellen bei Patienten mit axialer Spondylarthropathie
}

\author{
INAUGURAL-DISSERTATION \\ zur Erlangung des Doktorgrades \\ der Medizinischen Fakultät \\ der Georg-August-Universität zu Göttingen \\ vorgelegt von \\ Maria Elisabeth Vogt, geb. Struve \\ aus \\ Frankfurt an der Oder
}

Göttingen 2018 
Dekan:

Referentin:

Ko-Referent/in:

Drittreferent/in:

Datum der mündlichen Prüfung: 12. Juni 2019
Prof. Dr. rer. nat. H. K. Kroemer

Priv.-Doz. Dr. med. Susann Patschan

Prof. Dr. med. Rotraut Mößner

Prof. Dr. med. Margarete Schöm 
Hiermit erkläre ich, die Dissertation mit dem Titel „Die Rolle der endothelialen Progenitorzellen bei Patienten mit axialer Spondylarthropathie“ eigenständig angefertigt und keine anderen als die von mir angegebenen Quellen und Hilfsmittel verwendet zu haben.

Osnabrück, den 


\section{Inhalt}

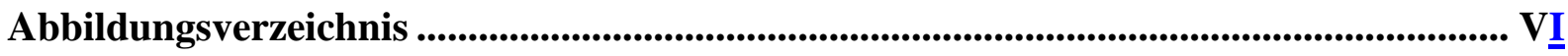

Tabellenverzeichnis ............................................................................................................... VII

Abkürzungsverzeichnis ............................................................................................. VIII

1. Einführung und Zielsetzung...............................................................................................1

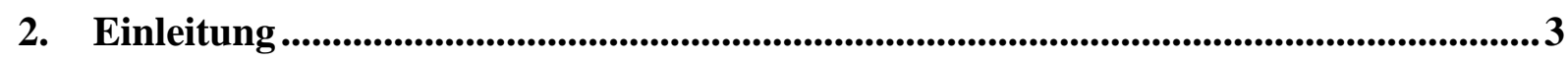

$2.1 \quad$ Spondyloarthritiden und axiale Spondylarthropathie .......................................... 3

2.2 Definition und Geschichte ........................................................................ 4

$2.3 \quad$ Epidemiologie / Krankheitsverlauf ................................................................. 4

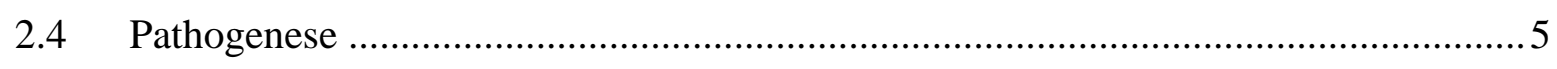

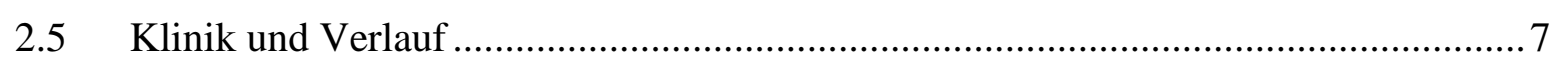

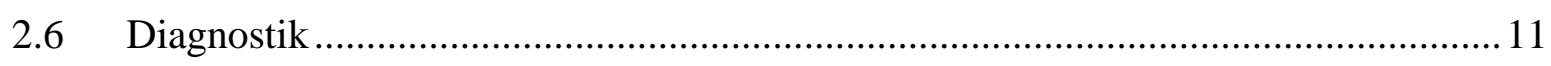

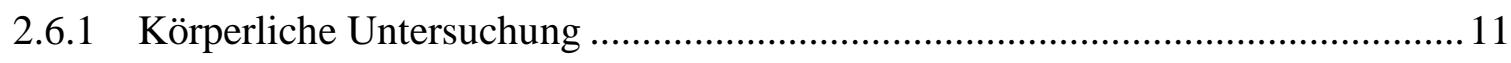

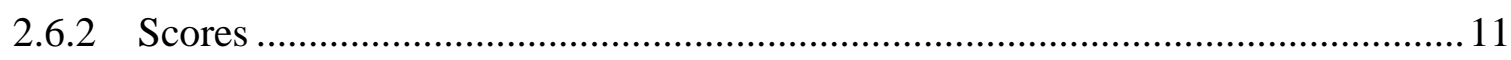

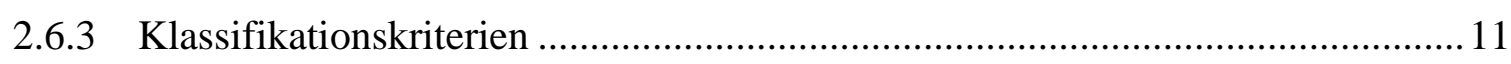

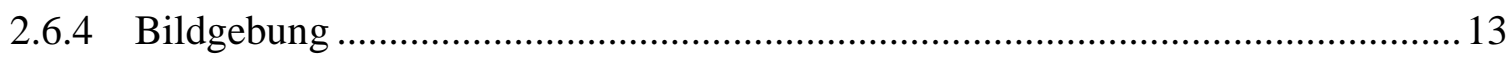

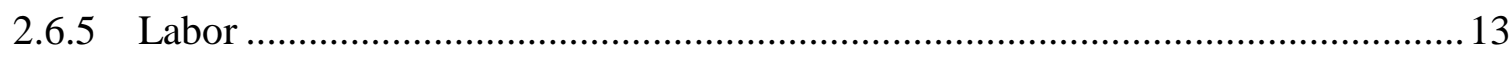

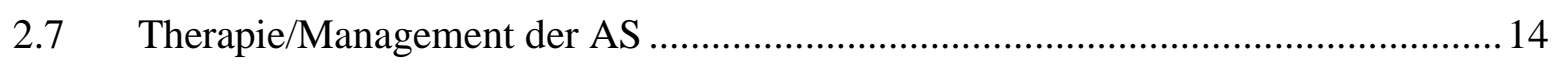

2.8 Atherosklerose / kardiovaskuläres Risiko bei Patienten mit axSpA........................ 16

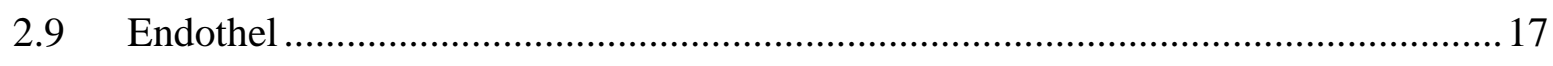

2.10 Vaskulogenese und Angiogenese …......................................................... 18

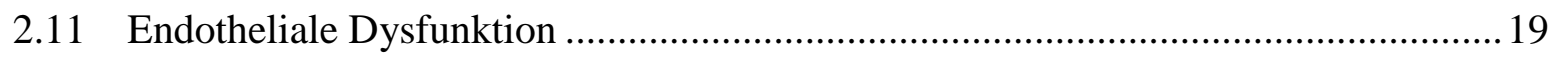

2.12 Endotheliale Progenitorzellen - Übersicht ...................................................... 19

2.13 Experimentelle Beschreibung; Isolierung und Kultivierung …..............................23

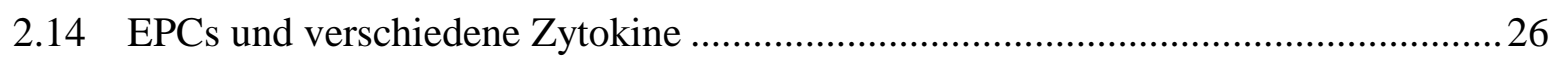

2.15 Weitere Stimulanzien und inhibierende Faktoren auf die EPC-Anzahl ...................29

2.16 EPCs im Rahmen pathologischer Zustände - Stand der Forschung .......................... 30

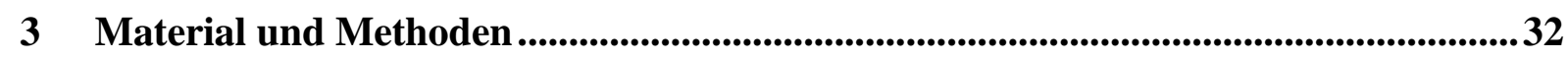

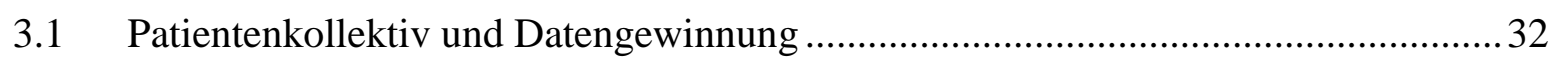

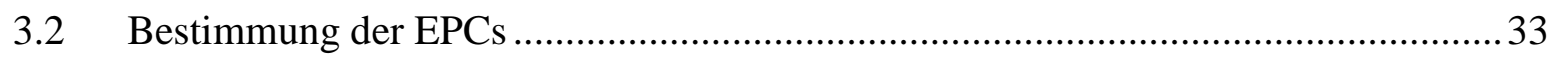

3.3 Scores und klinische Untersuchungsmethoden ............................................. 40 


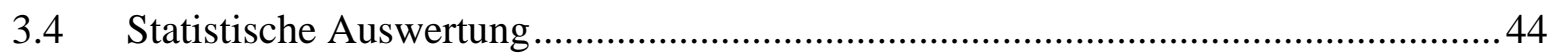

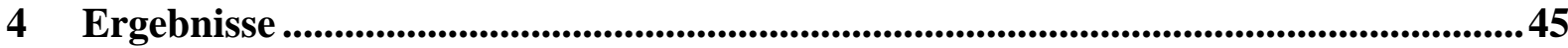

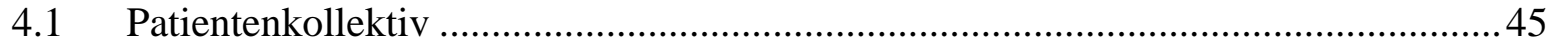

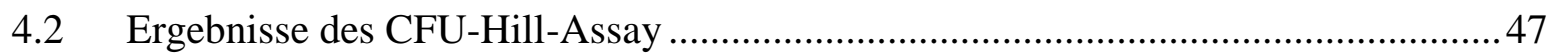

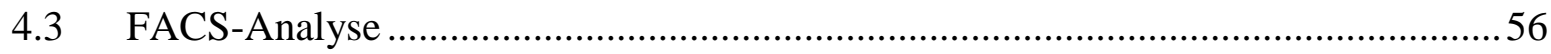

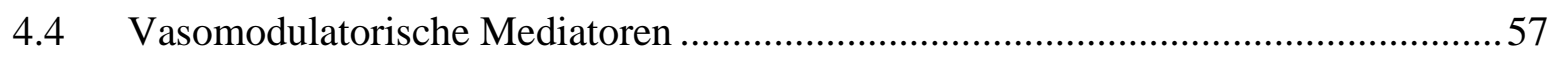

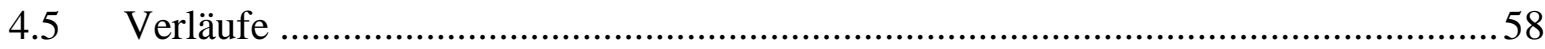

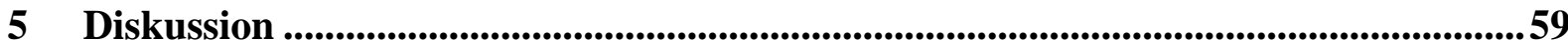

6 Zusammenfassung ......................................................................................................................67

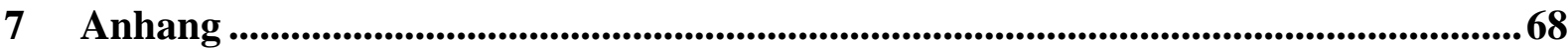

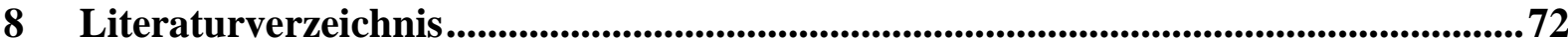




\section{Abbildungsverzeichnis}

Abbildung 1: Definitionen des entzündlichen Rückenschmerzes

Abbildung 2: Einteilung der radiologisch darstellbaren sakroiliakalen Veränderungen zur Verwendung in den modifizierten New-York-Kriterien

Abbildung 3: Modifizierte New-York-Kriterien für die Spondylitis ankylosans von 1984

Abbildung 4: ASAS-Klassifikationskriterien für die axSpA

Abbildung 5: Verschiedene EPC-Subtypen und deren Eigenschaften

Abbildung 6: Festlegen des gewünschten Messbereiches am FACScalibur (gating)

Abbildung 7: CFU-Hill-Assay, Kolonien an Tag 6, Bild 1

Abbildung 8: CFU-Hill-Assay, Kolonien an Tag 6, Bild 2

Abbildung 9: Schematische Darstellung Schober- und Ott-Maß

Abbildung 10: Schematische Darstellung Wirbelsäulen-Seitneigung

Abbildung 11: Schematische Darstellung Tragus-Wand-Abstand

Abbildung 12: Signifikanter Unterschied der Anzahl der CFU-ECs zwischen Patienten- und Kontrollgruppe

Abbildung 13: Signifikanter Unterschied der Anzahl der CFU-ECs der Männer versus der Anzahl der CFU-ECs der Frauen

Abbildung 14: Scatterplot zu dem Zusammenhang zwischen Anzahl der CFU-ECs und dem Patientenalter am Untersuchungstag

Abbildung 15: Scatterplot zu dem Zusammenhang zwischen Anzahl der CFU-ECs und der Erkrankungsdauer

Abbildung 16: Anzahl der CFU-ECs, eingeteilt nach dem BASDAI

Abbildung 17: Anzahl der CFU-ECs, eingeteilt nach Begleiterkrankungen

Abbildung 18: Anzahl der CFU-ECs, eingeteilt nach dem Nikotinkonsum

Abbildung 19: cEPCs (in \%) bei Patienten und Kontrollgruppe

Abbildung 20: cEPCs eingeteilt nach dem Geschlecht

Abbildung 21: Verlaufskontrolle nach einem mittleren Zeitraum von 33,2 $\pm 1,9$ Monaten 


\section{Tabellenverzeichnis}

Tabelle 1: Liste der verwendeten Verbrauchsmaterialien 38

Tabelle 2: Zusammenfassung der verwendeten Instrumente/Geräte 39

Tabelle 3: Liste der verwendeten Reagenzien 39

Tabelle 4: Deskriptive Statistik grundlegender Charakteristika des Patientenkollektivs 46

Tabelle 5: Klinische Messwerte zur Beurteilung der Wirbelsäulenbeweglichkeit

/des Krankheitsverlaufs 46

Tabelle 6: Deskriptive Statistik für die Anzahl der CFU-ECs in der Patientengruppe $\begin{array}{ll}\text { und Kontrollgruppe } & 47\end{array}$

Tabelle 7: Auflistung der p-Werte für die Anzahl der CFU-ECs, eingeteilt nach verschiedenen Variablen / Merkmalen 48

Tabelle 8: Deskriptive Statistik für die Anzahl der CFU-ECs, eingeteilt nach dem Geschlecht

Tabelle 9: Deskritptive Statistik für die Anzahl der CFU-ECs, eingeteilt nach dem ASDAS 


\section{Abkürzungsverzeichnis}

\begin{tabular}{|c|c|c|}
\hline acLDL & $=$ & acetylated low-densitiy lipoprotein \\
\hline Ankylose & $=$ & vollständige Gelenkversteifung \\
\hline AS & $=$ & ankylosierende Spondylitis = Morbus Bechterew \\
\hline ASAS & $=$ & Assessment of SpondyloArthritis international Society \\
\hline ASDAS & $=$ & Ankylosing Spondylitis Disease Activity Score \\
\hline $\operatorname{axSpA}$ & $=$ & axiale Spondylarthropathie \\
\hline BASDAI & $=$ & Bath Ankylosing Spondylitis Disease Index \\
\hline BASFI & $=$ & Bath Ankylosing Spondylitis Functional Index \\
\hline BASG & $=$ & Bath Ankylosing Spondylitis Global Score \\
\hline BASMI & $=$ & Bath Ankylosing Spondylitis Metrology Index \\
\hline BSA & $=$ & bovine serum albumin \\
\hline BSG & $=$ & Blutsenkungsgeschwindigkeit \\
\hline CAC & $=$ & circulating angiogenic cell \\
\hline $\mathrm{CD}$ & $=$ & cluster of differentiation \\
\hline CEC & $=$ & circulating endothelial cell, zirkulierende Endothelzellen \\
\hline CED & $=$ & chronisch entzündliche Darmerkrankung \\
\hline $\mathrm{CFU}$ & $=$ & colony forming unit \\
\hline CFU-EC & $=$ & colony forming unit-endothelial cell \\
\hline $\mathrm{CPC}$ & $=$ & circulating progenitor cell \\
\hline CRP & $=$ & C-reaktives Protein \\
\hline DMARD & $=$ & disease-modifying antirheumatic drug \\
\hline ECFC & $=$ & endothelial colony-forming cell \\
\hline ELISA & $=$ & Enzyme-linked Immunosorbent Assay \\
\hline Enthesitis & $=$ & Entzündung im Bereich von Sehnen-, Bänder- oder Kapselansätzen \\
\hline $\mathrm{EC}$ & $=$ & Endothelzellen \\
\hline eCFC & $=$ & late outgrowths EPC \\
\hline EPC & $=$ & endothelial progenitor cell \\
\hline
\end{tabular}




\begin{tabular}{|c|c|c|}
\hline ESSG & $=$ & European Spondyloarthropathy Study Group \\
\hline FACS & $=$ & fluorescence-activated cell sorting \\
\hline FBA & $=$ & Finger-Boden-Abstand \\
\hline FLK-1 & $=$ & 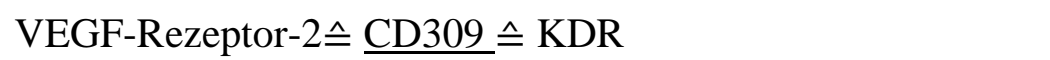 \\
\hline HDL & $=$ & high density lipoprotein \\
\hline HLA & $=$ & humanes Leukozyten-Antigen \\
\hline HSC & $=$ & hämatopoetische Stammzelle \\
\hline IL-6 & $=$ & Interleukin-6 \\
\hline KDR & $=$ & kinase insert domain receptor \\
\hline KHK & $=$ & koronare Herzkrankheit \\
\hline LDL & $=$ & low density lipoprotein \\
\hline LWS & $=$ & Lendenwirbelsäule \\
\hline $\mathrm{MC}$ & $=$ & myeloische Stammzelle \\
\hline MRT & $=$ & Magnetresonanztomographie \\
\hline NO & $=$ & Stickstoffmonoxid \\
\hline NSAR & $=$ & nichtsteroidale Antirheumatika \\
\hline nr-axSpA & $=$ & non-radiographic axial spondyloarthritis \\
\hline PBS & $=$ & phosphate-buffered saline \\
\hline PDGF & $=$ & platelet derived growth factor \\
\hline PPI & $=$ & Protonenpumpeninhibitoren \\
\hline RA & $=$ & rheumatoide Arthritis \\
\hline SDF-1 & $=$ & stromal cell derived factor $1 a$ \\
\hline $\mathrm{SpA}$ & $=$ & Spondyloarthritis, Spondyloarthropathie, Spondylarthropathie \\
\hline TGF & $=$ & transforming growth factor \\
\hline TPC & $=$ & tissue resident progenitor cell \\
\hline VEGF & $=$ & vascular endothelial growth factor \\
\hline
\end{tabular}




\section{Einführung und Zielsetzung}

„Apes, cattle, horses, the giant wolf (...) and dinosaurs have all left evidence in their skeletons of an ankylosing spondylitis which in their lifetime thousands of years ago must surely have severely limited their movement and caused them considerable pain." So beschrieb der Wissenschaftler Moody seine Beobachtungen bereits im Jahre 1923 (Moody 1923). Aktuelle Untersuchungen gehen von einer deutlich höheren Prävalenz der Gruppe der Spondyloarthritiden (bis zu 2\%) gegenüber der rheumatoiden Arthritis aus. Damit gehört die nr-axSpA zu den häufigsten rheumatischen Erkrankungen.

Mittlerweile stehen verschiedenste Therapiemöglichkeiten zur Verfügung. Das Wissen um die Erkrankung wächst stetig, eine Kontrolle der Grunderkrankung unter medikamentöser Therapie kann erreicht werden, ein vollständige Heilung jedoch weiterhin nicht.

Die Wissenschaft hat in den letzten Jahren weitere Aspekte der Erkrankung zutage gebracht. Dazu gehört unter anderem ein lebenslang erhöhtes Atheroskleroserisiko. Dieses ist bei axSpA-Patienten für kardiovaskuläre Ereignisse um 30-50 \% erhöht. Der genaue Pathomechanismus hierfür ist bisher jedoch nicht bekannt (van der Horst-Bruinsma und Nurmohamed 2012; Gherghe et al. 2015).

An den Pathomechanismen der Atherosklerose setzt auch die aktuelle Forschung zu endothelialen Progenitorzellen an. Diese seit einigen Jahren intensiv untersuchten Zellen haben ihren Platz unter anderem in der Förderung der Vaskulogenese, aber auch in der Instandhaltung von Blutgefäßen, insbesondere unter pathologischen Umständen. Sie haben Einfluss auf den Beginn und Fortschritt der Atherosklerose (Khakoo und Finkel 2005; Zhang et al. 2013). Bei verschiedensten vaskulären Erkrankungen, wie etwa der rheumatoiden Arthritis, der Psoriasisarthritis oder dem Lupus erythematodes, die auch mit einem erhöhten Atheroskleroserisiko einhergehen, wurden diese Zellen bereits untersucht und Einschränkungen in ihrer proliferativen Kapazität zutage gebracht (Westerweel und Verhaar 2009).

In der vorliegenden Arbeit wurde das System der endothelialen Progenitorzellen (EPCs), im Speziellen deren Funktion und Anzahl bei Patienten mit axialer Spondylarthropathie, untersucht. 
Folgenden Fragen wurde nachgegangen:

1. Welche Rolle spielen EPCs bei der axialen Spondylarthropathie?

2. Ist ihre Zahl oder Funktionsweise im Vergleich zur gesunden Kontrollgruppe verändert?

3. Korrelieren Anzahl bzw. Funktion der EPCs mit dem Schweregrad des klinischen Verlaufs, der angewandten medikamentösen Therapie oder der Aktivität der Erkrankung?

4. Spielen EPCs eine Rolle für den Progress der Erkrankung bei dem einzelnen Patienten?

Das Ergebnis unserer Studie, so die Hoffnung, könnte einen Effekt auf therapeutische Möglichkeiten oder prognostische Parameter haben. 


\section{Einleitung}

\subsection{Spondyloarthritiden und axiale Spondylarthropathie}

Die Gruppe der Spondyloarthritiden (SpA) umfasst eine heterogene Gruppe entzündlichrheumatischer Erkrankungen mit einer Reihe gemeinsamer pathophysiologischer und genetischer Merkmale. Genetisches Charakteristikum ist die Assoziation mit dem MHC-Klasse-I-Antigen HLA-B27, klinisch finden wir die Beteiligung des Achsenskeletts und der Enthesien (Braun und Sieper 2007).

$\mathrm{Zu}$ der Gruppe gehören die axiale Spondylarthropathie (axSpA) inklusive der ankylosierenden Spondylitis (AS), die Psoriasis-Arthritis, enteropathische Arthritiden (eine chronisch entzündliche Darmerkrankung begleitend), die reaktive Arthritis und die undifferenzierte Spondylarthropathie. Weiterhin gehören auch juvenile Spondylarthritiden dazu (Manger und Schulze-Koops 2012; Rudwaleit et al. 2009a).

Klinisch können die Erkrankungen in zwei Gruppen eingeteilt werden. Beim prädominant axialen Typ ist die Entzündung im Bereich der Sakroiliakalgelenke und Wirbelsäule vorherrschend. Eine Arthritis der peripheren Gelenke der unteren Extremität steht bei der prädominant peripheren Form im Vordergrund (van der Horst-Bruinsma und Nurmohamed 2012). In 20-40\% überschneiden sich die klinischen Erkrankungsbilder (Manger und SchulzeKoops 2012).

Als Prototyp der Erkrankungsgruppe gilt die AS, die in Deutschland eher unter dem Namen des Morbus Bechterew bekannt ist. Der undifferenzierten Spondylarthropathie werden Krankheitsbilder zugeordnet, die die Kriterien der anderen Subgruppen nicht erfüllen (Puchner 2012). Hierzu wurden in der Vergangenheit häufig auch Patienten mit frühen Formen der AS ohne röntgenologische Veränderungen gezählt.

2009 führten Rudwaleit et al. den Begriff der axialen Spondylarthropathie (axSpA) ein, um ein besseres Management der Erkrankung und eine Verkürzung der Zeit bis zur Diagnosestellung möglich zu machen. „Axiale Spondylarthropathie“ ist ein Sammelbegriff und beschreibt sowohl die AS, diagnostiziert nach den modifizierten New-York-Kriterien, als auch die frühe Form der AS ohne auffällige Bildgebung, die non-radiographic axial spondyloarthritis (nr-axSpA) (Rudwaleit et al. 2009b; Slobodin et al. 2012). Man geht davon aus, dass es sich bei der AS und der nr-axSpA um ein und dieselbe Erkrankung handelt, jedoch zu unterschiedlichen Zeitpunkten des Erkrankungsverlaufs. Dementsprechend bezeichnet die AS 
ein fortgeschrittenes Stadium mit radiologisch erkennbaren Veränderungen des Skelettsytems. Frühe Stadien beschreibt der Begriff der nr-axSpA (s. o.).

\subsection{Definition und Geschichte}

Die axSpA ist sowohl im Tierreich als auch beim Menschen seit der Antike bekannt und weit verbreitet. Mumifizierte Körper aus dem alten Ägypten (4500 B.C.) zeigen bereits die typische zu einem ,rigiden Block“ umgewandelte Wirbelsäule (Ankylose), dem Endstadium der AS (Zorab 1961). Trotzdem dauerte es bis zum späten 19. Jahrhundert, bis man versuchte, die pathologischen Hintergründe der Erkrankung zu verstehen und begann, sie überhaupt als eigene Entität wahrzunehmen. Zu ähnlichen Zeitpunkten beobachteten Bechterew in Russland (1892), Strümpell in Deutschland (1884) und Marie in Frankreich (1898) der AS eigene Symptome bei ihren Patienten - daher auch der Name Bechterew-Strümpell-MarieErkrankung (Zorab 1961).

Sie beschrieben eine Erkrankung, die bei ihren Patienten zur Ankylose geführt hatte. Bis zu diesem Zeitpunkt war zwischen der AS und anderen entzündlichen Erkrankungen der Wirbelsäule nicht unterschieden worden (Zorab 1961). Erstmals als eigenes Krankheitsbild erfasst wurde die AS 1961 von Bernhard Connor (Puchner 2012).

\subsection{Epidemiologie / Krankheitsverlauf}

Die AS gehört zu den häufigsten rheumatischen Erkrankungen mit einer Prävalenz von bis zu $1 \%$ in Europa (Herold 2013). Dies ist mit der Häufigkeit der rheumatoiden Arthritis zu vergleichen (Prävalenz $1 \%$, Herold 2013). Die axSpA scheint weltweit mit bis zu 1,4 \% wesentlich häufiger zu sein (Rudwaleit und Sieper 2005; Slobodin et al. 2012).

Je nach Literatur geht man davon aus, dass Männer im Gegensatz zu Frauen mehr als doppelt so häufig (2,5-fach) von der AS betroffen sind (Rudwaleit und Sieper 2005; Herold 2013). In jüngsten Studien konnte für die axSpA kein Geschlechtsunterschied nachgewiesen werden.

Frauen leiden häufiger an atypischen Symptomen und entwickeln insgesamt langsamer die typischen Veränderungen in der Bildgebung (Rudwaleit et al. 2009a; Slobodin et al. 2012; Slobodin et al. 2011). Daher ist der Diagnosezeitpunkt bei ihnen häufig besonders verzögert (Braun und Sieper 2007).

Manifestationsalter ist das junge Erwachsenenalter, meist zwischen dem 20. und 40. Lebensjahr (Herold 2013), im Schnitt im 26. Lebensjahr (Braun und Sieper 2007). Nur unter fünf 
Prozent (Braun und Sieper 2007) der Patienten sind bei der Erstmanifestation älter als 40 Jahre.

Bis zur Erstdiagnose vergehen häufig 5-7 Jahre (Puchner 2012; Golder und Schachna 2013). Laut einer australischen klinischen Studie kommt es im Schnitt sogar zu einer Verzögerung von etwa 8 Jahren (Reed et al. 2008). Zu den ersten Symptomen gehören vor allem Rückenschmerzen. Die Abgrenzung $\mathrm{zu}$ chronischen Rückenschmerzen anderer Genese ist insbesondere zu Beginn der Erkrankung schwer und erfordert klinische Erfahrung. Bisher sind keine unterstützenden spezifischen Laborparameter für die Erkrankung bekannt.

Mittlerweile scheint sich der Zeitraum bis zur Erstdiagnose, dank neuer diagnostischer Methoden, wie etwa der MRT, und neuer Diagnosekriterien, zu verkürzen (Reed et al. 2008).

Neunzig bis fünfundneunzig Prozent der AS-Patienten und achtzig bis neunzig Prozent der Patienten mit axSpA sind HLA-B27-positiv. Je häufiger das Auftreten des HLA-B27-Gens in einer Population, wie etwa in nördlich gelegenen Ländern, desto häufiger die Erkrankung. Am häufigsten tritt das HLA-B27-Gen in Eskimo-Populationen und bei den Haida-Indianern in Kanada auf (Braun und Sieper 2007).

HLA-B27-positive Patienten erkranken im Schnitt 3-10 Jahre früher als HLA-B27-negative Patienten (Feldtkeller et al. 2003; Manger und Schulze-Koops 2012). Eine familiäre Häufung ist zu beobachten (Herold 2013).

\subsection{Pathogenese}

Bereits 1973 konnte die Assoziation mit dem HLA-B27-Antigen nachgewiesen werden. Das genaue Zusammenspiel ist jedoch bis heute nicht geklärt (Shoenfeld 2017). Auch wenn die letzten Jahre weitere Fortschritte um das Wissen der Ätiopathogenese mit sich gebracht haben, sind die genauen Ursachen und auslösenden Faktoren des chronischen Prozesses nur teilweise verstanden.

Welche Antigene nun tatsächlich inadäquate Reaktionen des Immunsytems auslösen, ist weiterhin nicht genau bekannt. Nach einer gängigen Hypothese bestehen möglicherweise antigene Partialgemeinschaften zwischen bakteriellen Proteinen und dem HLA-B27-Antigen (Sieper und Braun 2014). 


\section{$\underline{\text { Genetische Faktoren }}$}

Das Risiko, an der axSpA zu erkranken, ist gegenüber der Normalbevölkerung über 52 Mal erhöht, wenn bei einem Verwandten ersten Grades die AS diagnostiziert wurde (Robinson und Brown 2014). Dieser ,genetische Effekt“" wird heute zu einem Großteil auf eine Assoziation mit dem HLA-B27-Antigen zurückgeführt. In den frühen 1970-er Jahren konnte diese Beziehung erstmals aufgezeigt werden (Brewerton et al. 1973). Der genaue molekulare Zusammenhang ist bis heute jedoch nicht geklärt. Über $90 \%$ der Kaukasier mit AS tragen das HLA-B27-Gen. Jedoch sind nicht mehr als 5\% aller HLA-B27-Positiven von der AS betroffen. HLA-B27-positive Verwandte von Erkrankten haben ein 5,6- bis 16-fach erhöhtes Risiko, zu erkranken (Slobodin et al. 2012; Braun und Sieper 2007; Calin et al. 1983).

Eine Theorie zu dem Zusammenhang zwischen der axSpA und dem HLA-B27 bezieht sich auf die einzig bekannte Aufgabe der HLA-Moleküle, nämlich der „Präsentation von Peptiden gegenüber T-Zellen“ (Sieper 2005). Die Hypothese hierzu besagt, dass die präsentierten Peptide eine „Immunantwort gegen bakterielle Antigene oder eine Kreuzreaktion z.B. gegenüber Peptiden von Autoantigenen bewirken“ (Sieper 2005).

Kürzlich erschienene Studien ziehen die Möglichkeit in Betracht, dass HLA-B27 im endoplasmatischen Retikulum nicht korrekt synthetisiert und gefaltet wird und infolgedessen eine fehlerhafte Struktur annimmt, oder aber, dass HLA-B27 schwere Kettendimere an der Zelloberfläche bildet, wodurch die Zellen von den T-Killer-Zellen erkannt werden (Slobodin et al. 2012; Taurog et al. 2009).

Mittlerweile sind mehrere Dutzend Subtypen des HLA-B27 bekannt (Robinson und Brown 2014; Holdsworth et al. 2009). Die axSpA tritt nur bei bestimmten Subtypen auf, etwa dem HLA-B2702 oder dem HLA-B2703. Für die verschiedenen HLA-B27-Subtypen scheint das Erkrankungsrisiko unterschiedlich hoch. So konnte im Zusammenhang mit bestimmten Subtypen eine Senkung des Erkrankungsrisikos nachgewiesen werden (etwa für HLA-B27025, Robinson und Brown 2014). Bekannt sind desweiteren zwei Subtypen, die explizit nicht mit der AS assoziiert sind (HLA-B2706 und HLA-B2709; Ball und Khan 2001; Brown 2009). Eine Erklärung hierfür ist bisher nicht gefunden.

Für die axSpA scheinen noch weitere genetische Dispositionen vorzuliegen und werden erforscht. So tritt bei eineiigen Zwillingen häufiger bei beiden Geschwistern die Erkrankung auf (60-75\%), als bei HLA-B27-positiven zweieiigen Zwillingen (24\%) (Braun und Sieper 2007). 


\section{$\underline{\text { Bakterielle Stimulation }}$}

Eine weitere Theorie zur Pathogenese der AS nimmt eine Interaktion zwischen Bakterien, wie etwa Klebsiellen, Shigellen, Yersinien etc., und dem HLA-B27 an (Braun und Sieper 2007). Tierexperimentell zeigte sich, dass weder die HLA-B27-positive transgene Maus noch die HLA-B27-positive transgene Ratte an der AS erkranken, wenn sie in einer keimarmen Umgebung (ohne $\beta$-2-Mikroglobulin) aufwuchsen (Taurog et al. 1994). Wie bei der RA oder der reaktiven Arthritis könnte es hier zu einer gestörten Barrierefunktion der Darmmukosa infolge einer Infektion kommen (Manger und Schulze-Koops 2012). Im Bereich der primären Entzündung konnten bisher keine bakteriellen Bestandteile nachgewiesen werden, sodass man am ehesten von einem auslösenden Effekt zu Beginn der Erkrankung vor dem pathologischen Immunprozess ausgeht (Sieper 2005).

Die initiale Läsion im Rahmen der Erkrankung ist eine Entzündung im Bereich der KnorpelKnochen-Grenze und enthesialer Strukturen, die man im MRT erkennen kann (Slobodin et al. 2012; Manger und Schulze-Koops 2012).

Neben knochenabbauenden Prozessen kommt es typischerweise auch zu osteoproliferativen Vorgängen. Pathophysiologisch erklärt werden die osteoproliferativen Veränderungen mit einer Reaktion infolge der Entzündung. Vermutlich werden verschiedene, noch zu identifizierende Zytokine freigesetzt, die den Verknöcherungsprozess initiieren und damit Entzündung und Osteoproliferation vorantreiben (Sieper 2005). Im Verlauf finden „reaktive fibrotische und ossifizierende Reparaturvorgänge“ (Manger und Schulze-Koops 2012) statt. Die verschiedenen proinflammatorischen Zytokine, insbesondere TNF- $\alpha$, sind ein weiterer Forschungsansatz zur Pathogenese der axSpA (Sieper 2005).

\subsection{Klinik und Verlauf}

Leitsymptom der AS ist der chronische Rückenschmerz. Definitionsgemäß persistiert dieser länger als 12 Wochen und tritt verstärkt nachts, insbesondere in der zweiten Nachthälfte, auf. Schmerzlokalisation ist typischerweise der Bereich der Lendenwirbelsäule und Sakroiliakalgelenke, in der Regel bilateral (90 \%) (Manger und Schulze-Koops 2012). Im Gegensatz zum nicht entzündlichen, degenerativ bedingten Rückenschmerz treten die Schmerzen besonders bei Ruhigstellung, ohne Bewegung (morgens) auf. Nach einer Studie von Rojas-Vargas et al. (2009) leiden etwa $72 \%$ der Patienten mit einer axSpA unter Rückenschmerzen. Die Patienten berichten häufig über Morgensteifigkeit. 
Auf internationaler Ebene gibt es bisher keine einheitliche Definition des entzündlichen Rückenschmerzes. Die in Abbildung 1 dargestellten Definitionen werden in der Klinik herangezogen.

\begin{tabular}{|c|c|c|}
\hline & Rudwaleit (nach Studiendaten) & Sieper (Expertenmeinung) \\
\hline Alter & $<45$ Jahre & $\leq 40$ Jahre \\
\hline Dauer & $\geq 3$ Monate & \\
\hline Beginn & & Schleichend \\
\hline Klinik & $\begin{array}{l}\text { Morgensteifigkeit > } 30 \text { Minuten } \\
\text { Keine Verbesserung durch Ruhe } \\
\text { Alternierender Gesäßschmerz } \\
\text { Aufwachen in der 2. Nachthälfte }\end{array}$ & $\begin{array}{l}\text { Besserung durch Bewegung } \\
\text { Keine Verbesserung durch Ruhe } \\
\text { Nächtliche Schmerzen }\end{array}$ \\
\hline Sensitivität & Bei 2 von 4 Kriterien: $70 \%$ & Bei 4 von 5 Kriterien: $80 \%$ \\
\hline Spezifität & Bei 2 von 4 Kriterien: $81 \%$ & Bei 4 von 5 Kriterien: $72 \%$ \\
\hline
\end{tabular}

Abbildung 1: $\quad$ Definitionen des entzündlichen Rückenschmerzes

(nach Rudwaleit et al. 2006, Sieper et al. 2009)

Strukturelle Veränderungen im Rahmen der Entzündung können mit der Zeit zu zunehmender Versteifung der Wirbelsäule und dadurch zu veränderter Körperhaltung und Bewegungseinschränkung (insbesondere thorakolumbal) führen (Puchner 2012). Das typische radiologische Bild zeigt nach Monaten oder Jahren Syndesmophyten, das heißt „Verknöcherungen im Bereich des Anulus fibrosus der Bandscheibe“ (Pschyrembel 2007) und als maximale Ausprägungsform eine Ankylose der Wirbelsäule. Je nach Stadium der Erkrankung kann es infolge der Bewegungseinschränkung, der veränderten Körperhaltung und Statik zu verschiedensten Symptomen kommen, etwa zu beeinträchtigten Thoraxexkursionen und verminderter pulmonaler Vitalkapazität (Manger und Schulze-Koops 2012). Eine komplette Versteifung der Wirbelsäule betrifft vermutlich nur $10 \%$ der Patienten (Puchner 2012).

Auch andere Gelenke können betroffen sein, typischerweise in Form einer asymmetrischen Mono- (24\%) oder Oligoarthritis (65\%) (Puchner 2012; Manger und Schulze-Koops 2012). Dies sind in der Regel stammnahe, große Gelenke. 20\% der Patienten leiden unter einer Beteiligung der Hüft- und Schultergelenke (Braun und Sieper 2007). Eine Beteiligung der Hüftgelenke geht mit einer schlechteren Langzeitprognose einher (Amor et al. 1994). 
Häufig (bei ca. 40-50 \% der AS-Patienten) zu finden sind weiterhin Enthesitiden (Entzündungen der Sehnenansätze), zumeist im Bereich der Achilles- oder Plantarsehne (Puchner 2012). Die Patienten klagen in der Regel über (Druck-) Schmerzen in der entsprechenden Region.

Extraskelettale Manifestationen finden sich typischerweise im Bereich der Augen und des Magen-Darm-Trakts (CED bei 3-10 \%, ileokoloskopisch ohne klinische Symptome in $70 \%$ entzündlich verändert; nach Manger und Schulze-Koops 2012).

25-40 \% der AS-Patienten (Puchner 2012) leiden mindestens einmal im Krankheitsverlauf an einer Uveitis. Die Entzündung ist auf die Uvea begrenzt, normalerweise unilateral, kann aber von einem Auge auf das andere wechseln. Gelegentlich führt eine anteriore Uveitis zur Erstdiagnose der Erkrankung (Puchner 2012; Martin et al. 2002). Das Auftreten der Uveitis korreliert positiv mit steigender Krankheitsdauer und mit dem Vorliegen des HLA-B27 (Rosenbaum 1992).

Selten sind innere Organe wie die Aorta in Form einer Aortitis bis hin zur Aorteninsuffizienz, die Niere (IgA-Nephritis), das Reizleitungssystem des Herzens (Erregungsleitungsstörungen) oder das Herz selbst (Kardiomyopathie) beteiligt (Puchner 2012).

Weiterhin findet sich bei einem Großteil der Patienten eine verminderte Knochendichte: Osteopenie bei $59 \%$, Osteoporose bei $18 \%$ der Patienten mit AS (Karberg et al. 2005; Bremander et al. 2011). Insgesamt erleiden AS-Patienten daher häufiger Frakturen im Bereich der Wirbelsäule, jedoch nicht im Bereich der peripheren Knochen. Unter einer anti-TNFTherapie steigen die Knochendichtewerte wieder an und das erhöhte Risiko, Frakturen zu erleiden, sinkt. Bei Patienten, die zusätzlich an einer CED leiden, ist das generelle Risiko, Frakturen zu erleiden, erhöht (Vosse und de Vlam 2009).

Eine Beteiligung der Haut in Form einer Psoriasis vulgaris findet man in bis $\mathrm{zu} 20 \%$ der AS-Patienten. Weitaus häufiger sind psoriasiforme Hautläsionen (Brophy und Calin 2001).

Der schleichende Beginn der axSpA geht in der Regel in einen schubweisen Verlauf über, nur selten akut und kontinuierlich fortschreitend. Typischerweise schreitet die Symptomatik von kaudal mit der Sakroiliitis nach kranial fort. Die axSpA scheint sich in fast jedem Stadium inaktivieren zu können. Die Verlaufsschwere der Erkrankung ist nur schlecht vorherzusagen (Puchner 2012). 
Signifikant ungünstige Prognosefaktoren nach einer französischen Studie sind neben der Coxitis eine BSG > 30, schlechtes Ansprechen auf die Therapie mit NSARs, eingeschränkte Beweglichkeit der LWS, ein früher Krankheitsbeginn (vor dem 17. Lebensjahr), Organmanifestationen oder eine Oligoarthritis (Puchner 2012). Auch Nikotinkonsum und unterlassene oder nur gelegentlich durchgeführte Krankengymnastik wirken sich negativ auf den Verlauf aus.

Die Mortalität ist insbesondere durch ein erhöhtes kardiovaskuläres Risiko erhöht (Manger und Schulze-Koops 2012). 


\subsection{Diagnostik}

\subsubsection{Körperliche Untersuchung}

Besonderen Wert wird bei der körperlichen Untersuchung auf die Beweglichkeit der Wirbelsäule gelegt. Im Kapitel „Material und Methoden“ werden die hier angewandten klinischen Messwerte zur Beurteilung von Erkrankungsschwere und -verlauf (Feldtkeller und van der Heijde 2005; Herold und Falkenbach 2005) näher erläutert. Stets ist zu bedenken, dass die Messungen eine Momentaufnahme auch von Muskeln und Sehnen widerspiegeln.

\subsubsection{Scores}

Zur Beurteilung des klinischen Verlaufs und der therapeutischen Maßnahmen wurden verschiedene Scores entwickelt. Siehe dazu Kapitel 3.

\subsubsection{Klassifikationskriterien}

Die Sakroiliitis ist das typische Kennzeichen der AS. Sie hat die Entwicklung von Diagnosekriterien vorherrschend mitbestimmt. Die ersten Klassifikationskriterien kamen noch ohne eine Darstellung der Sakroiliitis aus (Rom-Kriterien von 1961). Dies änderte sich bereits 1966 mit den folgenden New-York-Kriterien aus den USA. 1984 folgte die Weiterentwicklung zu den modifizierten New-York-Kriterien (Abbildung 2 und 3). Nun wurden klinische Parameter für den entzündlichen Rückenschmerz mit eingeführt (Braun und Sieper 2007).

\begin{tabular}{|l|l|}
\hline Einteilung & Veränderung \\
\hline Grad 0 & Keine Veränderung \\
\hline Grad 1 & Mögliche Veränderungen \\
\hline Grad 2 & $\begin{array}{l}\text { Minimale Veränderungen, minimale Sakroiliitis (geringe Sklerose, Erosio- } \\
\text { nen, keine Gelenkspaltveränderungen) }\end{array}$ \\
\hline Grad 3 & $\begin{array}{l}\text { Eindeutige Veränderungen, moderate Sakroiliitis (deutliche Sklerose, Ero- } \\
\text { sionen, Gelenkspaltverbreiterung oder -verschmälerung) }\end{array}$ \\
\hline Grad 4 & Ankylose \\
\hline
\end{tabular}

Abbildung 2: $\quad$ Einteilung der radiologisch darstellbaren sakroiliakalen Veränderungen zur Verwendung in den modifizierten New-York-Kriterien (s. Abbildung 3) 
Die modifizierten New-York-Kriterien werden bis heute nicht nur zur Klassifikation der AS verwendet, sondern dienen auch der Diagnostik des röntgenologischen Stadiums.

2009 führten Rudwaleit et al. mit der Definition der axialen Spondylarthropathie auch neue Klassifikationskriterien zur leichteren Einteilung der Patienten ein (sog. ASASKlassifikationskriterien, Abbildung 4) (Rudwaleit et al. 2009b). Diese stützen sich auf die klinischen Merkmale, das Vorhandensein des HLA-B27-Antigens und eine Sakroiliitis im MRT (siehe unten, Rudwaleit et al. 2009b). Die Sensitivität der Klassifikationskriterien beträgt 80-90 \%, die Spezifität 84,4 \% (Manger und Schulze-Koops 2012). Damit sind die ASAS-Klassifikationskriterien den vorherigen ESSG- (Leitsymptom entzündlicher Rückenschmerz oder unsymmetrische Beteiligung peripherer Gelenke) und Amor-Kriterien (Leitsymptom entzündlicher Rückenschmerz unzureichend definiert) überlegen.

$\begin{array}{lll}\text { Klinische Kriterien: } & \text { 1. } & \begin{array}{l}\text { tiefsitzende Kreuzschmerzen und Steifigkeit seit mehr als } 3 \\ \text { Monaten, Besserung bei Bewegung, nicht in Ruhe }\end{array} \\ \text { 2. } & \begin{array}{l}\text { Bewegungseinschänkung der Lendenwirbelsäule in } \\ \text { sagittaler und frontaler Richtung }\end{array} \\ \text { 3. } & \begin{array}{l}\text { Einschränkung der Thoraxexkursion im Vergleich zu } \\ \text { Gesunden gleichen Alters und Geschlechts }\end{array}\end{array}$

Radiolog. Kriterien: $\underline{\text { Sacroiliitis }}$ ( $\mathrm{Grad} \geq 2$ beidseits oder Grad 3-4 einseitig)

$\rightarrow$ Gesicherte AS: Radiologisches Kriterium \& mindestens 1 klinisches Kriterium erfüllt.

$\rightarrow$ Verdacht auf AS: 3 klinische Kriterien erfüllt oder radiologisches Kriterium erfüllt

Abbildung 3: $\quad$ Modifizierte New-York-Kriterien für die Spondylitis ankylosans (Braun und Sieper 2007)

Präsenz von Rückenschmerzen > 3 Monate und Erkrankungsbeginn < 45 Jahre:

HLA-B27 plus $\geq 2$ andere SpA-Merkmale

oder

Sakroiliitis (Bildgebung) plus $\geq 1$ anderes SpA-Merkmal

SpA-Merkmale: entzündl. Rückenschmerz, Arthritis, Enthesitis, anteriore Uveitis, Dactylitis, Prosiasis, CED, gutes Ansprechen auf NSAR, Familienanamnese für SpA, HLA-B27+, CRP erhöht

Sakroiliitis in der Bildgebung: $\quad 1$ - akute Entzündung in der MRT

2 - Sakroiliitis im Röntgen nach den mod. N.-Y.-Kriterien

Abbildung 4: $\quad$ ASAS-Klassifikationskriterien für die axSpA nach Rudwaleit et al. 2009b 
Vergingen zuvor häufig mehrere Jahre bis zu Erstdiagnose, ist nun eine Verkürzung dieser Zeit im klinischen Alltag festzustellen (Rudwaleit et al. 2009a).

\subsubsection{Bildgebung}

Die Bildgebung ist für die Diagnosestellung und Verlaufsbeurteilung der AS ausschlaggebend. Bei über $95 \%$ der Patienten mit AS zeigen sich strukturelle Veränderungen im Bereich der Sakroiliakalgelenke (Braun und Sieper 2007). 20-30 \% der Patienten entwickeln diese bereits in den ersten 2 Jahren mit entzündlichem Rückenschmerz (McGonagle et al. 1998). Bisher war die Röntgendiagnostik zur Darstellung von Knorpel- und Knochenschäden als Goldstandard anerkannt.

Diese Veränderungen sind jedoch zu Beginn der Erkrankung nicht vorhanden. Sie entstehen erst im Verlauf des chronischen Prozesses.

Sollen die entzündlichen Veränderungen im Bereich der Sakroiliakalgelenke (Sakroiliitis) dargestellt werden, ist die MRT die beste Darstellungsmethode. Hiermit können die Veränderungen zu Beginn der Erkrankung vor einer chronischen Schädigung dargestellt werden. Die gegenüber der Röntgendiagnostik höhere Sensitivtät und Spezifität führte zur Aufnahme der MRT in die neuen ASAS-Klassifikationskriterien (s.o. Slobodin et al. 2012; Manger und Schulze-Koops 2012).

\subsubsection{Labor}

Bisher ist kein die axSpA spezifisch kennzeichnender Laborwert bekannt.

In der Diagnostik stützt man sich auf das HLA-B27 und in der Initial- und Verlaufsbewertung auf systemische Entzündungsparameter wie das C-reaktive Protein (CRP). Weiterhin wird die BSG bestimmt, spielt jedoch nur eine untergeordnete klinische Rolle.

Etwa 80-95 \% der AS-Patienten und 60-85 \% der axSpA-Patienten sind HLA-B27 positiv (Sampaio-Barros et al. 2010; Rudwaleit et al. 2009a). Die Bestimmung des HLA-B27 weist eine recht hohe Spezifität (90-96 \%) und gut ausreichende Sensitivität (83-96 \%) auf (Rudwaleit et al. 2004). Die Subtypen des HLA-B27 werden in Mitteleuropa nicht standardmäßig bestimmt. Interessanterweise könnte dies bei chinesischen Patienten eine Rolle spielen, da in der chinesischen Population zwei Subtypen beobachtet wurden, die nicht mit der AS assoziiert sind (Braun und Sieper 2007). 
Die Korrelation zwischen Krankheitsaktivität und CRP ist begrenzt. Nur die Hälfte der Patienten zeigt überhaupt erhöhte Entzündungsparameter. Eine Erhöhung geht jedoch mit einer schlechteren Prognose einher (Spoorenberg et al. 1999; Braun und Sieper 2007).

\subsection{Therapie/Management der AS}

Ziele der therapeutischen Maßnahmen sind der Erhalt von Lebensqualität inklusive der Schmerzreduktion, außerdem das Vermeiden von strukturellen Schäden im Bereich des Skeletts. Die Bewegungsfähigkeit soll wiedererlangt und möglichst lange erhalten werden. Medikamentöse und nicht-medikamentöse Ansätze inklusive aufklärender und physiotherapeutischer Maßnahmen werden dazu kombiniert. Daten zu Patienten mit axSpA gibt es bisher kaum. Die für sie geltenden Empfehlungen resultieren aus den Erfahrungen mit der AS-Therapie.

In der Standardbehandlung werden NSAR als First-Line-Therapie seit Jahrzehnten mit einem Sportprogramm kombiniert (Kraag et al. 1990). Patienten mit axSpA sprechen häufig auf eine NSAR-Therapie sehr gut an. 70-80\% der Patienten berichten über eine gute bis sehr gute Besserung der Symptome (Gossec et al. 2005). Die physische Betätigung dient der Verbesserung der Muskelkraft und dem Erhalt der Wirbelsäulenbeweglichkeit.

Eine kontinuierliche Einnahme von NSAR verlangsamt den radiographischen Fortschritt der Erkrankung nach einer Studie von Wanders et al. (2005) deutlich. Das Ansprechen auf NSAR gilt als positives diagnostisches Zeichen (Amor et al. 1994). Bei etwa $50 \%$ der Patienten mit AS reicht jedoch eine alleinige Therapie mit NSAR zur Symptomkontrolle nicht aus (Zochling et al. 2006).

Synthetische DMARDs sind wesentlich weniger effektiv als NSAR. Sulfasalazin wirkt nicht auf die spinalen Symptome. Allein in den frühen Stadien der AS könnte es einen positiven Effekt haben. Auch Methotrexat scheint bei der AS, im Gegensatz zur rheumatoiden Arthritis, keine positive Wirkung zu haben (Chen et al. 2013). Trotzdem wurde das Medikament lange Zeit verschrieben. Es gab keine Alternativen.

Die medikamentöse Therapie wurde durch den Einsatz der TNF- $\alpha$-Blocker in den letzten Jahren revolutioniert. Nach den ASAS-Empfehlungen werden sie heute als Standardtherapie eingesetzt (Braun und Sieper 2007). Diese Medikamentengruppe wirkt hervorragend auf die klinischen und im MRT sichtbaren Zeichen und Symptome (Slobodin et al. 2012). Schmerz und Entzündung werden gelindert, die Gelenkfunktion verbessert. Eine Therapie mit 
TNF- $\alpha$-Blockern bewirkt bei über $50 \%$ der Patienten mit axialer Spondylarthropathie eine vollständige Remission (Barkham et al. 2009). Alle Verlaufsmessungen (BASDAI, BASFI, BASMI) verbesserten sich nach 24 und 102 Wochen und die Entzündungsparameter normalisierten sich (Braun und Sieper 2007). Laut Haroon et al. (2013) scheint eine Therapie mit TNF- $\alpha$-Blockern, insbesondere wenn diese zu einem frühen Erkrankungszeitpunkt begonnen wurde, den radiographischen Fortschritt zu reduzieren.

Eine chirurgische Therapie kommt nur bei ausgewählten Patienten mit körperlicher Behinderung, beispielsweise bei instabiler Wirbelsäule, infrage.

Neben der pharmakologischen Therapie spielen nicht-medikamentöse Maßnahmen, insbesondere die Physiotherapie, eine grundlegende Rolle. Studien zeigen, dass bei regelmäßiger Durchführung der Bewegungstherapie eine Verbesserung der körperlichen Funktion, der Schmerzen und des globalen Befindens nachweisbar ist (Dagfinrud et al. 2008). 


\subsection{Atherosklerose / kardiovaskuläres Risiko bei Patienten mit $\operatorname{axSpA}$}

Als systemische entzündlich-rheumatische Erkrankung wird die axSpA zunächst einmal mit einer Beteiligung der Wirbelsäule und der Sakroiliakalgelenke in Verbindung gebracht. Wie für andere chronisch entzündliche Erkrankungen, etwa die rheumatoide Arthritis oder den Lupus erythematodes, konnte jedoch auch für die axSpA ein erhöhtes kardiovaskuläres Risiko mit erhöhter Mortalität und Morbidität im Vergleich zur Gesamtbevölkerung nachgewiesen werden (van der Horst-Bruinsma und Nurmohamed 2012; Bremander et al. 2011). Peters et al. (2004) schätzten das Risiko für kardiovaskuläre Ereignisse als etwa doppelt so hoch wie für gleichaltrige Kontrollpersonen ein und geben entsprechend eine um 20-40\% erhöhte kardiovaskuläre Mortalität für AS-Patienten an. Dieses kardiovaskuläre Risiko ist äthiologisch multifaktoriell zu erklären. Eine durch den entzündlichen Prozess beschleunigte Atherosklerose mit beeinträchtigter endothelialer Funktion scheint der Hauptfaktor zu sein (Azevedo und Pecoits-Filho 2010; Sari et al. 2006).

An der Pathogenese könnte desweiteren eine Dysregulation des Lipidmetabolismus beteiligt sein, die jedoch nicht in allen Studien nachgewiesen wurde (Bremander et al. 2011; Prati et al. 2011) Dass eine Dyslipidämie prädisponierend für die Atherosklerose wirken kann, ist seit langem bekannt. In kleinen Studien zu den Lipoproteinen wurden bei der AS erniedrigte Cholesterol- und HDL-Werte festgestellt (Rössner 1978). Divecha et al. (2005) konnten nachweisen, dass bei Männern mit AS Cholesterol- und HDL-Werte erniedrigt waren und invers mit den Konzentrationen von CRP und IL-6 korrelierten.

Insbesondere Erkrankungen der Herzklappen treten bei axSpA-Patienten häufiger auf (60\% erhöhtes Risiko nach Szabo et al. (2011). Myokardinfarkte erleiden die Patienten zwei- bis dreimal so häufig wie die Normalbevölkerung (Peters et al. 2004; El Maghraoui 2011). Bereits vor manifesten Erkrankungen im Bereich des Herzens oder der Gefäße konnte bei axSpA-Patienten eine erhöhte Rigidität der Aorta und eine verringerte myokardiale Leistung nachgewiesen werden. Das Ausmaß dieser Veränderungen korrelierte dabei mit der Krankheitsaktivität (Moyssakis et al. 2009).

Auch die Wahrscheinlichkeit, zerebrovaskuläre Ereignisse zu erleiden, ist laut Szabo et al. (2011) erhöht. 
Männer und Frauen scheinen von den Konsequenzen der endothelialen Dysfunktion in ähnlichem Ausmaß betroffen zu sein. Insbesondere bei jungen axSpA-Patienten scheint ein erhöhtes kardiovaskuläres Risiko zu bestehen (um mind. 25 \% erhöht) (Szabo et al. 2011).

Poddubnyı̌ et al. beschrieben 2009 eine Korrelation zwischen der Krankheitsaktivität und dem Risiko, kardiovaskuläre Pathologien zu entwickeln. Je höher die Krankheitsaktivität, desto größer das Risiko.

Bedacht werden muss, dass auch NSAR das kardiovaskuläre Risiko erhöhen. Der Zusammenhang zwischen der NSAR-Einnahme und einem daraus resultierenden negativen Sekundär-Effekt wurde bisher nicht untersucht (Huang et al. 2013). Auch die Behandlung mit TNF- $\alpha$-Blockern könnte sich auf die endotheliale Funktion auswirken (El Maghraoui 2011). Nicht abschließend geklärt sind desweiteren die Auswirkungen der verminderten körperlichen Aktivität von AS-Patienten auf das kardiovaskuläre Risiko. Auch das gehäufte Auftreten des metabolischen Syndroms (Szabo et al. 2011), des Diabetes mellitus, der Hypertension (Bremander et al. 2011) oder die genetischen Prädispositionen bezüglich des kardiovaskulären Risikos sind noch ungeklärt.

Für die AS-Patienten resultiert ein im Vergleich zu Altersgenossen um 30 \% erhöhtes Risiko stationärer Behandlungen (Szabo et al. 2011). In einer europäischen Studie beobachteten Bakland et al. 2011 weiterhin eine erhöhte Mortalität unter 667 AS-Patienten im Vergleich zur Kontrollgruppe. Durchblutungsstörungen und Kreislauferkrankungen waren darunter die häufigste (in 40 \%) Todesursache (van der Horst-Bruinsma und Nurmohamed 2012).

\subsection{Endothel}

Das Endothel ist grundlegender Bestandteil der Gefäße, es kleidet die inneren Gefäßwände aus. Bei einem durchschnittlichen Erwachsenen besteht es aus etwa $10^{13}$ Endothelzellen, das entspricht insgesamt etwa einer Fläche von etwa $7 \mathrm{~m}^{2}$ (Lin et al. 2000).

Endothelzellen bilden die natürliche Grenzschicht zwischen dem Blut bzw. der Lymphflüssigkeit und dem umgebenden Gewebe. Sie regulieren den Nährstoff- und Blutbestandteiltransport und agieren als aktive Signalübermittler. Ein weiterer Mechanismus ist die Produktion verschiedenster Faktoren, die etwa der Änderung des Gefäßtonus oder der zellulären Adhäsion dienen und eine Reaktion auf Gefäßwandentzündungen oder thrombotische Ereignisse modulieren (Deanfield et al. 2007). Das Endothel ist an verschiedensten 
physiologischen Prozessen beteiligt, wie etwa der Hämostase, Entzündungen und der Angiogenese bzw. der Vaskulogenese (Lin et al. 2000).

\subsection{Vaskulogenese und Angiogenese}

Die erstmalige Ausbildung von Blutgefäßen während der pränatalen Entwicklung bezeichnet man als Vaskulogenese. Während der Entwicklung im Mutterleib differenzieren sich Gewebe zu Organen und werden funktionell aktiv, der gesamte Organismus wächst. Dies ist nur mit einem entsprechend ausgedehnten Gefäßsystem möglich, das die nötigen Nähr- und Botenstoffe an Ort und Stelle transportiert. Angioblasten differenzieren zu reifen Endothelzellen und lagern sich zu einem Gefäßsystem zusammen.

Für die Entwicklung des Körpers ist ein weiterer Mechanismus vonnöten - die Angiogenese. Hierunter versteht man den Umbau und das Wachstum des Gefäßsystems durch Teilung bereits bestehender differenzierter Endothelzellen sowohl beim Embryo als auch im adulten Organismus.

Das im Rahmen der Vaskulogenese angelegte Gefäßnetz wird durch den Prozess der Angiogenese weiter ausgebaut bzw. modifiziert. Dies geschieht per sprouting der Gefäße und einstülpendem Wachstum (Intusseption oder non-sprouting angiogenesis). Wesentlich beteiligt an diesem Prozess sind Stickstoffmonoxid (NO) und der vascular endothelial growth factor (VEGF) (Kalka et al. 2000).

Lange Zeit ging man davon aus, dass die Vaskulogenese lediglich pränatal stattfindet und dem erwachsenen Organismus nicht mehr zur Verfügung steht.

Mit dem Nachweis von an der postnatalen Vaskulogenese teilhabenden EPCs hat ein Umdenken stattgefunden. Die postnatale Vaskulogenese scheint im erwachsenen Organismus zeitlebens stattzufinden, insbesondere im Rahmen pathologischer Prozesse wie der Wundheilung, Neovaskularisation von ischämischem Gewebe oder Tumorwachstum (Khakoo und Finkel 2005; Korta et al. 2013). So werden die Homöostase der Gefäßwände, Umbauprozesse und die Regeneration der Gefäße im Zusammenspiel mit verschiedensten Zytokinen und angiogenen Wachstumsfaktoren garantiert. Wesentlich stimuliert wird die Gefäßneubildung durch Sauerstoffmangel, aber auch durch mechanische Faktoren, wie etwa durch einen erhöhten Blutfluss. 


\subsection{Endotheliale Dysfunktion}

Sind bestimmte Faktoren erfüllt, etwa bei Konfrontation mit kardiovaskulären Risikofaktoren, kann es zur endothelialen Dysfunktion und dadurch zur Erkrankung des Gefäßsystems kommen. Die klinisch bedeutsamste Konsequenz ist die Atherosklerose. Die endotheliale Integrität wird, wie oben beschrieben, durch verschiedene Mechanismen gewährleistet. Dazu gehören die reifen Endothelzellen, die sich lokal replizieren können und apoptotische bzw. funktionell geschädigte Zellen ersetzen. Außerdem dienen die zirkulierenden EPCs dem Erhalt des Endothels.

Die verschiedenen kardiovaskulären Risikofaktoren führen zu einer Aktivierung des ruhenden Endothels und einer Exprimierung von Chemokinen, Zytokinen etc. (Deanfield et al. 2007). Diese Aktivierung dient normalerweise der Protektion der Gefäße.

Man geht davon aus, dass dieser protektive Effekt bei ständiger Schädigung im Laufe der Zeit aufgebraucht wird. Dann kann es neben dem Ablösen endothelialer Zellen aufgrund eines schnelleren Alterungsprozesses zur endothelialen Dysfunktion kommen. Dies bedeutet eine Funktionseinschränkung aller dem Endothel eigenen Aufgaben, wie etwa der Gefäßpermeabilität oder der Hämostase (siehe oben). Es kommt zur erhöhten Permeabilität und dem Durchtritt von Blutbestandteilen. Eine Beeinträchtigung der endothelialen Funktion geht der Entwicklung morphologischer atherosklerotischer Veränderungen voran und kann zur Entwicklung von Läsionen und späteren klinischen Komplikationen beitragen (Deanfield et al. 2007).

Verschiedene klinische Untersuchungen zeigten, dass eine Dysfunktion des Endothels sich bereits im ersten Lebensjahrzehnt als Antwort auf Umwelt- und genetische Faktoren entwickeln kann (Deanfield et al. 2007).

\subsection{Endotheliale Progenitorzellen - Übersicht}

Endotheliale Progenitorzellen (EPCs) werden seit mittlerweile über 20 Jahren intensiv beforscht. Asahara et al. waren 1997 die ersten, die zu dieser Zellpopulation publizierten. Sie stellten fest, dass sich zirkulierende CD34-positive hämatopoetische Vorläuferzellen in vivo zu Endothelzellen differenzieren können und nannten diese Zellen endotheliale Progenitorzellen. 
Bis heute sind unzählige Veröffentlichungen zu diesem Thema erschienen. Trotzdem ist eine Charakterisierung der Zellen weiterhin nicht einfach, unter anderem weil bisher keine spezifischen Oberflächenmarker bekannt sind (Timmermans et al. 2009).

Man schätzt, dass EPCs einen Anteil von etwa 0,01\% an den peripheren mononukleären Zellen ausmachen (Ablin et al. 2009; Diskrepanz: 0,1-0,5\% (Kalka et al. 2000). Im Knochenmark soll ihr Anteil das Hundertfache ausmachen.

EPCs besitzen die Fähigkeit, in ischämische Gewebeareale zu gelangen und sich unter bestimmten Bedingungen zu Endothelzellen zu differenzieren (Yoder 2013). So steuern sie die Endothelregeneration und Gefäßneubildung auch im adulten Organismus. Man hat festgestellt, dass ihre Anzahl und Funktion bei verschiedensten entzündlichen Erkrankungen erniedrigt bzw. eingeschränkt sind (Ablin et al. 2009). EPCs wird heute großes therapeutisches Potenzial zugesprochen.

Urbich und Dimmeler entwickelten 2004 eine einfache Arbeitshypothese für EPCs:

1. EPCs sind dem Knochenmark entstammende Zellen, die peripher zirkulieren, sich aber funktionell und phänotypisch eindeutig von ausgereiften Endothelzellen unterscheiden.

2. In vitro können sie sich zu Endothelzellen differenzieren.

3. In vivo tragen sie zur Vaskulogenese und vaskulären Homöostase bei.

Yoder passte diese Definition 2012 neuen wissenschaftlichen Erkenntnissen an. Er definierte EPCs analog den embryonalen Angioblasten als grundsätzlich zirkulierende Zellen,

1. die eine Vielfalt von Oberflächenmarkern exprimieren, ähnlich denen der zirkulierenden, vaskulären Endothelzellen,

2. die am Endothel in hypoxischen/ischämischen Gewebearealen haften und

3. die sich an der Neubildung der Gefäße beteiligen.

Mittlerweile geht man davon aus, dass es verschiedene EPC-Populationen mit unterschiedlicher regenerativer Kapazität gibt (Khakoo und Finkel 2005; Zaccone et al. 2015). Ihnen gemein sind oben genannte Eigenschaften. 
Nach Mayr et al. (2011) entstammen die verschiedenen Zellen, die mit dem Namen EPC assoziiert sind, außerdem verschiedenen Ursprüngen:

1. hämatopoetischen Stammzellen (HSC)

2. myeloischen Zellen (MC)

3. anderen zirkulierenden Progenitorzellen (CPC, auch side population cells)

4. zirkulierenden reifen Endothelzellen, die sich von der Zellwand abgelöst haben (CEC)

Die genaue Entwicklung von einer Vorläuferzelle hin zur EPC ist bisher nicht nachgewiesen oder definiert (Piatkowski et al. 2013).

Mit der Annahme verschiedener Ursprungslokalisationen haben sich unterschiedliche Isolierungsverfahren entwickelt, an deren Ende verschiedene EPC-Subpopulationen (s. Abbildung 5) stehen:

Nach Asahara et al. (1997) erfolgte die ursprüngliche Isolierung aus peripherem venösem Blut. Mononukleäre Zellen wurden nach Zentrifugation in einem speziellen Medium kultiviert. Die mittels dieser Methode isolierten Zellen wurden zunächst generell als EPCs bezeichnet. Mit der Zeit wurde das Verfahren weiterentwickelt. Heute wird je nach Kultivierungszeitraum und -art zwischen verschiedenen Subpopulationen von EPCs unterschieden. Nach drei bis fünf Tagen Kultivierung findet man sogenannte zirkulierende angiogene Zellen (CACs), mit niedrigem proliferativem Potenzial. Diese Zellen sind nicht direkt an der Gefäßneubildung beteiligt, sondern wirken über eigens zur Förderung der Angiogenese produzierte Cytokine und angiogene Faktoren. Morphologisch zeichnen sie sich durch die Formation gestreckter, spindelförmiger Zellen aus (Hur et al. 2004; Sieveking et al. 2008).

Nach mindestens 14 Tagen der Kultivierung erscheinen late outgrowths EPCs (eCFC). Ihr Ursprung ist unklar (Piatkowski et al. 2013). Sie besitzen hohes proliferatives Potenzial und bilden in vitro vaskuläre Ausstülpungen sowie in vivo neue Gefäße (Werling et al. 2013; Prater et al. 2007; Zaccone et al. 2015). Ihre Kolonien haben eine kopfsteinpflasterartige Erscheinung. Auf ihrer Oberfläche findet man folgende Marker: CD31, CD34, CD144, KDR (negativ für CD45).

Hill et al. (2003) entwickelten eine weitere Methode zur EPC-Isolation. Die hier isolierten Zellen werden colony-forming unit-Endothelzellen (CFU-ECs), auch CFU-Hill genannt, und werden als Marker für das Gefäßsystem und die Angiogenese angesehen (Hill et al. 2003). Wurden im Mausmodell einer Ischämie im Bereich der hinteren Extremität CFU-ECs 
intravenös injiziert, konnte eine verbesserte Perfusion und Kapillardichte nachgewiesen werden - im Gegensatz zu Mäusen, denen reife Endothelzellen oder ausschließlich das Wachstumsmedium injiziert worden waren. Gleiches beobachtete man nach der Injektion von eCFCs (Hur et al. 2004). Wurden sogar beide Zellarten zusammen injiziert konnte ein synergistischer Effekt beobachtet werden (Yoon et al. 2005).

CFU-ECs scheinen die vaskuläre Gesundheit zu reflektieren. Ihre Anzahl korrelierte invers mit dem Framingham Score. Ihre Anzahl war erniedrigt, wenn bei den Probanden eine Hypertension, Typ-II-Diabetes oder eine Hypercholesterinämie vorlag. Auch COPD, RA, dekompensierte Herzinsuffizienz und Typ-I-Diabetes führten zu einer Minderung der CFU-EC. Bei instabiler AP oder einem Myokardinfarkt wurden innerhalb von sieben Tagen erhöhte CFU-ECs beobachtet. Verminderte CFU-ECs scheinen also für ein erhöhtes Risiko für vaskuläre Erkrankungen zu sprechen, während akuter kardiovaskulärer Stress zur Mobilisierung führt (Prater et al. 2007). CFU-ECs besitzen jedoch nur ein geringes proliferatives Potenzial (Yoder et al. 2007). Bisher konnte für sie, im Gegensatz zu den eCFCs, nur in vitro eine Einlagerung in Gefäßwände nachgewiesen werden (Hur et al. 2004) (genaue Methodenbeschreibung Kapitel 3.2.).

Da CACs und CFU-ECs bereits nach kurzer Zeit Kolonien bilden, werden sie zusammen als early outgrowth EPCs definiert (Hur et al. 2004; Zaccone et al. 2015). Es ist anzunehmen, dass die heterogene Gruppe der early EPCs die Vorläuferzellen der late EPCs beinhalten (Zaccone et al. 2015).

Aus dem Knochenmark isolierte murine mononukleäre Zellen differenzieren sich nach Kultivierung in preconditioned endothelial medium $\mathrm{zu}$ EPCs mit hohem proliferativem Potenzial und bilden in vitro tubuläre Strukturen aus. Nach Asahara et al. 1999 wandern sie in ischämisches Gewebe ein und sind so etwa fähig, die myokardiale Funktion zu verbessern.

Aicher und Heeschen 2007 untersuchten weitere Herkunftsmöglichkeiten der EPCs (Leber und Darm). Ihre Studien geben Anlass zu der Vermutung, dass es verschiedenste weitere Ressourcen für EPCs geben könnte. Progenitorzellen, die aus peripheren Geweben gewonnen werden, werden als gewebeständige Progenitorzellen (tissue resident progenitor cell = TPCs) bezeichnet.

Ingram et al. 2005 isolierten aus dem erwachsenen Organismus zirkulierende reife Endothelzellen und erstellten das Konzept von ECs und EPCs, die sich von der Gefäßwand gelöst haben. Potenzial und Funktion dieser EPCs sind noch unklar (Lin et al. 2000). 
Es sollten also stets Ursprung und Methode der Isolierung genannt werden, ist die Rede von EPCs. Mithilfe der Durchflusszytometrie werden die sogenannten zirkulierenden EPCs (cEPCs) anhand verschiedener Oberflächenmarker identifiziert. Das Fehlen spezifischer Oberflächenmoleküle hat zu einer Vielfalt an verwendeten Kombinationen geführt (Kap. 4.5) (Timmermans et al. 2009).

\begin{tabular}{|l|l|l|l|c|}
\hline \multicolumn{1}{|c|}{ CFU-Hill } & \multicolumn{1}{|c|}{ CAC } & \multicolumn{1}{|c|}{ eCFC } & TPC \\
\hline $\begin{array}{l}\text { Kulitivierung } \\
\text { mittels Hill- } \\
\text { Verfahren }\end{array}$ & $\begin{array}{l}\text { Kultivierung, } \\
\text { erscheinen nach 3-5 } \\
\text { Tagen }\end{array}$ & $\begin{array}{l}\text { Kultivierung, } \\
\text { erscheinen nach 4-7 } \\
\text { Tagen }\end{array}$ & FACS \\
\hline $\begin{array}{l}\text { Niedriges pro- } \\
\text { lif. Potenzial }\end{array}$ & $\begin{array}{l}\text { Niedriges prolif. } \\
\text { Potenzial }\end{array}$ & $\begin{array}{l}\text { Hohes } \\
\text { prolif. Potenzial }\end{array}$ & $\begin{array}{r}\text { gewebs- } \\
\text { ständig }\end{array}$ \\
\hline & $\begin{array}{l}\text { CD14, CD45, } \\
\text { binden UEA, } \\
\text { Aufnahme von LDL }\end{array}$ & $\begin{array}{l}\text { CD31, CD34, } \\
\text { CD144, KDR }\end{array}$ & $\begin{array}{l}\text { CD34, } \\
\text { CD133, KDR }\end{array}$ & \\
\hline \multicolumn{2}{|l|}{ Nachweis mittels Kultivierung } & Keine Kultivierung mög- \\
\hline
\end{tabular}

Abbildung 5: $\quad$ Verschiedene EPC-Subtypen und deren Eigenschaften

\subsection{Experimentelle Beschreibung; Isolierung und Kultivierung}

Zum experimentellen Nachweis von EPCs aus humanem peripherem Blut kann man sich verschiedener Methoden bedienen (s.o.), die im Folgenden genauer beschrieben werden sollen.

Zur Durchführung der ältesten und vielleicht einfachsten Methode nach Asahara et al. (1997) werden humane mononukleäre Zellen aus peripherem Blut gewonnen. Diese Zellen werden auf mit Fibronektin benetzte Kulturplatten aufgebracht und wachsen einige Tage in einem speziellen Nährmedium. In diesem Nährmedium befinden sich zusätzlich verschiedene Wachstumsfaktoren, wie etwa VEGF, FGF2, IGF1 und EGF. Asahara et al. (1997) gingen davon aus, dass EPCs sich nach 5-7 Tagen am Boden absetzen. Sie sind desweiteren fähig, AcLDL aufzunehmen und Ulex Europaeus Agglutinin I (UEA-1), ein pflanzliches Lectin, zu binden. Ein großer Nachteil dieser einfachen Methode ist laut Yoder (2013) die fehlende Spezifität der gewonnenen Zellen. So können etwa im Blut zirkulierende Thrombozyten die Versuchs- 
ergebnisse verfälschen. Auch die Kultivierungskonditionen, wie etwa Materialien aus Plastik können den Phänotyp der Zellen verändern (Urbich und Dimmeler 2004). Die mittels dieser Methode isolierten hämatopoetischen Zellen spiegeln jedoch durchaus die proangiogene Aktivität wider. Die isolierten Zellen differenzieren sich nicht zu langlebigen Endothelzellen, wirken aber proangiogen (Yoder 2013).

Ito et al. 1999 erweiterten diese erste Methode. Genauso wie zuvor plattierten sie die isolierten Zellen auf mit Fibronektin benetzten Platten aus. Einen Tag später entfernten sie die nicht haftenden Zellen und plattierten diese wiederum auf mit Fibronektin benetzten Platten aus. Das Replattieren nach 24 Stunden (Urbich und Dimmeler 2004) sollte der Entfernung jeglicher Monozyten, Makrophagen oder zirkulierender reifer Endothelzellen dienen, die die Ergebnisse hätten verfälschen können.

Nach 5-9 Tagen (Zaccone et al. 2015) entstehen bei dieser Methode zentral runde und peripher spindelartige Zellen. Diese wurden später (s.u.) als CFU-ECs definiert und spiegeln die Anzahl der mutmaßlichen EPCs wider (Zaccone et al. 2015).

Hill et al. (2003) optimierten die Methode weiter, indem sie den Zeitraum vor dem Replattieren auf 48 Stunden verlängerten. Diese Variante hat sich heute durchgesetzt. Die so gewonnenen mutmaßlichen EPCs werden colony forming unit Hill (CFU-Hill, entsprechend CFU-EC) genannt. Mittels dieses Versuches konnte nachgewiesen werden, dass eine signifikant inverse Korrelation zwischen der Konzentration der zirkulierenden CFU-Hill und den kardiovaskulären Risikofaktoren nach dem Framingham-Score bei Menschen besteht (Hill et al. 2003).

Nach 7 Tagen Kultivierung zeigen CFU-ECs folgende Oberflächenmarker: CD34, CD105, CD144, VEGFR2, D31, Tie-2 und E-selectin (Zaccone et al. 2015). Sie besitzen die Fähigkeit AcLDL aufzunehmen (Critser und Yoder 2010).

Eine zweite Methode der Kultivierung sieht vor, dass die mononukleären Zellen 4 Tage in einem Medium wachsen. Anschließend werden die dem Boden anhaftenden Zellen analysiert, der Rest verworfen. Die so gewonnenen Zellen sind die bereits beschriebenen CACs. Diese sind phänotypisch und funktionell den CFU-ECs sehr ähnlich (Critser und Yoder 2010).

Nach einer dritten Methode werden mononukleäre Zellen auf einem Substrat aus Kollagen Typ 1 (zur Unterstützung endothelialen Wachstums) für 10-21 Tage kultiviert. In dieser Zeit 
werden nicht anhaftende Zellen wiederholt entfernt. Die Zellen, die nach dieser Zeit Kolonien bilden, entsprechen den ECFC (Critser und Yoder 2010).

In der Wissenschaft erfolgt die durchflusszytometrische Phänotypisierung typischerweise mit Hilfe der fluorescence-activated cell sorting-Analyse (FACS-Analyse). Die EPCs werden anhand ihrer exprimierten Zelloberflächen-Antigene identifiziert (Ablin et al. 2009) und als cEPCs bezeichnet. Auch in der vorliegenden Arbeit wurde die FACS-Analyse angewandt. Bisher sind keine spezifischen Oberflächenmarker für EPCs identifiziert. Stattdessen werden eine Reihe von Markern ersatzweise genutzt, die die vaskulären Eigenschaften der cEPCs widerspiegeln (Yoder 2013).

Seit den ersten Publikationen von Asahara et al. (1997) sind CD34 und FLK1 als Marker für cEPCs gebräuchlich.

FLK1 (der Maus entstammend) oder KDR (menschlich, entspricht dem VEGFR-2 oder CD309) sind Rezeptoren für VEGF. Diese Oberflächenantigene sind weit verbreitet, etwa auch auf endothelialen und kardialen Zellen. So erklärt sich, dass FLK1 allein kein helfender Diskriminator, jedoch in Kombination geeignet ist, cEPCs zu identifizieren.

CD34 wird eigentlich auf der hämatopoetischen Stammzelle exprimiert. Allerdings ist CD34 auch ein weit verbreiteter Marker, der auf verschiedensten Zellen zu finden ist, etwa auf Tumorzellen, in sehr niedriger Anzahl auf epithelialen und mesenchymalen Zellen (Hirschi et al. 2008; Urbich und Dimmeler 2004). Jedoch auch die Kombination von FLK und CD34 ist nicht ausreichend, da CD34+/FLK+-Zellen auch CECs darstellen könnten.

Peichev et al. (2000) führten aus diesem Grund das Oberflächenantigen CD133 ein. Dieses ist ein 5-Transmembran-Zelloberflächen-Glycoprotein, das auf vielen epithelialen, hämatopoetischen Zellen zu finden ist. Dieser auch Prominin oder AC 133 genannte Marker ist ein höchst konserviertes Antigen mit bisher unbekannter biologischer Aktivität. CD133 ist nicht auf reifen Endothelzellen und mononukleären Zellen zu finden (Urbich und Dimmeler 2004; Khakoo und Finkel 2005; Zaccone et al. 2015). Zum Zeitpunkt der hämatopoetischen Zelldifferenzierung wird CD133 herabreguliert.

Peichev et al. (2000) diskutierten, dass endotheliale Zellen, die beide Moleküle (CD133 und KDR) exprimieren, unreifere Vorläuferzellpopulationen darstellen müssten, als Zellen, die nur eines der Antigene exprimieren. Da KDR auch auf embryonalen Angioblasten zu finden ist, gingen sie davon aus, dass dieses Antigen auch auf CD133-positiven Zellen mit angio- 
blastischer Aktivität (= cEPC) exprimiert werden könnte. Nach verschiedenen Versuchen definierten Peichev et al. (2000) menschliche EPCs als zirkulierende CD34-positive Zellen, die CD133 und KDR ko-exprimieren (Yoder 2013).

In verschiedensten Studien konnten seitdem statistisch signifikante Zusammenhänge zwischen der Blutkonzentration der cEPCs und den Krankheitsstadien verschiedener Erkrankungen nachgewiesen werden. Mithilfe der FACS-Messung konnte gezeigt werden, dass fast alle (> 90\%; Khakoo und Finkel 2005) CD133+FLK+CD34+-Zellen auch CD45 tragen, ein nicht auf Endothelzellen vorkommendes übliches Leukozyten-Antigen. Damit sind sie per definitionem hämatopoetischer Abstammung.

Initial versuchte man, auf EPCs den von-Willebrand-Faktor (vWF) und ähnliche, der Endothelzelle eigene Oberflächenmarker nachzuweisen. Dies gelang nicht. Plattierte man die Zellen jedoch für etwa eine Woche auf Fibronektin aus, wurde vWF exprimiert. Eine These dazu ist, dass CD133+/CD34+/VEGFR+-Zellen eine unreifere EPC mit sehr hohem proliferativen Potenzial darstellen. Diese Zellen bilden in der Folge CD133-/CD34+/VEGFR2+-Zellen mit einer limitierten proliferativen Kapazität.

$\mathrm{Zu}$ den typischen Oberflächenmarkern, die auf hämatopoetischen Zellen exprimiert werden, gehören CD34, CD117, CD105, CD144, CD184, CD309 und azetyliertes LDL (Yoder 2013).

\subsection{EPCs und verschiedene Zytokine}

Im Bereich geschädigter Arteriolen, Kapillaren und Venolen wirken EPCs reparativ, indem sie sich zu Endothelzellen differenzieren und in die Gefäßwände einlagern (Ablin et al. 2009).

Die basale Aufnahme von EPCs in das gesunde Gewebe ist sehr niedrig (Urbich und Dimmeler 2004). In geschädigtem Gewebe variiert die Aufnahme je nach Ausmaß des Schadens jedoch enorm (zwischen 0-90 \%). Die Zahlen der aufgenommenen EPCs in ischämisches Gewebe sind verschwindend gering. Trotzdem wird ihnen hier eine hohe Regenerationskraft zugesprochen. Diese große Wirkung ist auf ein Zusammenspiel mit verschiedenen pro-angiogenetischen und vasoprotektiven Wachstumsfaktoren zurückzuführen, wie im Tiermodell nachgewiesen werden konnte (Urbich und Dimmeler 2004). Zytokine und Wachstumsfaktoren werden lokal sezerniert und bewirken auf der einen Seite eine Mobilisierung und Bewegung der Zellen in geschädigte Areale. Auf der anderen Seite sind EPCs anscheinend auch selbst fähig, größere Mengen an Wachstumsfaktoren, wie etwa VEGF, SDF-1a, GM-CSF, HGF und IGF-1 zu exprimieren (Urbich und Dimmeler 2004). 
Diese Wachstumsfaktoren wiederum dienen der Proliferation, Migration und dem Überleben der reifen Endothelzellen (parakrine Effekte).

Physiologisch geht man davon aus, dass das vorherrschende Signal zur Mobilisierung der EPCs aus dem Knochenmark ein ischämischer Schaden ist. Dadurch werden VEGF oder SDF-1 vermehrt gebildet und in das Gefäßsystem abgegeben. Diese Signalmoleküle induzieren wiederum die Mobilisierung von EPCs aus dem Knochenmark. Das geschieht mittels eines Mechanismus, der von Proteinasen abhängig zu sein scheint (MMP-9 = MatrixMetalloproteinase). Weitere Faktoren, die mobilisierend auf EPCs wirken, sind unter anderem CG-CSF, GM-CSF und Erythropoetin (Urbich und Dimmeler 2004).

Die Mechanismen des Homings der EPCs und der Differenzierung bedürfen allerdings weiterer Forschung. Sie sind bisher nur schlecht verstanden (Urbich und Dimmeler 2004).

\section{Vascular Endothelial Growth Factor}

Einer der am ausgiebigsten untersuchten Mediatoren ist VEGF, der ursprünglich zunächst in Tumorgewebe nachgewiesen wurde. Sein Rezeptor KDR wird bereits seit langem zur Identifikation von EPCs herangezogen und machte auch eine Wirkung des VEGF selber auf EPCs wahrscheinlich. VEGF ist ein homodimeres Glycoprotein mit einem molekularen Gewicht von $45 \mathrm{kDa}$. Der Faktor wird von normalen Zellen synthetisiert, scheint desweiteren insbesondere in hypoxischem Geweben sowie bei bestimmten Tumorarten (Lymphomen) erhöht zu sein. VEGF wirkt lokal (parakrin), aber auch als Hormon im gesamten Organismus (Asahara et al. 1999). Im Tiermodell bewirkt die Gabe von exogenem VEGF eine Mobilisierung von EPCs in den Blutkreislauf. Dies geschieht schnell, innerhalb von 24 Stunden. Auch beim Menschen konnte, eng an die VEGF-Level geknüpft, eine Erhöhung der EPCs nachgewiesen werden. Bei Patienten nach Myokardinfarkt, Verbrennungen oder nach BypassOperationen beschrieben Urbich und Dimmeler (2004) miteinander korrelierende Spiegel von VEGF und EPCs. Zu dieser Beobachtung gibt es jedoch unterschiedliche Studienergebnisse (Groger et al. 2010; Piatkowski et al. 2013). Man geht davon aus, dass VEGF für die Differenzierung der EPCs, ähnlich wie zum Zeitpunkt der embryonalen Entwicklung, eine eminente Rolle spielt (Khakoo und Finkel 2005; Urbich und Dimmeler 2004). Im Gegensatz $\mathrm{zu}$ anderen Wachstumsfaktoren fördert VEGF nicht nur das Gefäßwachstum, sondern erhöht auch die Gefäßpermeabilität (Kalka et al. 2000). 


\section{SDF-1}

SDF-1 (stromal-cell-derived factor-1a oder CXCL12) ist ein weiterer chemotaktischer Faktor der hämatopoetischen Stammzelle. Auch für ihn wurde nachgewiesen, dass eine EPCZellbewegung ausgelöst wird. SDF-1a wird bei Tumorwachstum oder im Rahmen einer Hypoxie ausgeschüttet (Fang und Salven 2011; Foresta et al. 2011; Peichev et al. 2000; Schuh et al. 2008).

\section{Angiopoetin-1 / Angiopoetin-2}

Auch Angiopoetine scheinen eine bedeutende Rolle im Rahmen der Angiogenese und Neovaskularisation zu spielen. Hierbei sind Angiopoetin-1 und -2 die beiden am besten untersuchten Proteine der Gruppe, mit einem Molekulargewicht von jeweils etwa $70 \mathrm{kDa}$. Angiopoetin-1 und -2 wirken über eine Aktivierung des Tyrosinkinase-Rezeptors (Tie-2). Angiopoetin-1 teilt einen Großteil der VEGF-Eigenschaften. Während VEGF zu einem frühen Zeitpunkt der Gefäßbildung seine Aufgaben übernimmt, ist Angiopoetin-1 später am Gefäßremodeling, Maturation und Stabilisierung des Gefäßsystems beteiligt. Angiopoetin-1 ist ein potenter Mobilisierer der EPCs aus dem Knochenmark und schützt die Blutgefäße vor zu großem Plasma-Leck (Pfaff et al. 2006; Balaji et al. 2015). Antiopoetin-2 wiederum fungiert als Antagonist des Angiopoetin-1. Es wird nur dort exprimiert, wo Entzündung und vaskuläres Remodeling stattfinden.

\section{PDGF (platelet derived growth factor)}

PDGF umfasst eine Gruppe weiterer Wachstumsfaktoren, die äußerst wichtig für das Überleben und die Funktion verschiedenster Zellen zu sein scheinen. PDGF wird von EPCs sezerniert (Wyler von Ballmoos et al. 2010) und erhöht die Rekrutierung und Proliferation von perivaskulären Zellen in Gewebearealen, in denen Angiogenese stattfindet.

\section{TGF- $\beta$ (transforming growth factor- $\beta$ )}

Auch diese weitere Zytokinfamilie, der verschiedene Isoformen angehören, gehört zu den von EPCs sezernierten Zytokinen in geschädigten Gewebearealen. TGF- $\beta$ wird, wie auch oben genannten Zytokinen, eine wichtige Rolle im Rahmen der Angiogenese zugesprochen (Evrard et al. 2012). Weitere Zytokine mit unterschiedlichen Wirkungen auf die verschiedenen EPCSubpopulationen sind G-CSF und GM-CSF (Tura et al. 2010). TNF- $\alpha$ scheint inhibierend zu wirken (Chen et al. 2011; Xu et al. 2011). 


\subsection{Weitere Stimulanzien und inhibierende Faktoren auf die EPC-Anzahl}

Stimulierende und inhibierende Faktoren modulieren die Anzahl der EPCs und beeinflussen die vaskuläre reparative Kapazität des Körpers.

Bereits bei gesunden Probanden konnten unterschiedliche EPC-Zahlen festgestellt werden. So besitzen Kinder einen vielfach höheren EPC-Spiegel als ältere Menschen (Jie et al. 2009). Wird regelmäßig Sport betrieben, wirkt dies der mit dem Alter sinkenden EPC-Anzahl entgegen, jedoch erst ab einem Mindestmaß an sportlicher Betätigung. Wird die sportliche Betätigung beendet, scheint der EPC-Spiegel schnell wieder zu sinken (Steiner et al. 2005; Walther et al. 2008; Laufs et al. 2005).

Auch Östrogene bewirken eine Mobilisierung von EPCs aus dem Knochenmark in die Peripherie. Die Reendothelialisierung der Carotiden geht wesentlich schneller vonstatten bei Mäusen, die mit Östrogenen behandelt wurden, als bei jenen, die keine Östrogene erhielten (Iwakura et al. 2006).

Desweiteren wirken externe Faktoren auf das System der EPC. Dazu gehört etwa Rotwein. Der Genuss scheint die Anzahl der EPCs zu erhöhen und ihre Funktionalität zu verbessern (Huang et al. 2010). Nikotinkonsum, Risikofaktoren für die KHK oder Hypercholesterinämie auf der anderen Seite wirken inhibierend auf das System der EPC (Hill et al. 2003; Vasa et al. 2001).

Ferner haben verschiedene Medikamente Einfluss auf die Funktion und Anzahl der EPCs. So konnte in veschiedenen Studie gezeigt werden, dass bestimmte HMG-CoA-ReduktaseInhibitoren (Statine) die Anzahl der zirkulierenden EPCs erhöhen (Walter et al. 2002; Llevadot et al. 2001). Dieser positive Effekt scheint jedoch nur über einen Zeitraum von maximal einem Monat anzudauern, ehe die Anzahl der cEPCs unter Statin-Therapie (Atorvastatin und Simvastatin) sinkt (Hristov et al. 2007). Bei der RA wurden insgesamt erniedrigte EPC-Level gemessen. Wurden die Patienten jedoch mit Infliximab, einem TNF- $\alpha$-Blocker, behandelt, schienen die Zahlen wieder zu steigen (Urbich und Dimmeler 2004). Die Wirkung weiterer Medikamente ist steter Bestandteil der Forschung. 


\subsection{EPCs im Rahmen pathologischer Zustände - Stand der Forschung}

Im Tierversuch beobachteten Asahara et al. (1999) erstmals, dass EPCs sich in Bereichen der Neovaskularisation von ischämischem Gewebe ansiedeln und dort den Blutfluss sowie die Endorganfunktion verbessern (Urbich und Dimmeler 2004). Auch im Rahmen einer akuten renalen Ischämie, die im Mausmodell induziert wurde, konnte zumindest eine erhöhte Mobilisierung der EPCs zunächst in die Milz, später dann in die medullopapilläre Region der Niere mit schützendem Effekt nachgewiesen werden (Patschan et al. 2006).

Klinische Untersuchungen bestätigten ähnliche Beobachtungen auch für den Menschen. So führen aus dem Knochenmark ausgeschwemmte EPCs beim akuten ischämischen Insult zu einem besseren funktionellen Outcome (Sobrino et al. 2007). Bei Patienten nach Myokardinfarkt konnten EPCs in den Gefäßen der Infarktzone nachgewiesen werden. Infundierte EPCs verbesserten hier signifikant den Blutfluss, die kardiale Funktion und verminderten die ventrikuläre Narbenbildung (Urbich und Dimmeler 2004). Die Forschungsergebnisse zu dem Vorliegen von EPCs in ischämischen Arealen haben die Hoffnung geweckt, dass diese Zellen auch für therapeutische Zwecke, im Sinne etwa einer therapeutischen Vaskulogenese, genutzt werden können.

Als biologische Marker für kardiovaskuläre Erkrankungen tragen EPCs dazu bei, den Beginn und die Entwicklung der Atherosklerose zu verzögern und entsprechend das kardiovaskuläre Risiko zu senken (Ablin et al. 2009; Zhang et al. 2013). Eine Imbalance zwischen atheroprotektiven und proatherosklerotischen Faktoren, steht in direktem Zusammenhang zu einer Beeinflussung der EPC-Level und ihrer Funktion im Sinne einer verminderten vaskuloprotektiven Kapazität. Man nimmt an, dass eine dauerhafte Schädigung des Endothels zu einem Erschöpfen der EPC-Speicher führt. Ihr Angebot scheint limitiert zu sein (Urbich und Dimmeler 2004; Khakoo und Finkel 2005; Yoder 2013).

Die Zahl der cEPCs ist bei Patienten mit erhöhtem kardiovaskulären Risiko bzw. in Anwesenheit kardiovaskulärer Risikofaktoren signifikant vermindert (Rehman et al. 2003). Beispielsweise Diabetes, Hypercholesterinämie, Hypertension und Rauchen beeinträchtigen die Zahl und die funktionelle Aktivität der EPCs auch bei gesunden Freiwilligen (Urbich und Dimmeler 2004).

Da die entzündlichen rheumatischen Erkrankungen, wie auch die axSpA, meist mit einem erhöhten Atheroskleroserisiko einhergehen, interessierte die Funktionsweise der EPCs bei diesen Erkrankungen besonders: 
Verschiedene Arbeiten zur RA, dem Prototyp der rheumatischen Erkrankungen, zeigten ein wiederholt beeinträchtigtes EPC-System im Rahmen dieser Erkrankung (Herbrig et al. 2006; Grisar et al. 2005; Patschan et al. 2014).

Studien zu EPCs beim systemischen Lupus erythematodes zeigen unterschiedliche Ergebnisse. Westerweel et al. (2007) wiesen beim Lupus erythematodes verminderte EPCs (CD34+KDR+) mittels FACS-Analyse nach. Patschan et al. (2013) beschrieben zwar unveränderte EPC-Zahlen im Vergleich zu Gesunden, jedoch auch eine beeinträchtigte Regenerationsfähigkeit und Mobilisierung der Zellen.

Ablin et al. (2009) untersuchten EPCs im Rahmen der Psoriasisarthritis. Für die Psoriasis geht man, unabhängig von anderen Risikofaktoren, von einer um 57 \% erhöhten kardiovaskulären Mortalität aus (Ablin et al. 2009; Mehta et al. 2010). Die Ursachen hierfür sind bisher nicht bekannt. Methodisch wurden die EPCs per FACS-Analyse anhand der Oberflächenmarker CD34, KDR und CD133 bestimmt. Neben einer klinischen Untersuchung erfolgten weiterhin die Bestimmung der VEGF und CRP-Level. Hier zeigte sich eine Korrelation mit dem durchgeführten BASDAI-Index. Die Ergebnisse dieser Studie lassen an einer signifikanten Rolle der EPCs an der Pathogenese der Psoriasisarthritis zweifeln.

Auch Patienten mit axSpA haben ein dauerhaft erhöhtes Atheroskleroserisiko. Das System der EPCs bei dieser Erkrankung wurde bisher jedoch nur in einer Studie von Verma et al. (2015) untersucht. Verma et al. (2015) führten eine FACS-Analyse durch und konnten bei AS-Patienten signifikant niedrigere Zahlen an CD34+/CD133+-Zellen nachweisen. Sie schlossen daraus auf ein mögliches großes therapeutisches Potenzial der Zellen für diese Erkrankung. Es muss jedoch bemerkt werden, dass die Autoren vermutlich keine Zellen analysierten, die als EPCs definiert werden, sondern tatsächlich hämatopoietische Vorläufer auszählten. Daher haben diese Ergebnisse für uns eine nur limitierte Aussagekraft. 


\section{$3 \quad$ Material und Methoden}

In die vorliegende Arbeit wurde ein Patientenkollektiv von 50 Patienten einbezogen. Im Vorfeld wurde die Studie durch die Ethikkommission der Universitätsmedizin Göttingen genehmigt. Alle Patienten wurden mündlich und schriftlich aufgeklärt und haben die Einverständniserklärung vor Einschluss in die Studie unterschrieben.

Um in die Studie einbezogen zu werden, musste eine axiale Spondylarthropathie (radiogen oder nicht radiogen) vorliegen. Nach der Aufklärung erfolgten Anamnese, klinische Untersuchung und Blutentnahme. Die Zellisolierung wurde im Labor der Abteilung durchgeführt. Die Vorgehensweisen sind im Folgenden einzeln aufgezeigt.

\subsection{Patientenkollektiv und Datengewinnung}

Für die vorliegende Arbeit wurde das Patientenkollektiv in der Rheuma - und Nierenambulanz des Universitätsklinikums Göttingen innerhalb eines Zeitraumes von 31 Monaten erhoben. Dafür wurde sowohl die Zustimmung der Ethikkommission (Ethikantragsnummer: 17/2/08) wie auch das Einverständnis der untersuchten Patienten schriftlich eingeholt. Die Studie wurde der Ethikkomission vorgelegt und genehmigt. Die Grundsätze der Deklaration von Helsinki wurden in den Untersuchungen berücksichtigt.

Eingeschlossen wurden Patienten mit einer axialen Spondylarthropathie (insgesamt 33 radiogen, 17 nicht radiogen) gemäß der ASAS-Kriterien nach Rudwaleit et al. (2009a) (s. Einleitung). Zur Einteilung des entzündlichen Rückenschmerzes wurden die Empfehlungen der ASAS-Experten von 2006 herngezogen (Rudwaleit et al. 2006). Die Einteilung bezüglich einer vorhandenen bzw. nicht vorhandenen positiven Familienanamnese erfolgte nach Rudwaleit et al. (2009b). Patienten mit Psoriasisarthritis, reaktiver Arthritis oder enteropathischer Arthritis wurden aus der Studie ausgeschlossen.

Die benötigte Blutentnahme erfolgte im Rahmen der klinischen Routine. Die Proben wurden zeitnah verarbeitet, spätestens innerhalb von vierundzwanzig Stunden. Persönliche Angaben $\mathrm{zu}$ organischen Erkrankungen und den zurzeit eingenommenen Medikamenten wurden erfragt, alle weiteren Daten aus der Akte des Patienten entnommen. Weiterhin erfolgte eine kurze körperliche Untersuchung mit dem Hauptaugenmerk auf die Wirbelsäulenbeweglichkeit. 


\subsection{Bestimmung der EPCs}

Um das System der EPCs bei Patienten mit axSpA beurteilen zu können, wurden jeweils ein CFU-Hill-Assay und eine FACS-Messung durchgeführt. Anschließend folgte desweiteren ein ELISA.

\section{Zellisolation aus heparinisiertem Blut}

Zur Isolation der Lymphozyten und Monozyten wurde heparinisiertes Blut verwendet. Dieses wurde spätestens innerhalb von vierundzwanzig Stunden verarbeitet. In der Regel erfolgte die Verarbeitung direkt im Anschluss an die Blutentnahme. Der gesamte Prozess der Isolierung fand unter sterilen Bedingungen statt. Hierzu stand eine Sterilbank zur Verfügung.

Das Blut wurde in Lithium-Heparin-Röhrchen gewonnen. Ein Volumen von durchschnittlich etwa $20 \mathrm{ml}$, entsprechend zwei gefüllten großen Monovetten, war für die folgenden Versuche notwendig.

Die einzelnen Proben wurden per Pipette zunächst in einem Greiner-Röhrchen $(50 \mathrm{ml})$ auf 15 ml Ficoll-Trennlösung (Ficoll-Paque ${ }^{\mathrm{TM}}$ Plus) geschichtet. Diese Trennlösung enthält Polysucrose. Zur optimalen Schichtung ist ein Vermischen der beiden Flüssigkeiten zu vermeiden.

Anschließend wurden die Proben eine halbe Stunde bei 1400 Umdrehungen pro Minute zentrifugiert. Die Bremse war hierbei ausgeschaltet. So konnten die mononukleären Zellen in einer bestimmten Schicht gehalten werden, was die anschließende Gewinnung erleichterte.

Mit Hilfe der Trennlösung hatte sich im Greiner-Röhrchen nun eine Dreischichtung gebildet. Ficoll (Dichte: 1,077 g/ml) hatte einen Dichtegradienten erzeugt. Die Erythrozyten- und Granulozytenfraktion befand sich am Boden des Greiner-Röhrchens unterhalb der Trennlösung. Die gewünschte Lymphozyten- und Monozytenfraktion, inklusive der EPCs, bildete die Schicht darüber.

Zuoberst schichtete sich das Plasma. Hiervon wurden $2 \mathrm{ml}$ abpippetiert und in einem Eppendorf-Röhrchen bei $-20{ }^{\circ} \mathrm{C}$ eingefroren. Diese Proben dienten einem späteren ELISA zur Bestimmung der VEGF-Konzentration.

Zur Isolierung der EPCs wurde nun die Lymphozyten- und Monozytenfraktion abpipettiert, die sich an der Grenze zwischen Ficoll-Trennlösung und Plasma befand. 
Mit etwa $50 \mathrm{ml}$ PBS (phosphate-buffered saline) aufgefüllt, wurden die Zellen anschließend 10 Minuten bei 1400 Umdrehungen mit Bremse zentrifugiert. Es bildete sich ein Zell-Pellet am Boden des Greiner-Röhrchens. Der Überstand wurde verworfen.

PBS ist eine isotonische Pufferlösung, die das Arbeiten bei konstantem pH-Wert ermöglicht. Dies ist für die empfindlichen menschlichen Zellen unbedingt erforderlich. Insbesondere um ein mögliches Zellwachstum bzw. eine Kolonienbildung zu überprüfen, ist die Gewährleistung eines stabilen $\mathrm{pH}-\mathrm{Werts}$ unabdingbar.

Nach der Isolation der Lymphozyten und Monozyten mit den EPCs folgten FACS-Analyse und CFU-Hill-Assay.

\section{Ermittlung der Zellzahl}

Die Zell-Pellets wurden wiederum mit $50 \mathrm{ml}$ PBS aufgefüllt und darin gelöst.

Ein Hämozytometer (Neubauer-Zählkammer) wurde vorbereitet. Das Glas musste vor der Verwendung frei von Staub, Zellen oder anderen Rückständen sein. Das Deckglas wurde auf die einem Objektträger ähnliche Grundplatte gedrückt bis Newton’sche Interferenzfarben sichtbar wurden. Diese gewährleisten die gewünschte Höhe des Zwischenraums $(0,1 \mathrm{~mm})$ und somit die Vergleichbarkeit der verschiedenen Proben. $12 \mu \mathrm{l}$ der Teilchensuspension wurden auf die Oberfläche gegeben und unter einem Mikroskop bei 125 facher Vergrößerung ausgezählt. Stets wurden mehrere Eckquadrate ausgezählt und der errechnete Mittelwert, um eventuelle Verteilungsfehler auszugleichen, weiter verwendet. Standardmäßig wird der Mittelwert pro Eckquadrat mit zehn multipliziert, um die Zellzahl pro $\mu$ l (Mikroliter) zu erhalten. Hieraus ergibt sich die Gesamtzellzahl in $50 \mathrm{ml}$ PBS.

Die gewonnenen Zellen wurden für die Anlage der Zellkultur und zur FACS-Analyse verwendet.

Für die FACS-Analyse wurden $1,5 \times 10^{6}$ Zellen/100 $\mu$ l verwendet. Der Rest diente der Anlage der Zellkultur und wurde im weiteren Verlauf auf die verschiedenen Wells aufgeteilt.

Die Röhrchen wurden nun ein weiteres Mal bei 1400 Umdrehungen mit Bremse zentrifugiert, die Überstände verworfen. 


\section{Aufbereitung der Zellen für die quantitative Messung am FACS-Gerät}

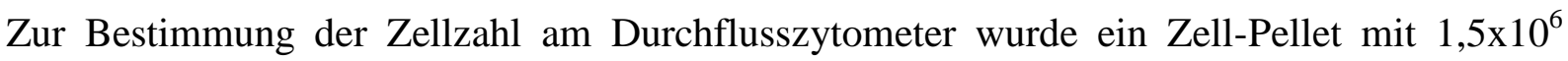
Zellen/100 $\mu 1$ in $666 \mu$ l PBS BSA (1 \%) gelöst. Fünf Versuchsansätze wurden mit jeweils 100

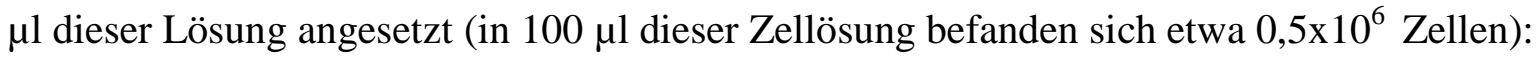

1. ungefärbte Vergleichsprobe

2. isotyp-Kontrollprobe

3. Kontrolle, gefärbt mit sekundärem Antikörper

4. Antikörper gegen CD133 und FLK

5. Antikörper gegen CD133 und cKit

In einem ersten Schritt wurde zu allen Ansätzen $1 \mu \mathrm{FcR}$ blocking reagent gegeben, um unspezifische Bindungen abzufangen. Nach 10 Minuten Inkubation bei $4{ }^{\circ} \mathrm{C}$ wurde mit $2 \mathrm{ml}$ PBS-BSA gewaschen und 5 Minuten bei 1400 Umdrehungen pro Minute zentrifugiert. Die Überstände wurden verworfen.

In einem zweiten Schritt wurden Probe 4 und 5 mit den beiden Primärantikörpern versetzt

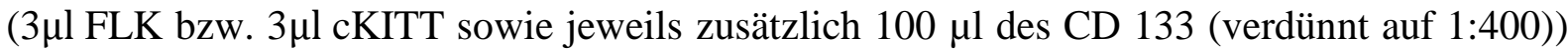
Probe 4 diente der Oberflächenmarkierung der EPCs. Beide Proben wurden 30 Minuten bei 4 ${ }^{\circ} \mathrm{C}$ inkubiert, anschließend mit PBS-BSA gewaschen und zentrifugiert. Der Überstand wurde verworfen.

In einem letzten Schritt wurde Probe 2 zur Kontrolle mit $1 \mu$ l eines unspezifischen Antikörpers (IgG-FITC/IgG2a-PE) versetzt, um diese auf unspezifische Bindungen zu testen. Die Proben 3, 4, 5 wurden mit $1 \mu$ l eines sekundären Antikörpers (PE goat anti rabbit FAB) versetzt. Es erfolgte die erneute Inkubation bei $4{ }^{\circ} \mathrm{C}$ für maximal 30 Minuten (bei längerem Zeitraum hätte es zu unspezifischen Bindungen kommen können). Anschließend wurden wiederum alle Proben mit PBS-BSA gewaschen und zentrifugiert.

Nun erfolgte jeweils die Lösung in $500 \mu \mathrm{l}$ PBS-BSA und die Messung am Durchflusszytometer. 


\section{Durchflusszytometrie zur quantitativen Beurteilung der EPCs}

Zur quantitativen Beurteilung der EPCs wurde die Durchflusszytometrie mittels FACSCalibur herangezogen. Dieses Gerät dient der gleichzeitigen Messung und Analyse von Zellen oder Bestandteilen von Zellsuspensionen.

Dazu besteht das FACS-Gerät

1. aus einem Flüssigkeitssystem, das die einzelnen Partikel in einem Strom zwecks Analyse zum Laserstrahl transportiert,

2. aus einem optischen System, bestehend aus Lasern und optischen Filtern zur Beleuchtung der einzelnen Partikel in dem Flüssigkeitsstrom,

3. aus einem elektronischen System, das dafür sorgt, dass die Lichtsignale in elektrische Signale umgewandelt werden, diese Ergebnisse entsprechend speichert und zur Auswertung bereitstellt.

Die Zellen werden einzeln nacheinander durch einen Mikrokanal einer Küvette geleitet. Der Laserstrahl trifft auf die Zellen. Entsprechend ihren physikalischen Eigenschaften (Größe, innere Komplexität) wird die Streuung des Lichtes gemessen und analysiert. Zellmembran, Nukleus und jedes granuläre Material der Zellen beeinflussen die Streuung des Lichtes. Vorwärtsgerichtetes Streulicht ist proportional zur Größe der Zelloberfläche. Seitwärtsgerichtetes Streulicht spiegelt die Granularität oder die innere Komplexität wider. Zugleich kann das FACS-Gerät Fluoreszenzfarben messen.

Am FACS-Calibur wurden jeweils alle 5 Röhrchen gemessen. Die ungefärbten Proben dienten dem sogenannten gating (Abbildung 6). Bei dieser ersten Messung wird der Bereich bestimmt, in dem die Zellen basierend auf ihrer Zellgröße und Granularität gezählt werden sollen.

Zur Beurteilung der EPC-Zahlen werden CD133 / FLK-1-doppelt-positive Zellen in der myelo-monozytären Zellpopulation gezählt. CD133/cKit-positiv sind hämatopoetische undifferenzierte Stammzellen zu Vergleichszwecken.

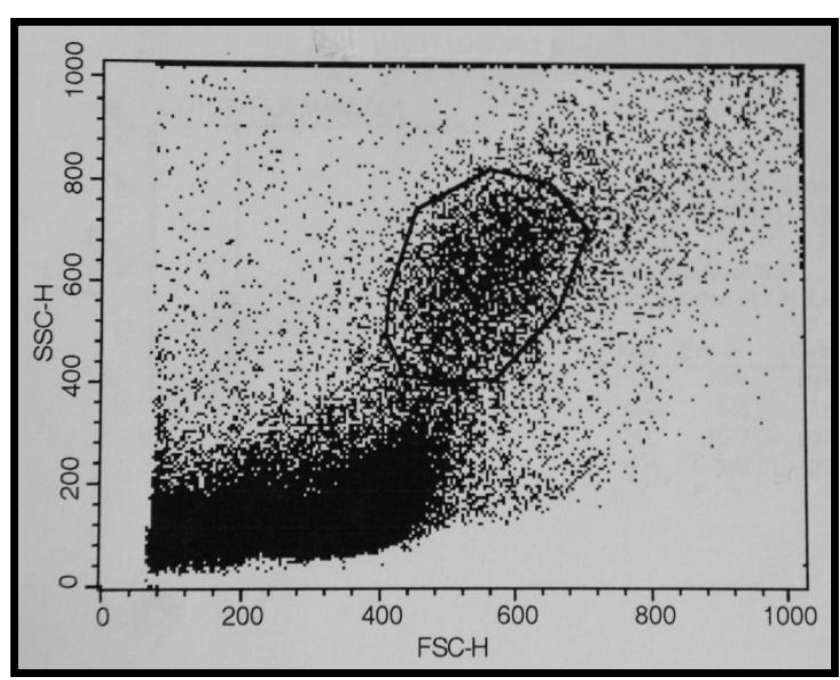

Abbildung 6: Festlegen des gewünschten Messbereiches am FACScalibur (,gating“) SSC=side scatter (Seitwärtsstreulicht), FSC=forward scatter (Vorwärtsstreulicht) 
Vor der Auswertung wurden falsch positive Zellen in der Sekundärantikörper-Kontrolle abgezogen, um unspezifische Bindungssignale auszuschließen.

\section{CFU-Hill-Assay}

Die Durchführung des etablierten 5-day-CFU-Hill-Colony-Assay erfolgte nach Hill et al. (2003).

Die 6er Wellplatten wurden zum Ausplattieren vorbereitet. Dazu wurden die einzelnen Wells mit $2 \mathrm{ml}$ Fibronektin (0,1 prozentig) benetzt und eine Stunde bei Raumtemperatur inkubiert. Anschließend wurde das Fibronektin abpippettiert und die Wellplatten eine weitere Stunde steril getrocknet. Sie waren nun zur Beschichtung bereit.

Auf die gleiche Art und Weise wurde mit den ersten sechs Wells der 24er Wellplatten verfahren, die erst am dritten Tag benötigt wurden. Well 4-6 wurden vor der FibronektinBenetzung mit sterilen Glasplättchen bestückt.

Das Pellet mit den isolierten Zellen wurde in einem Nährmedium, dessen Komponenten (EndoCult ${ }^{\circledR}$ Basal Medium und EndoCult ${ }^{\circledR}$ Supplements) vorher entsprechend zusammengefügt worden waren, gelöst. $2 \mathrm{ml}$ der Nährmedium-Zellsuspension enthielten $5 \times 10^{6}$ Zellen. Jedes Well wurde mit $2 \mathrm{ml}$ der Zellsuspension bestückt.

Well 1 wurde hinterher ausgezählt und diente dem Vergleich. Die restlichen Zellen wurden auf die nächsten fünf Wells verteilt, mit jeweils ähnlicher Zellzahl. Hiermit wurden in der Folge spezifische Färbungen für weitere Messungen am Zellkulturmikroskop durchgeführt.

Das 6er Well wurde 2 Tage bei $37{ }^{\circ} \mathrm{C}$, über $95 \%$ Luftfeuchtigkeit und $5 \% \mathrm{CO}_{2}$ im Wärmeschrank inkubiert. Dieser Schritt diente der Entfernung von reifen Endothelzellen und Monozyten. Sie hatten sich nach dieser Zeit auf dem Plattenboden abgesetzt.

Nach zwei Tagen wurden die sich noch in Lösung befindlichen EPCs auf das vorbereitete 24er Well übertragen und mit frischem Nährmedium aufgefüllt. Der Inhalt von Well 1 wurde exakt in Well 1 des 24er Wells übertragen, der Rest auf die nächsten 5 Wells verteilt. Nochmals wurden die Proben über drei Tage unter gleichen Bedingungen inkubiert.

Am sechsten Tag wurden die gebildeten Kolonien unter dem Mikroskop gezählt. CFU-Hill-Kolonien weisen in ihrem Zentrum runde Zellen auf. In der Peripherie finden sich radiär in alle Richtungen angeordnete spindelförmige Zellen. 


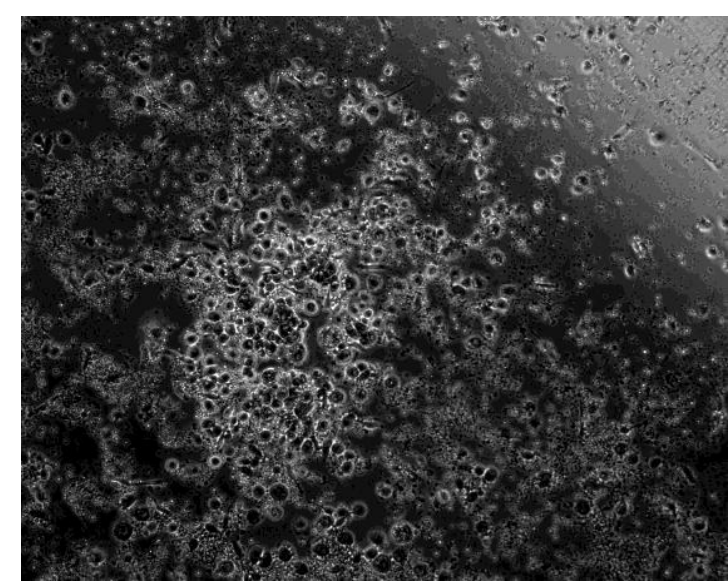

Abbildung 7: CFU-Hill-Assay, Kolonien an Tag 6 Bild 1

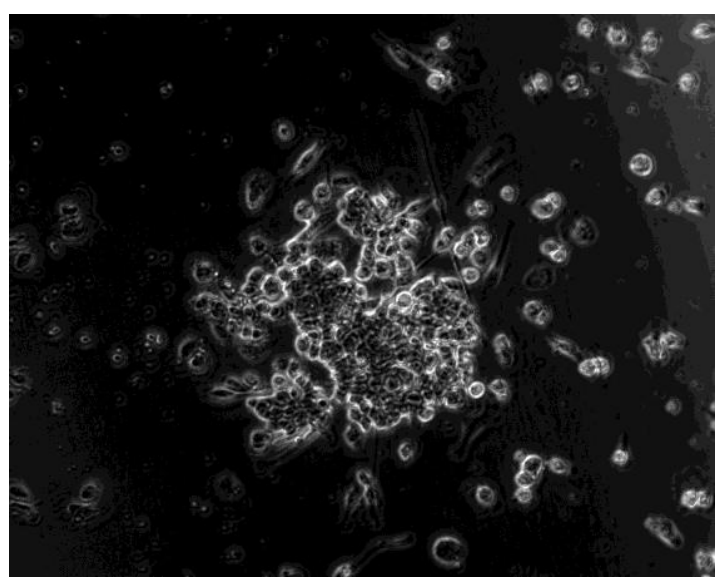

Abbildung 7: CFU-Hill-Assay, Kolonien an Tag 6 Bild 2

\section{Bestimmung von VEGF, PDGF, TGF- $\beta$, Angiopoetin-1 und -2}

Die Serumkonzentration der folgenden vasomodulatorischen Mediatoren wurde mittels Sandwich-ELISA bestimmt: VEGF, PDGF, TGF- $\beta$, Angiopoetin -1 und -2.

Diese ELISA-Methode wurde aufgrund der sehr geringen Antigenkonzentrationen gewählt. Hierzu wurde jeweils der Untergrund eines Wells mit dem sogenannten Fangantikörper (capture antibody) bemantelt. Die das Antigen enthaltende Probe wurde hinzugefügt und das entsprechend gesuchte Antigen (in diesem Falle jeweils einer der oben genannten vasomodulatorischen Mediatoren) an den Fangantikörper gebunden. Anschließend wurde ein zweiter unmarkierter Detektionsantikörper, der den Sandwich-ELISA vervollständigt, hinzugegeben. Zur Quantifizierung wurde zuletzt mittels sekundär markiertem Antikörper eine enzymatische Farbreaktion katalysiert. Diese erlaubte eine genaue Quantifizierung des Ergebnisses.

\section{Materialien zur einmaligen Nutzung}

\begin{tabular}{|c|c|c|}
\hline Material & Hersteller & Katalognummer \\
\hline E-Cup, $1,5 \mathrm{ml}$ & Eppendorf AG, Hamburg & 0030125.150 \\
\hline Pipettenspitzen, diverse & Eppendorf AG, Hamburg & \\
\hline Röhrchen, 50ml & Sarstedt AG\& Co, Nümbrecht & 62.547 .254 \\
\hline $\begin{array}{l}\text { Röhrchen, 5ml, } \\
\text { für FACS-Analyse }\end{array}$ & Sarstedt AG\& Co, Nümbrecht & 55.1579 \\
\hline 24-Well cell Culture Plate & CELLSTAR & 662160 \\
\hline MULTIWELL $^{\text {TM }} 6$ Well & FALCON & 353046 \\
\hline
\end{tabular}

Tabelle 1: $\quad$ Liste der verwendeten Verbrauchsmaterialien 


\section{Materialien}

\begin{tabular}{|l|l|}
\hline Gerät & Hersteller \\
\hline CO2 INCUBATOR (Wärmeschrank) & Sanyo \\
\hline Eppendorf-Pipetten & Eppendorf AG, Hamburg \\
\hline FACS-Calibur & Becton Dickinson \\
\hline Gefrierschrank & Sanyo \\
\hline Kühlschrank & Liebherr \\
\hline Mikroskop: Diavert Inverses Zellkulturmik- & $\begin{array}{l}\text { Leica Microsystems } \\
\text { roskop Olympus IX-81 }\end{array}$ \\
\hline Sterilbank Clean Air Typ CA/R & Biohazard \\
\hline Vortex Genie 2 & Bodo Schmidt GmbH \\
\hline Zentrifuge: Megafuge 1.0R & Heraeus instruments GmbH \\
\hline Zentrifuge: Rotixa/A & Hettich \\
\hline
\end{tabular}

Tabelle 2: $\quad$ Zusammenfassung der verwendeten Instrumente / Geräte

\begin{tabular}{|c|c|c|}
\hline Substanz & Herstellerfirma & Katalognummer \\
\hline Biocoll 1,0777 g/ml & Biochrom AG, Belin & L6115 \\
\hline BSA pH 7.0 & LabClinics SA & K41-001 \\
\hline Dil AcLDL & Molecular Probes & L3484 \\
\hline Endocult Basal Medium & StemCell Technologies Inc & 05901 \\
\hline Endocult Supplement & StemCell Technologies Inc & 05902 \\
\hline FcR Blocking Reagent & Millenyi Biotec & $120-000-442$ \\
\hline \multicolumn{3}{|l|}{ Fibronektin } \\
\hline $\begin{array}{l}\text { FLK = mouse-anti-human } \\
\text { VEGFR2 }\end{array}$ & R\&D Systems, Minneapolis & FAB 357F \\
\hline \multicolumn{3}{|l|}{ Formalin } \\
\hline \multicolumn{3}{|l|}{ Hydrochlorid } \\
\hline Lectin from Ulex europaeus & SIGMA-ALDRICH & L9006-1MG \\
\hline $\mathrm{PBS}$ pH7.4 & GIBCO & $10010-015$ \\
\hline sekundärer PE-Antikörper & $\begin{array}{l}\text { Jackson Immunoresearch, } \\
\text { Baltimore, USA }\end{array}$ & $111-116-144$ \\
\hline
\end{tabular}

Tabelle 3: $\quad$ Liste der verwendeten Reagenzien 


\subsection{Scores und klinische Untersuchungsmethoden}

Im Rahmen der klinischen Untersuchung wurden verschiedene Untersuchungsmethoden zur Beurteilung der Beweglichkeit angewandt, die im Folgenden kurz erläutert werden. Aus einem Teil der klinischen Messwerte ergab sich der BASMI. Weiterhin wurden von allen Probanden mehrere Fragebögen zur Krankheitsaktivität und dem allgemeinen Gesundheitszustand bearbeitet (s.u.).

\section{Ott-Maß (oberes Schober-Zeichen)}

Bei der Messung der Brustwirbelsäulenbeweglichkeit in der Sagittalen nach Ott (s. Abbildung 9) werden beim stehenden Patienten auf Höhe des Dornfortsatzes des Vertebra prominens und $30 \mathrm{~cm}$ kaudal Markierungen vorgenommen. Die Strecke wird erneut bei maximaler Beugung des Rumpfes nach vorne gemessen. Hier ist bei dem Gesunden eine Verlängerung auf mindestens 33-36 cm zu erwarten (Ostendorf et al. 2014).

\section{Modifiziertes Schober-Maß nach Macrae und Wright}

Es wird die Beweglichkeit der Lendenwirbelsäule beurteilt. Es werden Markierungen $5 \mathrm{~cm}$ unterhalb des Dornfortsatzes des 5. Lendenwirbels (aufrecht stehend) und $10 \mathrm{~cm}$ kranial davon vorgenommen. Nach Anteflexion bei gestreckten Beinen wird der Abstand erneut gemessen. Eine Verlängerung um mindestens $8 \mathrm{~cm}$ erwartet man bei Wirbelsäulengesunden. Das modifizierte Schober-Maß (s.Abbildung 9) ist Bestandteil des BASMI (Feldtkeller und van der Heijde 2005).

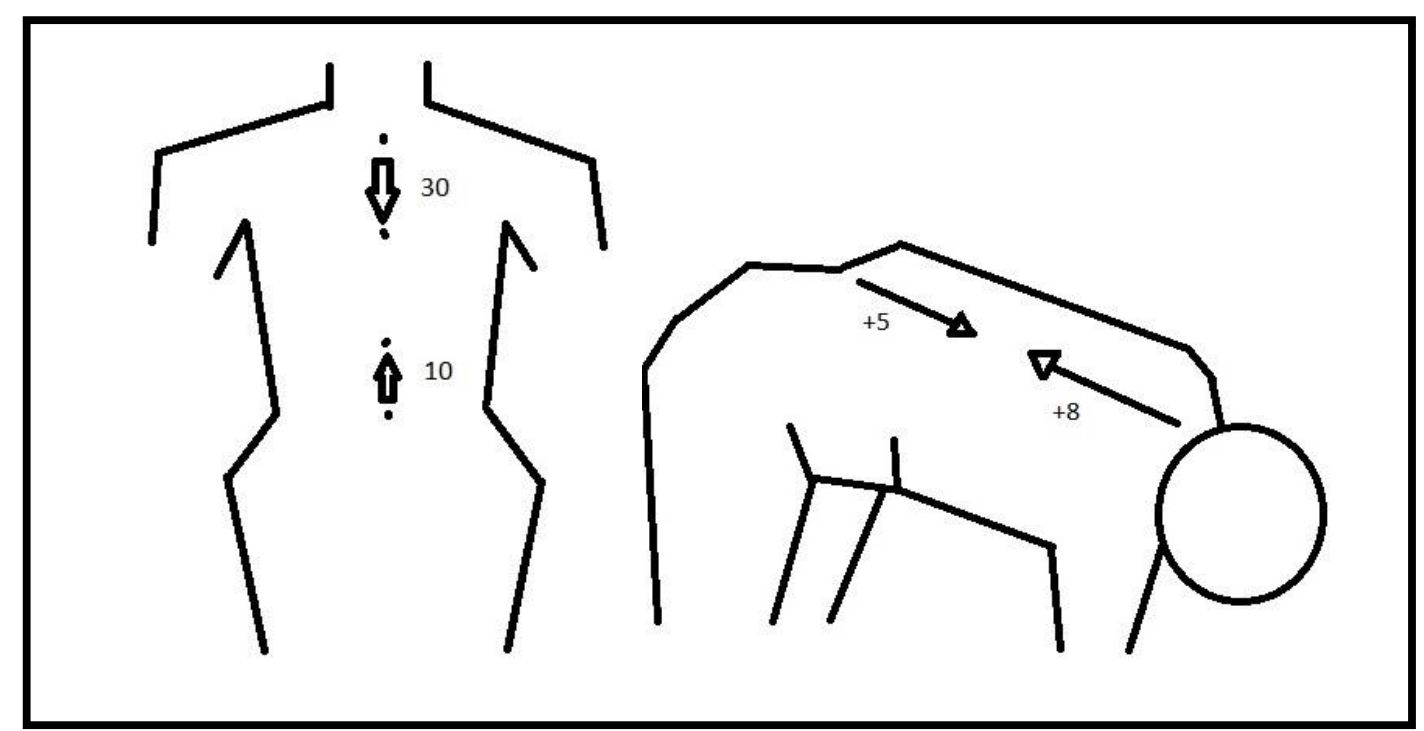

Abbildung 9: $\quad$ Schematische Darstellung Schober- und Ott-Maß

- $\quad$ (zu den Details der Messung sei auf den Text verwiesen) 


\section{Finger-Boden-Abstand (FBA)}

Der Patient beugt sich bei gestreckten Beinen so weit es geht nach vorne. Der Abstand zwischen Mittelfingerspitze und Fußboden wird gemessen. Dieser Messwert dient der Beurteilung von Wirbelsäule sowie der Hüftgelenke und der ischiocruralen Muskulatur. Er wird in der Klinik häufig zur Verlaufsbeobachtung verwendet (Feldtkeller und van der Heijde 2005).

\section{Wirbelsäulen-Seitneigung}

Am aufrecht stehenden Patienten wird der Abstand zwischen Fußboden und der am Körper geführten ausgestreckten Mittelfingerspitze gemessen. Eine erneute Messung erfolgt in maximaler Seitneigung, bei weiterhin durchgestreckten Beinen (keine Drehung!). Aus der Differenz zwischen erstem und zweitem Wert, für beide Seiten gemessen, wird der Mittelwert gebildet (Norm $>10 \mathrm{~cm}$ ) und dient der Berechnung des BASMI (van der Heijde et al. 2008).

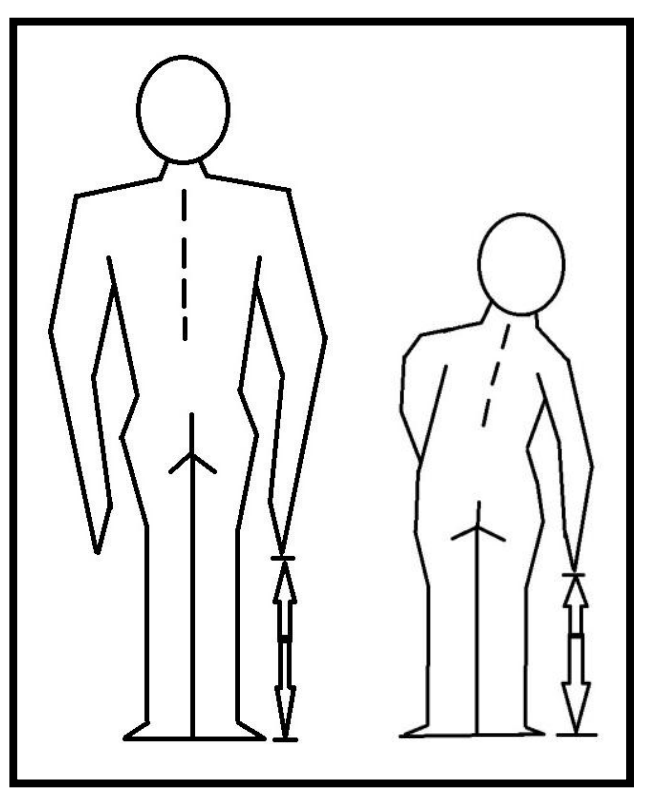

Abbildung 10: Schematische Darstellung Wirbelsäulen-Seitneigung (für Details zur Messung sei auf den Text verwiesen)

\section{Fußknöchel-Abstand}

Dieses Maß dient der Beurteilung der Hüftgelenksbeweglichkeit. Beim liegenden Patienten wird der Abstand zwischen den Innenknöcheln bei maximal gespreizten Beinen (gestreckte Knie, Fußspitzen nach oben) gemessen (Norm $>100 \mathrm{~cm}$ ). Dieser Wert geht in den BASMI mit ein (Feldtkeller und van der Heijde 2005). 


\section{Tragus-Wand-Abstand}

Diese Messung dient der Beurteilung der Kyphose. Der Abstand zwischen Tragus und Wand wird beim aufrecht mit dem Rücken und den Fersen an der Wand stehenden Patienten gemessen und ist ebenfalls Bestandteil des BASMI (Feldtkeller und van der Heijde 2005).

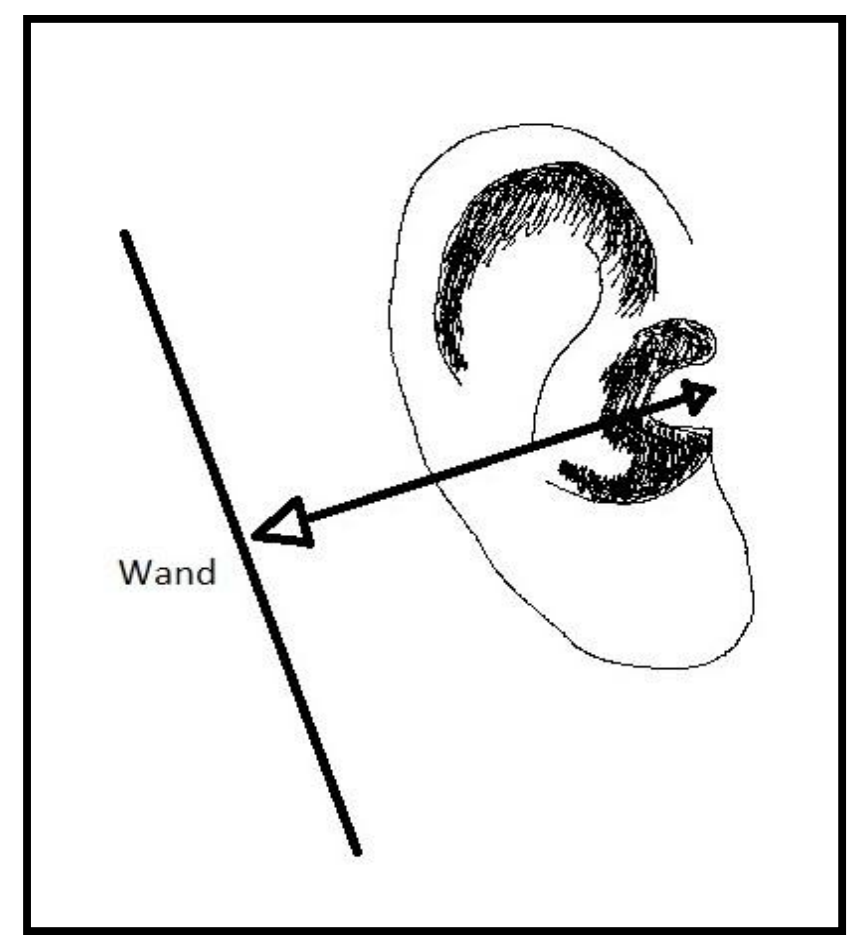

Abbildung 11: Schematische Darstellung Tragus-Wand-Abstand, (für Details zur Messung sei auf den Text verwiesen)

\section{Halswirbelsäulen-Rotation}

Bei aufrecht sitzendem Patienten, mit geradeaus gerichtetem Blick wird der Kopf, so weit es geht, nach rechts und links rotiert $\left(\right.$ Norm $\left.>70^{\circ}\right)$. Der Winkel zwischen maximaler Drehung und der Null-Stellung dient der Berechnung des BASMI. Die Schultern dürfen nicht mitgedreht werden (Feldtkeller und van der Heijde 2005).

\section{BASMI}

Der Bath Ankylosing Spondylitis Metrology Index wird aus verschiedenen klinischen Messwerten zur Beurteilung der Wirbelsäulenbeweglichkeit und eventueller Einschränkungen gebildet. Dazu gehören das modifizierte Schober-Maß, die Lendenwirbelsäulen-Seitneigung, maximaler Fußknöchelabstand, Tragus-Wand-Abstand, Halswirbelsäulen-Rotation (Berechnung s. Anhang). Dieser Index wurde 1994 in der englischen Stadt Bath eingeführt. In 
der Klinik werden die einzelnen Messwerte häufiger verwendet als dieses Summenmaß (van der Heijde et al. 2008).

\section{BASDAI/ASDAS}

Der wichtigste und zurzeit am häufigsten in der Klinik eingesetzte Score ist der BASDAIIndex (Bath Ankylosing Spondylitis Disease Index). Dies ist ein Fragebogen (s. Abbildungsverzeichnis) mit $10 \mathrm{zu}$ beantwortenden Fragen über den Alltag des Patienten und dient der Beurteilung der Krankheitsaktivität. Ein BASDAI $\geq 4$ spricht für eine hohe Krankheitsakivität (Garrett et al. 1994).

Erst kürzlich wurde ein optimierter Score zur Verwendung empfohlen, der ASDAS (Ankylosing Spondylitis Disease Activity Score). Hier werden im Unterschied zum BASDAI unter anderem Laborparameter (C-reaktives Protein) berücksichtigt (van der Heijde et al. 2009; Slobodin et al. 2012). Folgende Einteilung für den ASDAS wurde anhand vorliegender Daten von Experten definiert: $<1.3=$ inaktiv, 1.3-2.0 = moderat, 2.1-3.4 = hoch, $\geq=$ sehr hohe Krankheitsaktivität (Machado et al. 2011). Die Berechnung des ASDAS erfolgte mittels des ASDAS-Rechners (s. Literaturverzeichnis).

\section{BASFI}

Seit 1997 dient der BASFI (Bath Ankylosing Spondylitis Functional Index) der Erhebung von körperlichen Beeinträchtigungen der Patienten im alltäglichen Leben. Auch dazu wird ein Fragebogen beantwortet (s. Anhang) und anschließend ein Score zwischen 0 (keine Einschränkungen) und 10 (maximale Einschränkungen) errechnet (Calin et al. 1994).

\section{BAS-G}

Der BAS-G (Bath Ankylosing Spondylitis Global Score) soll auf einer Skala zwischen 0 und 10 den allgemeinen Gesundheitszustand der Patienten beurteilen (s. Anhang). Dieser Score korreliert mit BASDAI und BASFI (Jones et al. 1996). 


\subsection{Statistische Auswertung}

Die Auswertung der Ergebnisse erfolgte mit dem Programm STATISTICA von statsoft.

Zunächst wurden die Daten mittels des Shapiro-Wilks-W-Tests jeweils auf Normalverteilung getestet. Statistica verwendet eine durch Royston 1992 beschriebene Eweiterung dieses Tests. Bei den erhobenen Daten liegt keine Normalverteilung vor.

Weiterhin wurde die deskriptive Statistik, insbesondere mit dem Mittelwert und der Standardabweichung, mittels STATISTICA erstellt. Da keine Normalverteilung vorliegt, wurden „nicht-parametrische Verfahren“ zur Prüfung der statistischen Signifikanz verwendet. Hierzu wurde der Mann-Whitney-U-Test angewendet. Im Unterschied zum normalen t-Test bei Normalverteilung basiert dieser nicht auf den Mittelwerten, sondern auf der Basis der Rangsummen. Ein signifikanter Unterschied, das heißt ein überzufälliger Zusammenhang, wurde bei einem p-Wert unter einem Signifikanzniveau von 0,05 definiert.

Zur Darstellung der Zusammenhänge verschiedener Variablen wurde der Korrelationskoeffizient mittels Spearmans R, zudem das Signifikanzniveau berechnet.

Zur Veranschaulichung der Ergebnisse wurden Box-Plots und Scatterplots erstellt. 


\section{$4 \quad$ Ergebnisse}

\subsection{Patientenkollektiv}

In die vorliegende Studie wurden 50 Patienten eingeschlossen, davon $42 \%$ Frauen und $58 \%$ Männer. Die Patienten hatten zum Zeitpunkt der Untersuchung ein mittleres Alter von $45( \pm 15)$ Jahren.

$74 \%$ der Patienten waren HLA-B27-positiv. Über eine für die Spondylitis ankylosans positive Familienanamnese (eingeteilt nach Rudwaleit et al. 2009b: AS, reaktive Arthritis, Psoriasis, CED, Uveitis) berichteten $38 \%$ der Patienten.

Bei 33 Patienten (66 \%) war eine manifeste Spondylitis ankylosans diagnostiziert. Bei 17 Patienten (34\%) lag eine nicht radiogene axiale Spondylarthropathie vor.

Die mittlere Erkrankungsdauer seit der Erstdiagnose betrug 9 ( +9$)$ Jahre. Die Erstmanifestation lag im Schnitt etwa $18( \pm 13)$ Jahre zurück.

Zum Zeitpunkt der Untersuchung betrug das mittlere CRP $8,1 \mathrm{mg} / \mathrm{l}( \pm 18,7)$ und die mittlere BSG 11/21 mm ( \pm 18/23 mm). Damit hatten $42 \%$ der Patienten ein erhöhtes CRP.

Krankengymnastik führten 30 von 50 Patienten $(60 \%)$ regelmäßig durch. Eine von den Probanden beschriebene Morgensteifigkeit hielt im Schnitt 32,6 $( \pm 35,4)$ Minuten an.

Begleiterkrankungen waren in der Patientenkohorte sehr häufig. So fand sich mindestens eine definierte (AS, reaktive Arthritis, Psoriasis, CED, Uveitis) Erkrankung bei insgesamt 25 Patienten $(50 \%)$.

$32 \%$ der Patienten litten an einer arteriellen Hypertonie. Die für die axSpA typische Uveitis war bei $20 \%$ der Patienten schon einmal aufgetreten. Eine chronisch entzündliche Darmerkrankung fand sich bei $10 \%$. Ein Diabetes mellitus (Typ2) wurde nur bei 2 Patienten behandelt $(4 \%)$.

Der BMI betrug im Schnitt 26,1 $( \pm 5,0)$. Damit waren die Patienten leicht übergewichtig (Präadipositas, nach Herold et al. 2013). 38 \% der Patienten rauchten. Die mittlere Packungsjahr-Anzahl betrug 12 . 
$82 \%$ der Patienten nahmen NSAR ein, davon $71 \%$ regelmäßig als festen Bestandteil der medikamentösen Therapie und der Rest der Patienten (29 \%) nur bei Bedarf. Protonenpumpen-Inhibitoren gehörten bei $54 \%$ der Patienten zur medikamentösen Therapie. $8 \%$ wurden mit Statinen behandelt. Bei 32 Patienten (64\%) erfolgte eine Therapie mit selektiven Immunsuppressiva (Adalimumab, Etanercept, Infliximab) zum Zeitpunkt der Untersuchung. Sulfasalazin nahmen $30 \%$ der Patienten ein.

\begin{tabular}{|l|l|l|l|l|l|l|l|}
\hline Variablen & $\mathbf{n}$ & Min & Median & Mittelwert & Max & SD & NA \\
\hline Alter (Jahre) & 50 & 21 & 46 & 45 & 80 & 15 & 0 \\
\hline Erkrankungsdauer (Min) & 38 & 0 & 7 & 9 & 33 & 9 & 12 \\
\hline Morgensteifigkeit (Min) & 49 & 0 & 30 & 33 & 150 & 35 & 1 \\
\hline CRP (mg/l) & 45 & 0,1 & 2,4 & 8,1 & 119,1 & 18,6 & 5 \\
\hline BASDAl & 48 & 0 & 3,1 & 3,4 & 8,9 & 2,2 & 2 \\
\hline Schober (cm) & 47 & 0,5 & 3,5 & 3,6 & 7 & 1,4 & 3 \\
\hline Ott (cm) & 46 & 0 & 2 & 2,4 & 8 & 1,6 & 4 \\
\hline
\end{tabular}

Tabelle 4: $\quad$ Deskriptive Statistik der grundlegenden Charakteristika des Patientenkollektivs Alter auf volle Jahre gerundet, $\mathrm{SD}=$ Standardabweichung, NA=ohne Angabe

\begin{tabular}{|l|l|l|l|l|l|l|l|}
\hline Variablen & $\mathbf{n}$ & Min & Median & Mittelwert & Max & SD & NA \\
\hline FBA (cm) & 38 & 0 & 12 & 17 & 60 & 18 & 12 \\
\hline Ott (cm) & 46 & 0 & 2 & 2,4 & 8 & 1,6 & 4 \\
\hline Schober (cm) & 47 & 0,5 & 3,5 & 3,6 & 7 & 1,4 & 3 \\
\hline WS-SN re (cm) & 44 & 2 & 13 & 14 & 26 & 6 & 6 \\
\hline WS-SN li (cm) & 44 & 1 & 12 & 13 & 29 & 7 & 6 \\
\hline TWA re (cm) & 44 & 9 & 16 & 17 & 38 & 6 & 6 \\
\hline TWA li (cm) & 44 & 10 & 15 & 17 & 36 & 6 & 6 \\
\hline HWS-Rot. re (cm) & 38 & 20 & 45 & 49 & 90 & 17 & 12 \\
\hline HWS-Rot. li (cm) & 38 & 20 & 45 & 50 & 90 & 18 & 12 \\
\hline
\end{tabular}

Tabelle 5:

Klinische Messwerte zur Beurteilung der Wirbelsäulenbeweglichkeit/des Krankheitsverlaufs WS-SN=Wirbelsäulen-Seitneigung, FBA=Finger-Boden-Abstand,

TWA=Tragus-Wand-Abstand, HWS-Rot.=Halswirbelsäulenrotation, re=rechts, li=links

Desweiteren wurden verschiedene klinische Messwerte zur Beurteilung der Wirbelsäulenbeweglichkeit und des Krankheitsverlaufs erhoben (siehe Tabelle 5). Hieraus wurde außerdem 
der BASMI berechnet. Dieser betrug im Mittel 4,3 $( \pm 1,83)$. Die Patienten beantworteten weiterhin Fragebögen zum BASDAI $(3,4 \pm 2,2)$, BASFI $(3,2 \pm 3,0)$ und BASG $(4,4 \pm 2,7)$.

Bei 17 Patienten erfolgte nach mindestens einem halben Jahr eine Kontrolle im Verlauf inklusive Anamnese und Untersuchung (siehe Kapitel 4.5).

\subsection{Ergebnisse des CFU-Hill-Assay}

Zur Beurteilung der Fähigkeit zur klonalen Expansion wurde der CFU-Hill-Assay durchgeführt. Die Anzahl der EPC-Kolonien (entsprechend CFU-ECs) der Patienten waren mit $25( \pm 20,0)$ Kolonien deutlich verringert gegenüber den Kolonien der Kontrollgruppe mit einer Anzahl von $37( \pm 25,6)$.

\begin{tabular}{|l|l|l|l|l|l|l|}
\hline Variable & N & Min & Median & Mittelwert & Max & SD \\
\hline Kolonien P & 50 & 0 & 20 & 25 & 100 & 20 \\
\hline Kolonien K & 42 & 0 & 31,5 & 37 & 100 & 25,6 \\
\hline
\end{tabular}

Tabelle 6: $\quad$ Deskriptive Statistik für die Anzahl der CFU-ECs in der Patientengruppe (P) und Kontrollgruppe (K)

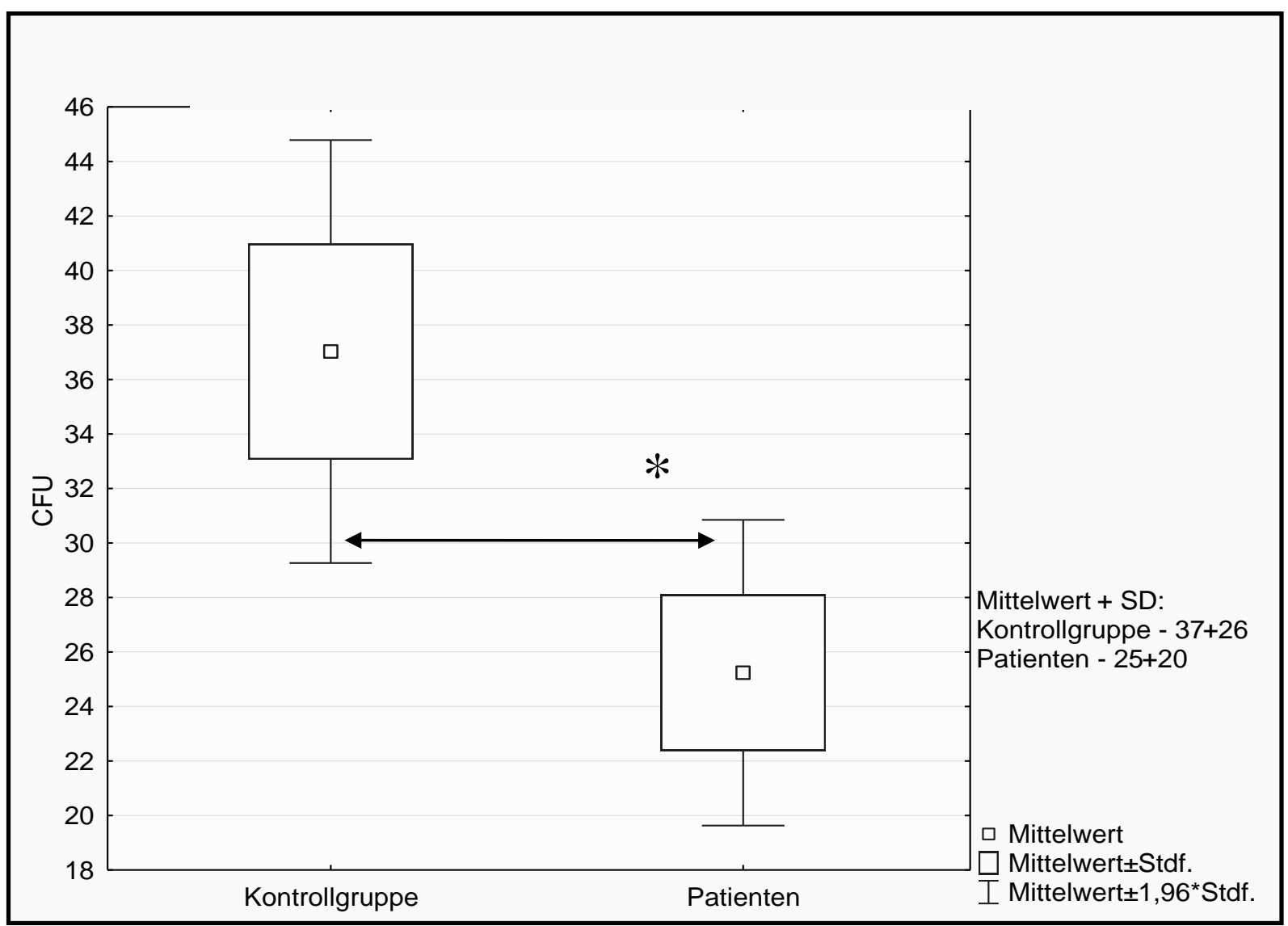

Abbildung 12: Signifikanter Unterschied der Anzahl der CFU-ECs zwischen Patienten- und Kontrollgruppe $\mathbf{p}=\mathbf{0 , 0 2}$ (signifikant ab $\mathbf{p}=<\mathbf{0 , 0 5}$ ) 
Zur anschließenden Signifikanzprüfung wurde der Shapiro-Wilks-W-Test auf Normalverteilung durchgeführt. Für beide Stichproben wurden mittels dieses Tests keine Normalverteilungen nachgewiesen, daher wurden im Folgenden nichtparametrische Verfahren angewandt.

Der Zusammenhang zwischen CFU-ECs der Kontrollgruppe und des Patientenkollektivs wurde mittels Mann-Whitney-U-Test auf Signifikanz getestet. Der Unterschied der CFU-EC zwischen Patienten- und Kontrollgruppe ist mit einem p-Wert von $\mathbf{0 , 0 2}$ deutlich statistisch signifikant. Die Anzahl der CFU-ECs bei den Patienten ist um fast ein Viertel (23\%) niedriger als die CFU-EC der Kontrollgruppe.

Im Folgenden finden sich die Ergebnisse der Gegenüberstellung der CFU-EC-Anzahl verschiedenster Untergruppen. Einen signifikanten Unterschied zeigte lediglich die Anzahl der CFU-ECs, eingeteilt nach dem Geschlecht. Alle anderen Untergruppen wiesen keine Signifikanzen auf.

\begin{tabular}{|l|l|l|l|}
\hline Variable & p-Wert & Variable & p-Wert \\
\hline Geschlecht (männl./weibl.) & $\mathbf{0 , 0 3} *$ & NSAR (Einnahme ja /nein) & 0,69 \\
\hline Alter bei Probenentnahme & 0,23 & Biologika (Einnahme ja /nein) & 0,23 \\
\hline Alter bei Erstdiagnose & 0,095 & Statine (Einnahme ja /nein) & 0,9 \\
\hline HLA-B27 (neg./pos.) & 0,9 & PPI (Einnahme ja /nein) & 0,36 \\
\hline BMI & 0,7 & BASMI & 0,37 \\
\hline Morgensteifigkeit & 0,2 & BASFI & 0,86 \\
\hline HTN (vorh./nicht vorh.) & 0,13 & BASG & 0,87 \\
\hline Nikotin (ja/nein) & 0,3 & BASDAI < 4 / $\mathbf{4}$ & 0,08 \\
\hline CRP (< 5 mg/dl / > $\mathbf{~ m g / d l ) ~}$ & 0,78 & Schober & 0,68 \\
\hline Krankengymnastik (ja/nein) & 0,8 & Ott & 0,15 \\
\hline & & FBA & 0,89 \\
\hline
\end{tabular}

Tabelle 7: $\quad$ Auflistung der p-Werte für die Anzahl der CFU-ECs, eingeteilt nach verschiedenen Variablen / Merkmalen; signifikant ab p<0,05 


\section{CFU-ECs und Geschlecht}

Der Mann-Whitney-U-Test ergab für die CFU-ECs der weiblichen und männlichen Patienten einen signifikanten Unterschied mit einem p-Wert von 0,03. Die Anzahl der CFU-ECs bei Männern ist in unserer Studie um mehr als ein Drittel vermindert gegenüber den CFU-ECs der Frauen.

\begin{tabular}{|l|l|l|l|l|l|l|}
\hline Variablen & $\mathrm{n}$ & Min & Median & Mittelwert & Max & SD \\
\hline männlich & 29 & 0 & 16 & 20 & 54 & 14 \\
\hline weiblich & 21 & 0 & 33 & 32 & 100 & 25 \\
\hline
\end{tabular}

Tabelle 8: $\quad$ Deskriptive Statistik für die Anzahl der CFU-ECs, eingeteilt nach dem Geschlecht

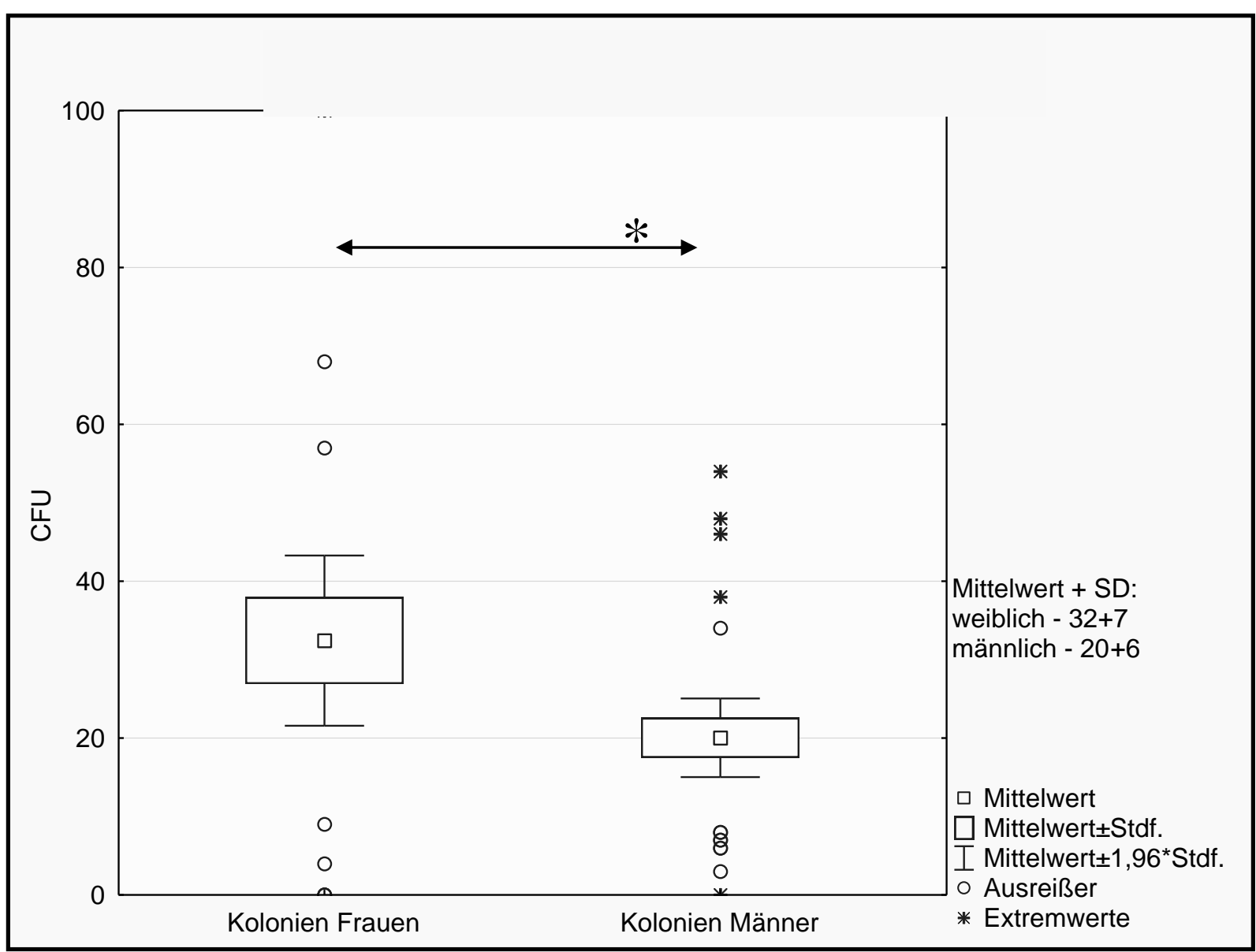

Abbildung 13: Signifikanter Unterschied, Anzahl der CFU-ECs der Männer versus Anzahl der CFU-ECs der Frauen, $\mathbf{p}=\mathbf{0 , 0 3}$ (signifikant ab $\mathbf{p}=<0,05$ ) 


\section{CFU-ECs und Alter zum Zeitpunkt der Untersuchung}

Werden die Patienten nach ihrem Alter zum Zeitpunkt der Untersuchung eingeteilt, zeigt sich eine gewisse Tendenz zur geringeren CFU-Anzahl mit zunehmendem Patientenalter, wie im nachfolgenden Scatterblot $\mathrm{zu}$ erahnen. Diese Beobachtung ist jedoch statistisch nicht signifikant $(\mathrm{p}=0,23)$.

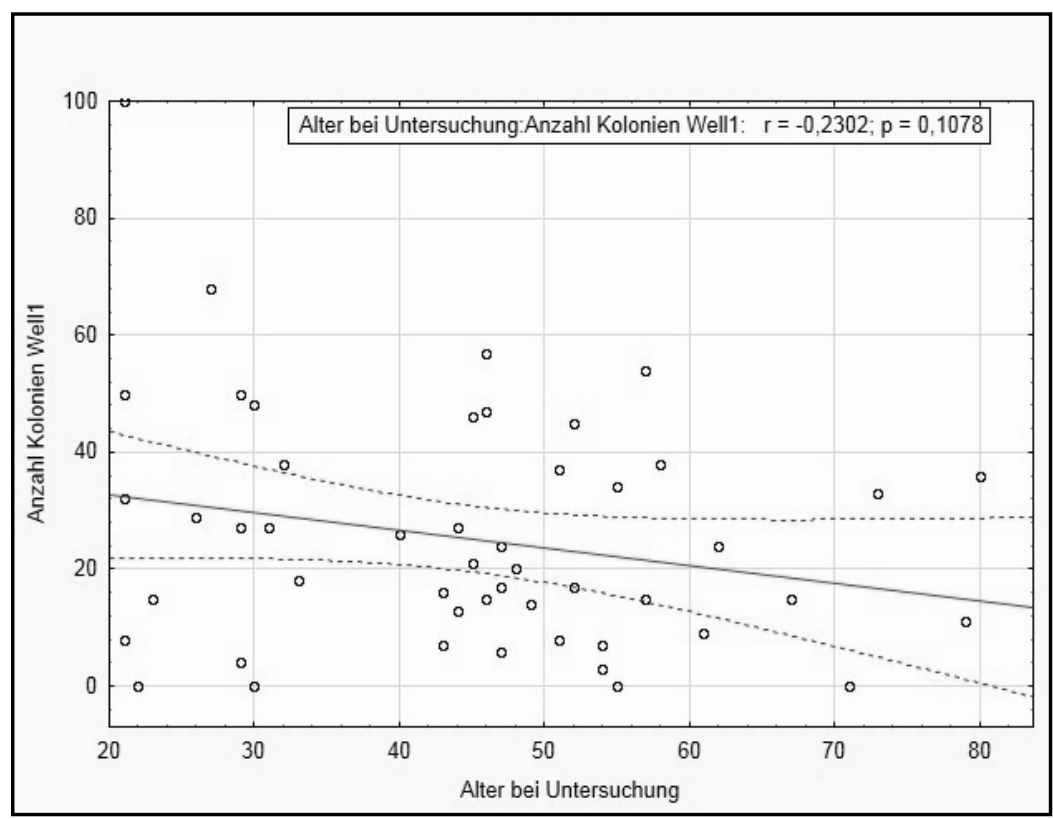

Abbildung 14: Scatterplot zu dem Zusammenhang zwischen Anzahl der CFU-ECs und dem Patientenalter am Untersuchungstag

\section{CFU-ECs und BMI}

Patienten mit einem niedrigen BMI scheinen tendentiell eine höhere Anzahl an CFU-ECs aufzuweisen. Diese Beobachtung ist jedoch nicht signifikant $(p=0,7$, signifikant $a b p<0,05$, $\mathrm{N}=41)$.

\section{CFU-ECs und HLA-B27}

Die Patienten wurden in zwei Gruppen nach dem Vorliegen des HLA-B27 Merkmals eingeteilt. Auch hier zeigte sich kein signifikanter Unterschied in der Bildung der CFU-EC ( $\mathrm{p}=0,9$, signifikant ab $\mathrm{p}<0,05$; HLA-B27 pos.: $\mathrm{N}=39$ (78 \%), CFU-EC - $\overline{\mathrm{x}}: 25$; HLA-B27 neg: $\mathrm{N}=11(22 \%), \mathrm{CFU}-\mathrm{EC}-\overline{\mathrm{x}}: 26)$. 


\section{CFU-ECs und Erkrankungsdauer}

Mit zunehmender Erkrankungsdauer (gemessen am Jahr der Erstdiagnose) zeigt sich eine Tendenz zu verminderter Bildung der CFU-ECs $(\mathrm{p}=0,095$, signifikant ab $\mathrm{p}<0,05)$. Diese Bebachtung ist nicht signifikant und könnte auch mit dem steigenden Alter der Patienten zusammenhängen (s. Diskussion).

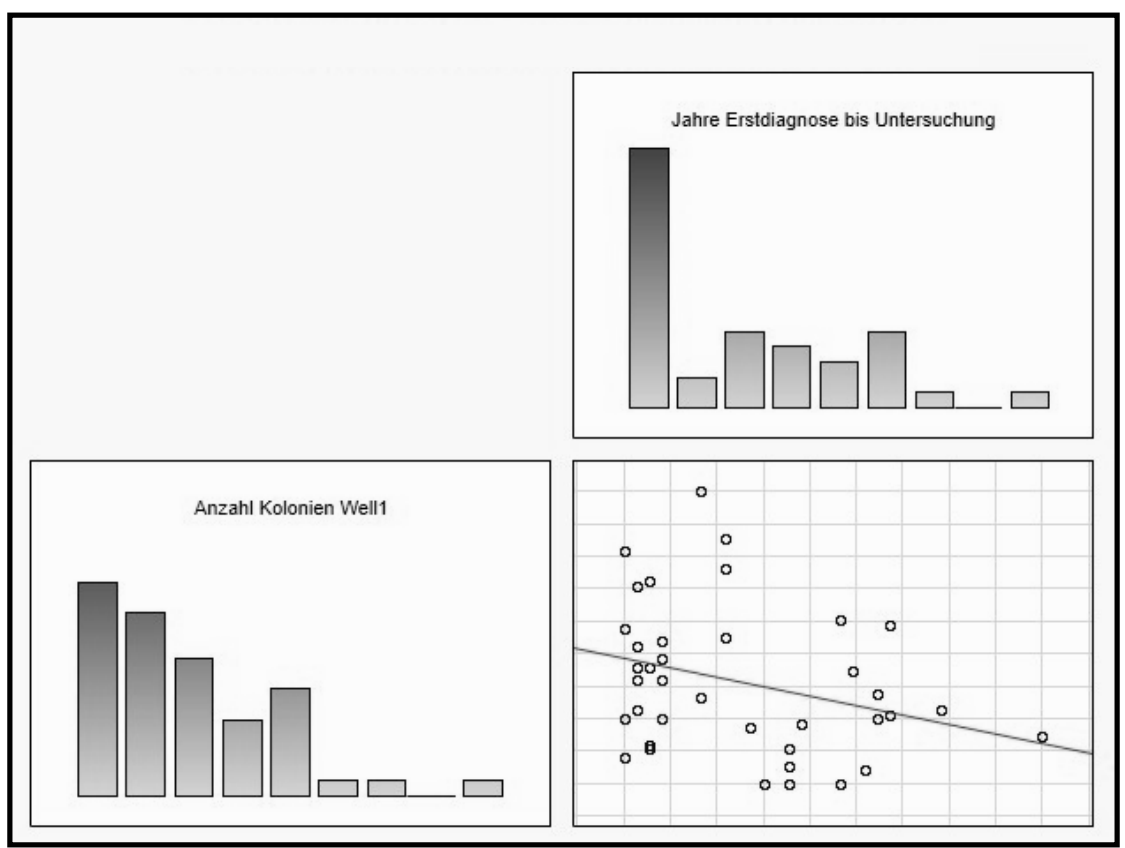

Abbildung 15: Scatterplot zu dem Zusammenhang zwischen Anzahl der CFUECs und der Erkrankungsdauer

\section{CFU-ECs und Krankheitsaktivität}

Zur Beurteilung des Zusammenhangs zwischen Krankheitsaktivität und CFU-EC wurden die Patienten nach dem ASDAS und BASDAI-Index in verschiedene Gruppen eingeteilt.

Die Patienten wurden entsprechend dem BASDAI in 2 Gruppen eingeteilt. Eine hohe Krankheitsaktivität entsprach einem BASDAI $\geq 4(\mathrm{~N}=16)$, eine niedrige Krankheitsaktivität einem BASDAI $<4(\mathrm{~N}=32)$.

Mittels des ASDAS wurden einmal vier Gruppen und einmal zwei Gruppen gebildet.

Die Berechnung des ASDAS erfolgte mittels des ASDAS-Rechners der ASAS.

Es zeigte sich die Tendenz zu einer höheren Anzahl an CFU-EC bei hoher Krankheitsaktivität, sowohl entsprechend dem BASDAI, als auch dem ASDAS. Die Anzahl der CFU-EC ist bei einem BASDAI $<4$ signifikant vermindert gegenüber der Kontrollgruppe $(\mathbf{p}=\mathbf{0 , 0 0 1})$. 


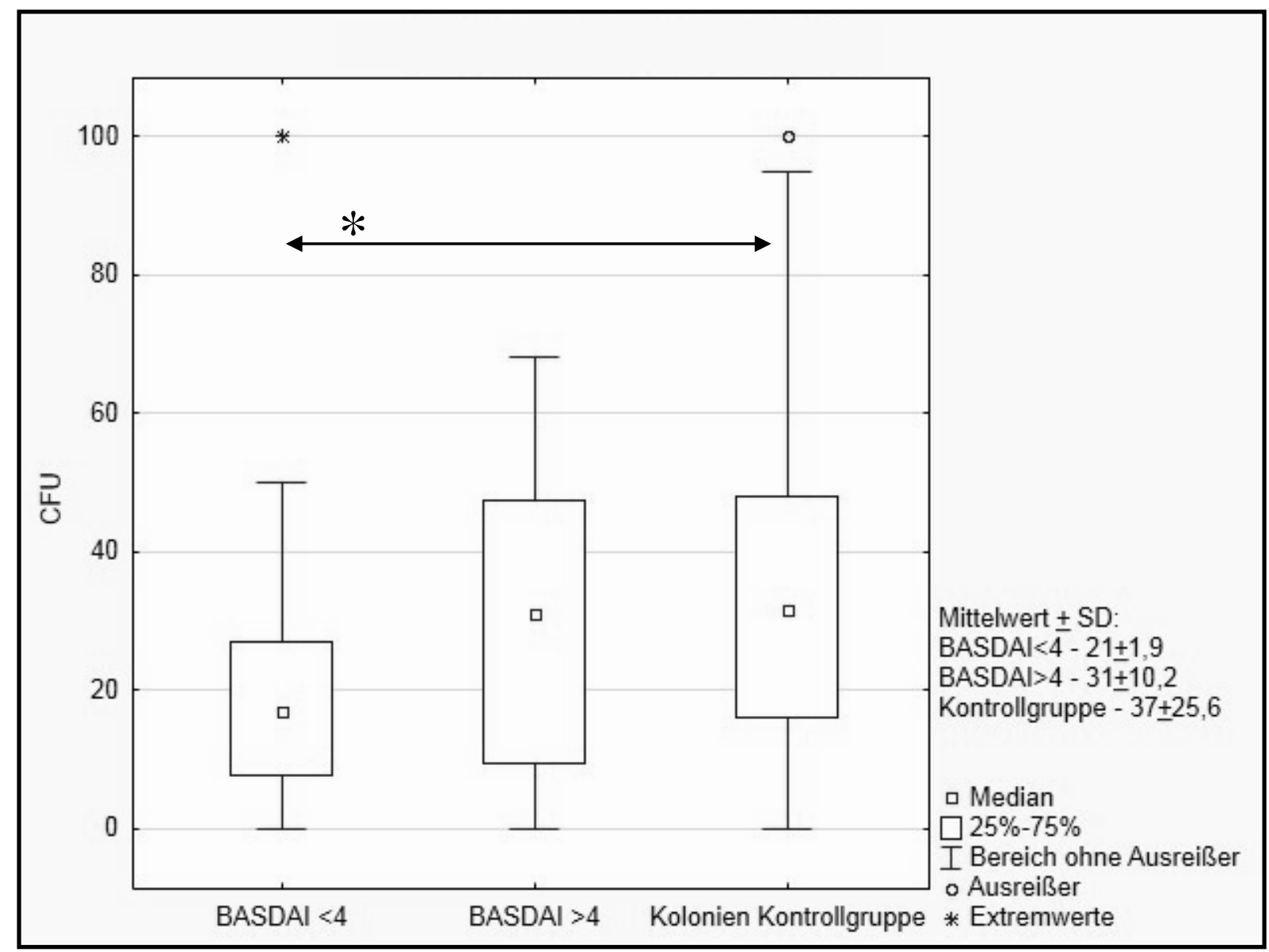

Abbildung 16: $\quad$ Anzahl der CFU-ECs, eingeteilt nach dem BASDAI

signifikanter Unterschied zwischen den CFU-EC bei BASDAI $<4$ und den CFU-ECs der Kontrollgruppe mit p=0,001 (p=signifikant $\mathbf{a b}<\mathbf{0 , 0 5})$

Die Tendenz zu einer geringeren Anzahl an CFU-ECs bei geringerer Krankheitsaktivität zeigt auch die Einteilung nach dem ASDAS. Patienten aus Gruppe 1 nach dem ASDAS (entsprechend inaktiv) haben signifikant niedrigere CFU-ECs verglichen mit der Kontrollgruppe (Mittelwert Gruppe 1: 16, Kontrollgruppe: 37, $\mathrm{p}=0,02$ (signifikant $a b<0,05$ ). Ein Vergleich zwischen den erstellten ASDAS-Gruppen zeigte keine signifikanten Unterschiede auf. Die Gruppen waren teilweilse sehr klein (3 Patienten in Gruppe 4).

\begin{tabular}{|l|l|l|l|l|l|l|}
\hline Variablen & $\mathbf{n}$ & Min & Median & Mittelwert & Max & SD \\
\hline ASDAS (inaktiv) & 9 & 4 & 14 & 16 & 29 & 10 \\
\hline ASDAS (moderat) & 13 & 6 & 18 & 22 & 47 & 12 \\
\hline ASDAS (hoch) & 18 & 0 & 19 & 22 & 57 & 20 \\
\hline ASDAS (sehr hoch) & 3 & 15 & 16 & 33 & 68 & 30 \\
\hline
\end{tabular}

Tabelle 9: $\quad$ Deskritptive Statistik für die Anzahl der CFU-ECs, eingeteilt nach dem ASDAS 
Nach dem ASDAS erfolgte aufgrund der geringen Größe der Untergruppen eine weitere Einteilung in eine Gruppe mit hoher $(\mathrm{N}=24 ; \overline{\mathrm{x}}=21)$ und eine mit niedriger Krankheitsaktivität $(N=20 ; \bar{x}=22)$. Hier fand sich kein statistisch signifikanter Unterschied $(p=0,4)$.

\section{CFU-ECs und Begleiterkrankungen}

Viele Patienten wiesen typische Begleiterkrankungen auf (s.o.). Bei Patienten mit Begleiterkrankungen zeigte sich im Vergleich zur Kontrollgruppe eine signifikant geringere Anzahl von Kolonien $(\mathbf{p}=\mathbf{0 , 0 1})$.

Bei Patienten mit einer arteriellen Hypertonie lagen die niedrigsten CFU-EC Zahlen vor (19 vs. 22 bei Patienten mit verschiedenen Begleiterkrankungen). Auch dieser Unterschied ist im Vergleich zur Kontrollgruppe signifikant.

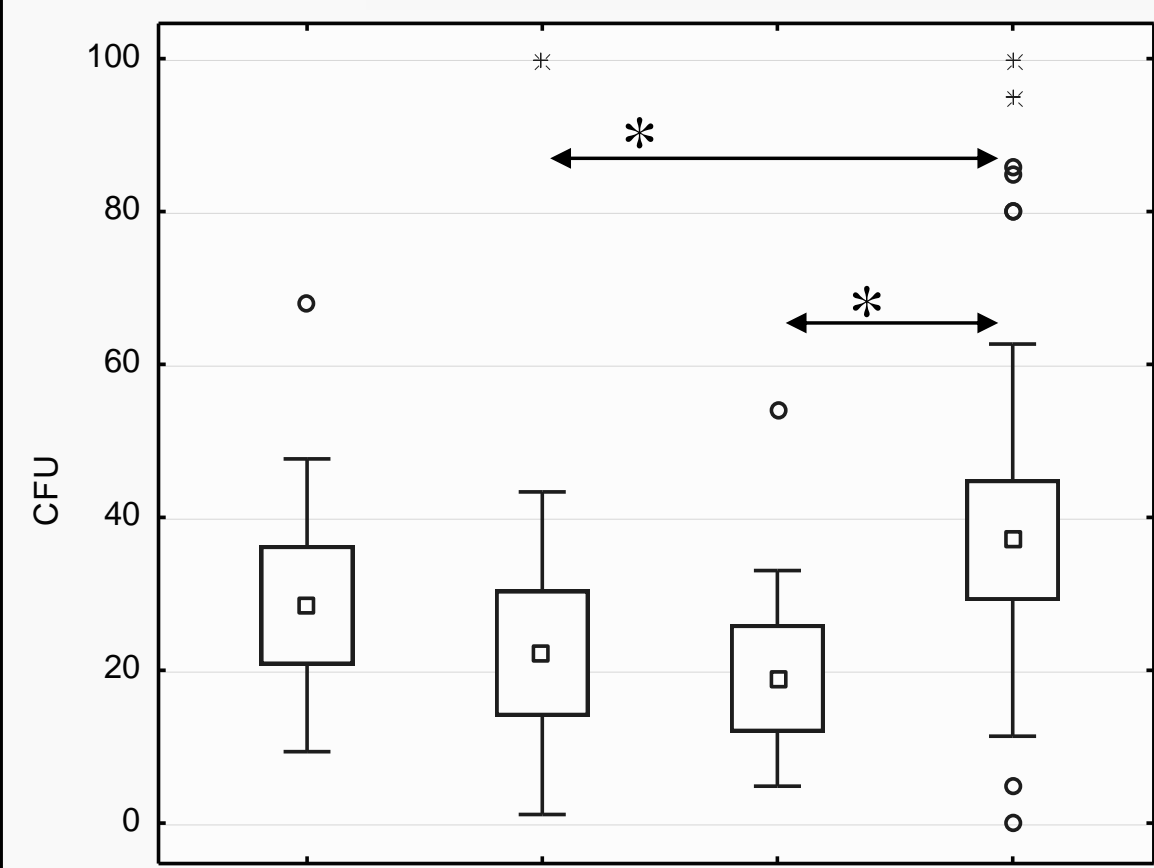

Pat. ohne Begleiterkr.
Pat. mit HTN

Pat. mit Begleiterkr.

Mittelwerte + SD:

ohneBegleiterkr.- 29+19

mitBegleiterkr.- 22+21

mit HTN $-19+14$

Kontrollgruppe $-37+26$

口 Mittelwert

$\square$ Mittelwert $\pm 2 *$ Stdf .

I Mittelwert \pm Stdabw.

- Ausreißer

* Extremwerte

Abbildung 17: Anzahl der CFU-ECs, eingeteilt nach Begleiterkrankungen Signifikante Unterschiede zwischen Patienten mit Begleiterkrankungen $(\mathrm{p}=\mathbf{0 , 0 1})$ und Kontrollgruppe, sowie Patienten mit arterieller Hypertonie (HTN) und Kontrollgruppe (p=signifikant $\mathbf{a b}<0,05$ ) 


\section{CFU-ECs und Morgensteifigkeit}

Die Morgensteifigkeit wirkt sich unserer Studie nicht signifikant auf die Bildung der Kolonien aus. Es zeigt sich eine Tendenz zu einer höheren Anzahl an CFU-ECs bei länger andauernder Morgensteifigkeit $(\mathrm{p}=0,2)$.

\section{CFU-ECs und Medikamente}

Das Patientenkollektiv wurde mit unterschiedlichsten Medikamenten behandelt. Die Einnahme von NSAR wirkte sich nicht auf die Bildung der Kolonien aus $(\mathrm{p}=0,9)$. Die Behandlung mit Biologika (Adalimumab, Etanercept, Infliximab; $N=32$; CFU-ECs: $\overline{\mathrm{x}}=28$ ) zeigt lediglich eine Tendenz zu vermehrten CFU-EC im Vergleich zu Patienten ohne BiologikaTherapie $(\mathrm{N}=18$; CFU-ECs: $\overline{\mathrm{x}}=20 ; \mathrm{p}=0,23)$.

Auch die Einnahme von Statinen oder PPIs scheint sich nicht auf die Bildung der CFU-EC auszuwirken $(\mathrm{p}=0,9$ und $\mathrm{p}=0,36)$.

\section{CFU-ECs und Beweglichkeit/allgemeiner Gesundheitszustand}

Im Rahmen der klinischen Untersuchung wurden verschiedene klinische Messwerte zur Beschreibung der Beweglichkeit der Patienten und des Krankheitsverlaufs erhoben (siehe Tabelle 8). Hieraus wurde außerdem der BASMI $(4,3 \pm 1,83)$ berechnet. Es ergaben sich keine Signifikanzen für den Zusammenhang zwischen CFU-ECs und BASMI (p =0,37), BASFI $(p=0,03)$, BAS-G $(p=0,87)$, Schober $(p=0,68)$, Ott $(p=0,15)$ oder FBA $(p=0,89)$.

\section{CFU-ECs und Krankengymnastik}

Der grundlegende Therapieansatz der axSpA ist eine regelmäßige Krankengymnastik. Auf die Bildung der CFU-EC wirkt sich die Durchführung der Krankengymnastik in dieser Studie jedoch nicht aus $(\mathrm{p}=0,8)$.

\section{CFU-ECs und CRP}

Als empfindlicher Laborwert wird das CRP bei der axSpA stets mitbestimmt. Das Patientenkollektiv wurde nach dem CRP in zwei Gruppen eingeteilt.

Gruppe1: $\quad<0,5 \mathrm{mg} / \mathrm{dl}$ (normal) - $5 \mathrm{mg} / \mathrm{dl}$ (mäßig erhöht) - $\quad \mathrm{N}=26$; CFU-EC $\overline{\mathrm{x}}=21$

Gruppe2: $\quad 5 \mathrm{mg} / \mathrm{dl}$ (deutlich erhöht) - > $10 \mathrm{mg} / \mathrm{dl}$ (hoch) $-\quad \mathrm{N}=19 ;$ CFU-EC $\overline{\mathrm{x}}=24$

Ein Unterschied in der CFU-Bildung je nach CRP-Wert zeigte sich nicht $(p=0,58)$. 


\section{CFU-ECs und Rauchen}

Es zeigt sich eine Tendenz zu einer geringeren Anzahl an CFU-ECs bei Rauchern. Der Unterschied zu Nichtrauchern ist statistisch jedoch nicht signifikant $(\mathrm{p}=0,37)$.

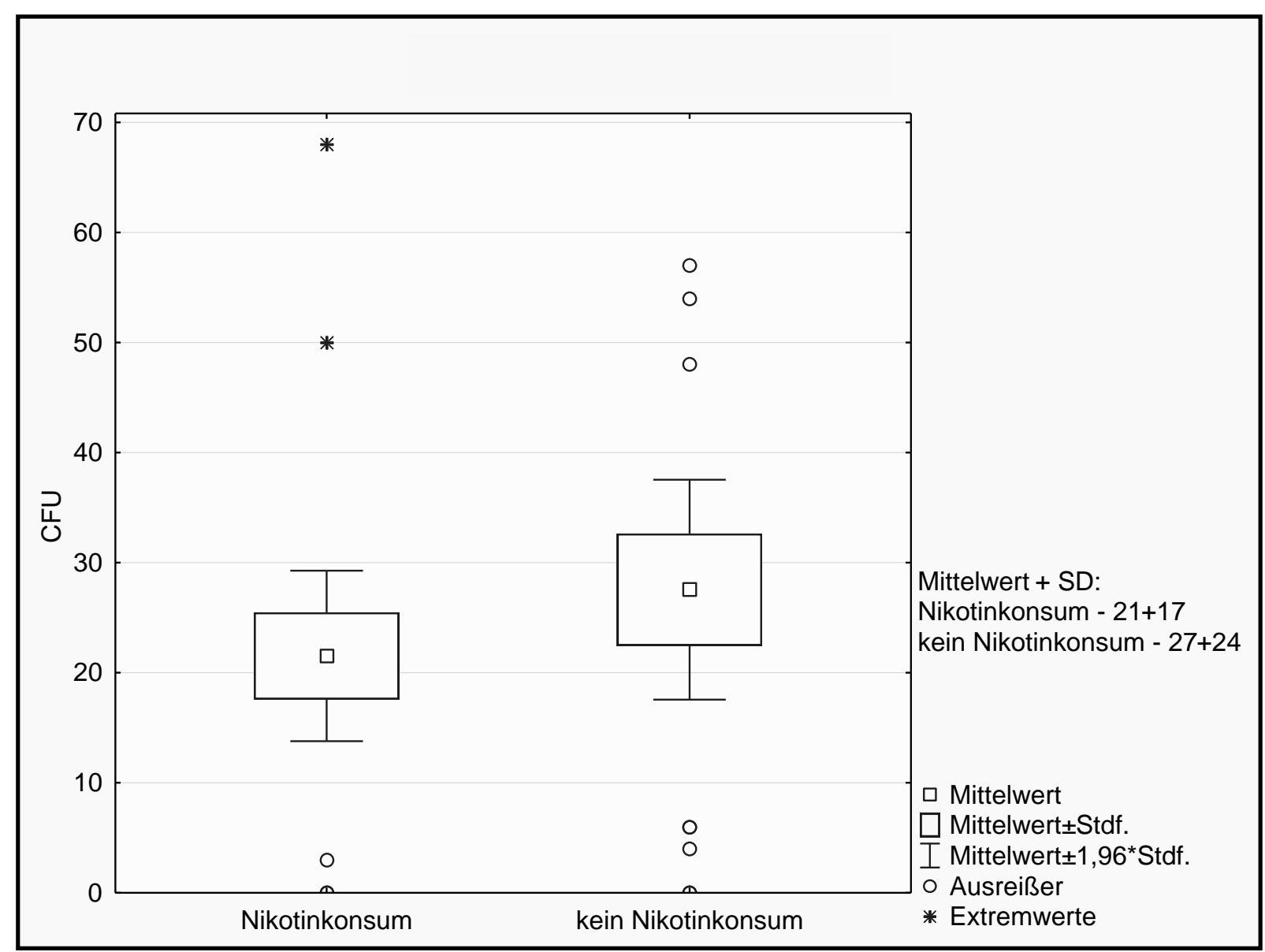

Abbildung 18: Anzahl der CFU-ECs, eingeteilt nach dem Nikotinkonsum 


\subsection{FACS-Analyse}

Zur quantitativen Beurteilung der cEPCs wurden die Patientenproben aufbereitet und mittels FACS-Gerät analysiert. Doppeltpositive Zellen für CD133 und FLK entsprechen dabei cEPCs. Verglichen mit der gesunden Kontrollgruppe ist hier kein signifikanter Unterschied erkennbar. Mittelwert sowie Median sind nahezu identisch $(\mathrm{p}=0,69, \mathrm{~N}$ Patienten $=49$, $\mathrm{N}$ Kontrollgruppe $=10$ ).

Auch konnte keine statistisch signifikante Korrelation zwischen den gemessenen CFU-EPCs und den durch das FACS gemessenen CD133+/FLK+-Zellen aufgezeigt werden.

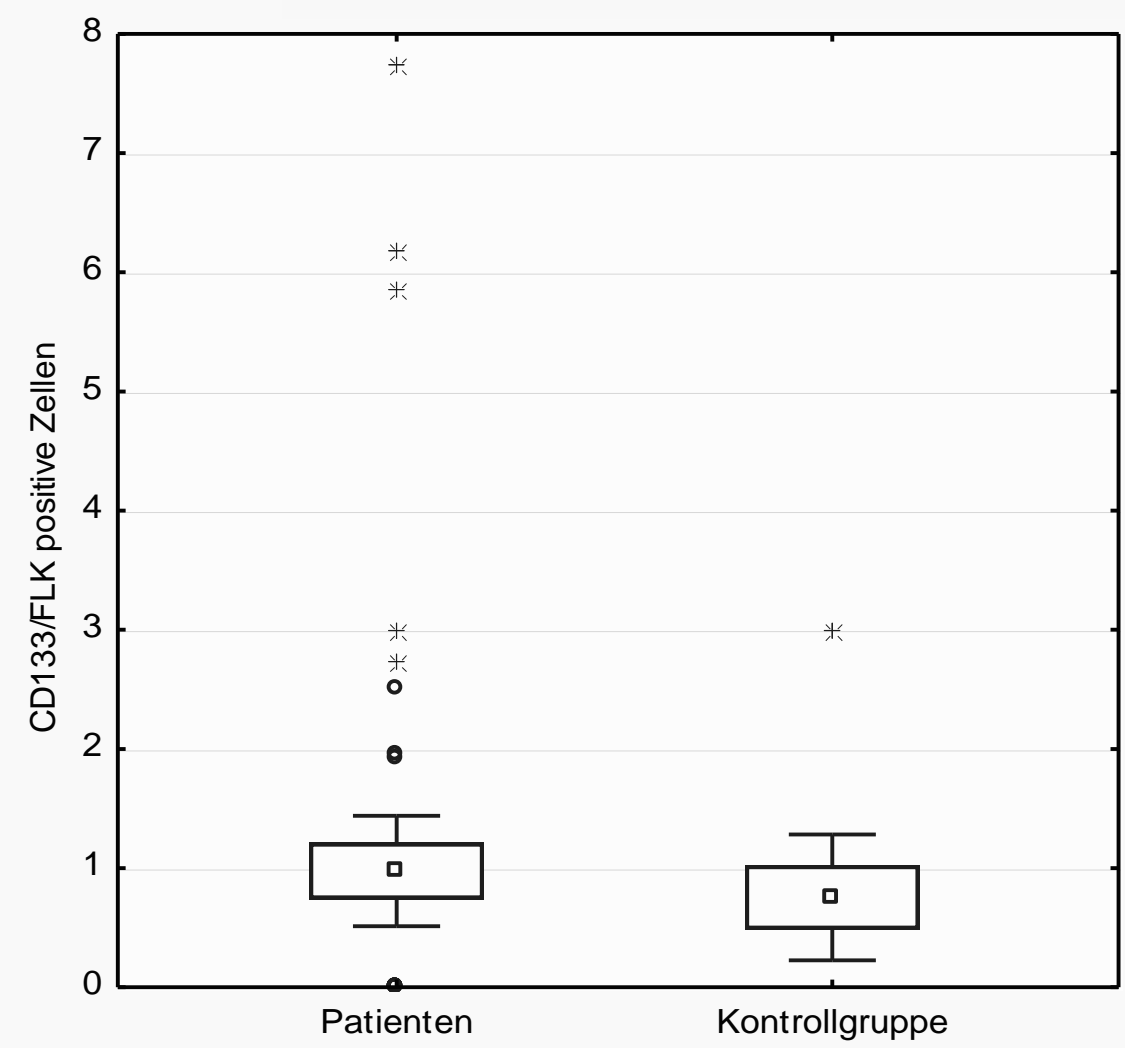

Mittelwert + SD:

Patienten - 0,97+1,65

Kontrollgruppe - 0,75+0,85

Mittelwert

$\square$ Mittelwert \pm Stdf .

I Mittelwert $\pm 1,96 *$ Stdf.

- Ausreißer

* Extremwerte

Abbildung 19: $\quad$ cEPCs (in \%) bei Patienten und Kontrollgruppe 


\section{FACS und Krankheitsaktivität}

Eine Aufteilung der cEPCs nach der Krankheitsaktivität, gemessen am BASDAI, zeigte eine statistisch nicht signifikante Tendenz zu einer höheren Anzahl an cEPCs bei hoher Krankheitsaktivität (entsprechend BASDAI > 4; $\mathrm{p}=0,1$ ).

\section{FACS und Geschlecht}

Eine Einteilung der per FACS gemessenen cEPCs nach dem Geschlecht zeigte keinen signifikanten Unterschied $(p=0,08)$. Es findet sich eine Tendenz zu einer geringeren Anzahl an cEPCs bei männlichen Patienten.

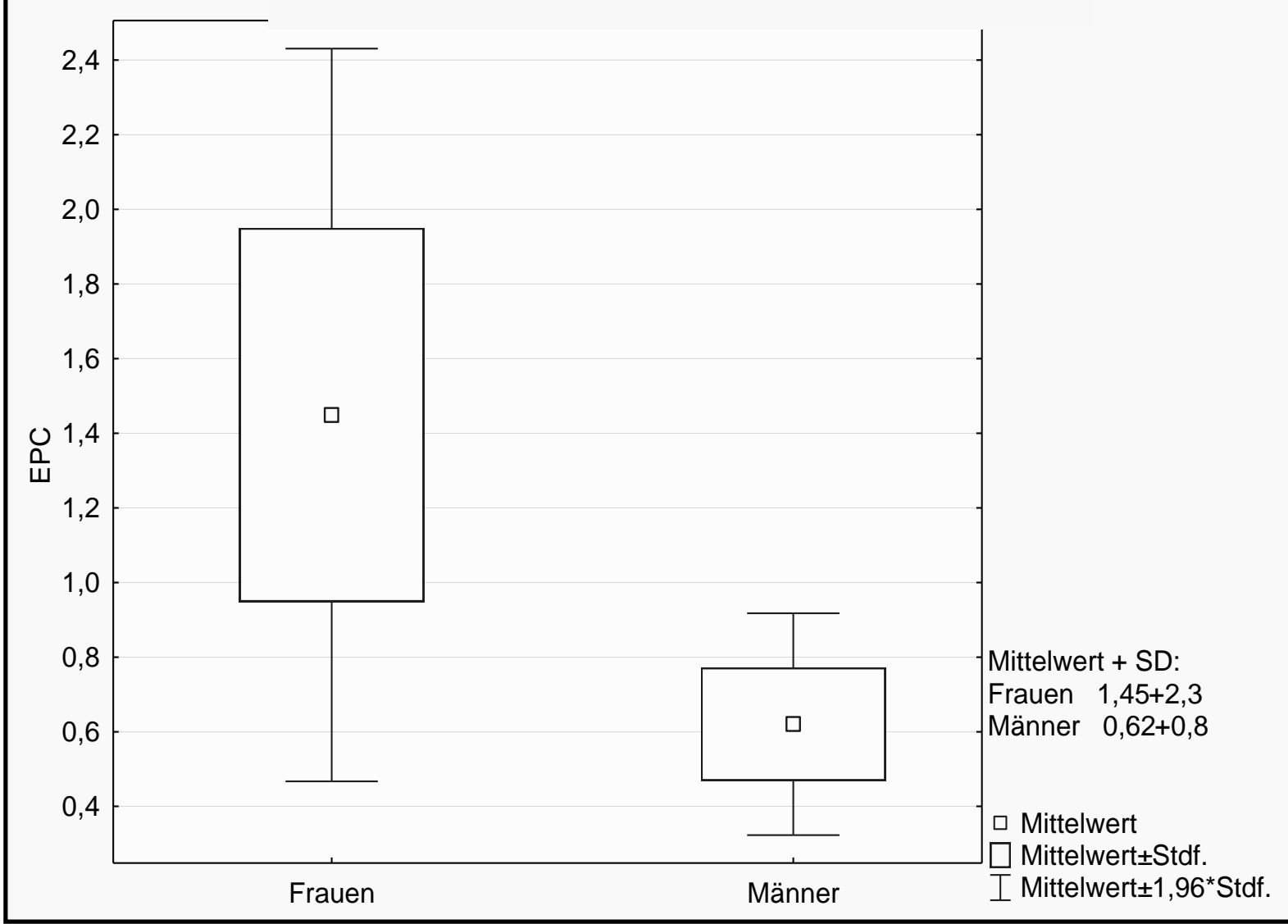

Abbildung 20: cEPCs (in \%) eingeteilt nach dem Geschlecht

\subsection{Vasomodulatorische Mediatoren}

Unterschiede zwischen den Konzentrationen der verschiedenen vasomodulatorischen Mediatoren (VEGF, PDGF, TGF- $\beta$, Angiopoetin -1 und -2) bei Kontrollgruppe und Patienten waren statistisch nicht signifikant. 


\subsection{Verläufe}

Es erfolgte eine Verlaufsuntersuchung nach einem mittleren Zeitraum von 33,2 \pm 1,9 Monaten. Diese konnte bei 34 von 50 Patienten durchgeführt werden (68\%).

Hierzu wurde untersucht, inwiefern sich bestimmte Parameter (BASDAI, Ott-Maß, FingerBoden-Abstand) im zeitlichen Verlauf vom Zeitpunkt der ersten Untersuchung bis zur Verlaufsvorstellung in Abhängigkeit von den CFU-ECs, cEPCs, dem Geschlecht und des mittleren Serumgehalts des VEGF, des Angiopoetin -1 und -2, des PDGF, des TGF- $\beta$ zum Zeitpunkt der Erstvorstellung entwickelten. Es wurden zu jedem Parameter 2 Gruppen gebildet (> und < dem Mittelwert) und deren Differenz von BASDAI, Ott-Maß und FingerBoden-Abstand im Beobachtungszeitraum miteinander verglichen. Es zeigten sich keine signifikanten Unterschiede.

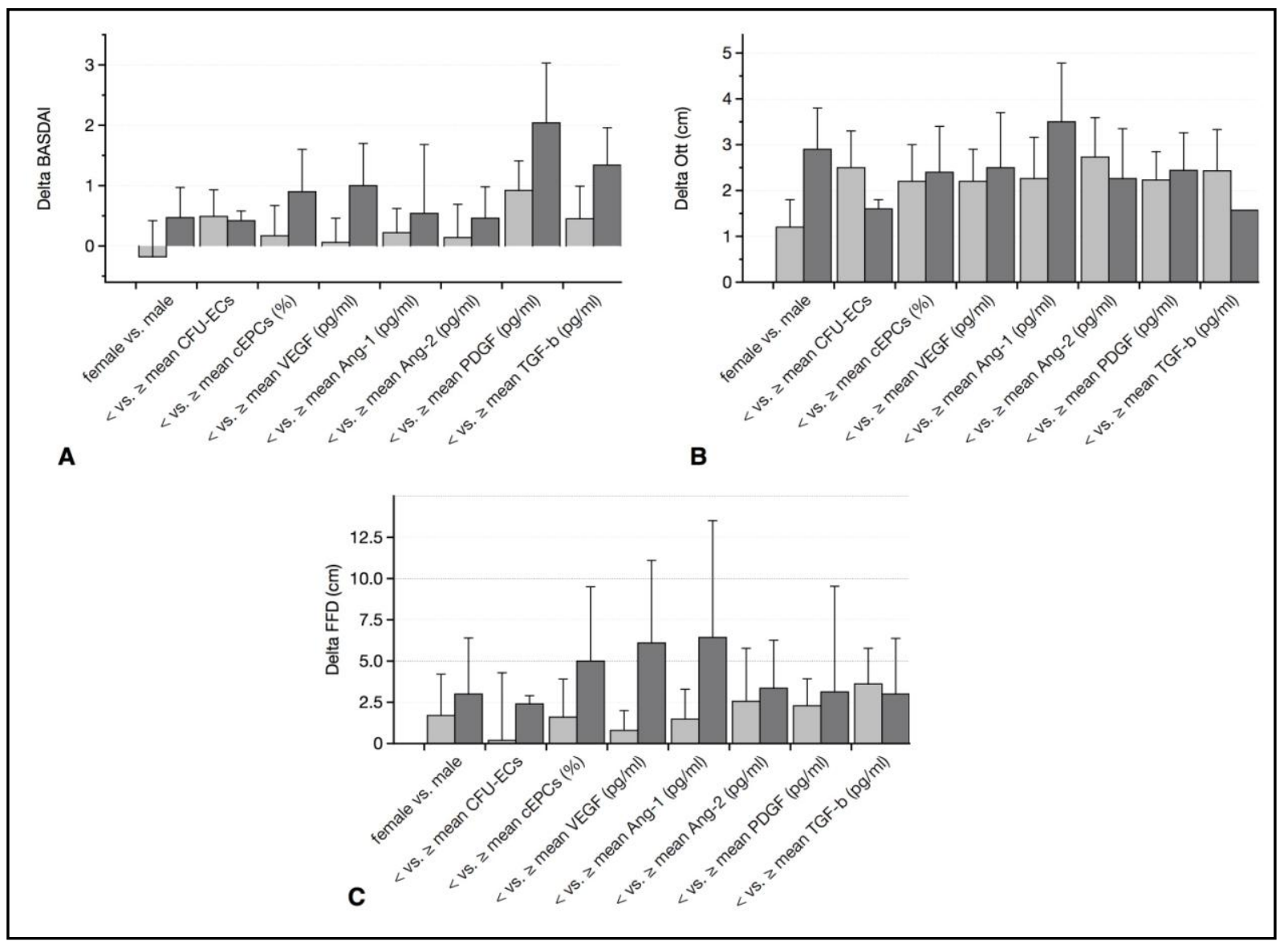

Abbildung 21: Verlaufskontrolle nach einem mittleren Zeitraum von 33,2 $\pm 1,9$ Monaten (durchgeführt bei 34 von 50 Patienten). Die Parameter Geschlecht, mittlere Anzahl der EPC Kolonien, periphere zirkulierende EPCs, mittlere VEGF-Level, Angiopoetin-1 und-2, PDGF und TGF-b wurden verwendet, um Differenzen des BASDAI, Ott-Zeichens und Finger-Boden-Abstand (beides in $\mathrm{cm}$ ) zu vergleichen. Hierbei zeigten sich keine Signifikanzen. 
Die axiale Spondylarthropathie gehört zu den entzündlich-rheumatischen Erkrankungen. Immer wieder wurde in Zusammenhang mit der Erkrankung ein erhöhtes Atheroskleroserisiko beobachtet. Von Han et al. wurde es als um das 1,5-fache erhöht im Vergleich zu gesunden Individuen angegeben.

Die Mechanismen, denen dieses erhöhte Risiko unterliegt, sind bisher nicht vollständig verstanden und Grundlage weiterer Forschung. Traditionelle Risikofaktoren allein liefern hier keine ausreichende Erklärungsgrundlage.

Ziel dieser Arbeit war es der Frage nachzugehen, ob endotheliale Progenitorzellen in ihrer Funktion oder Anzahl bei der axialen Spondylarthropathie verändert sind und ob sie für die genannte Problematik einen Erklärungsansatz bieten.

Forschungsergebnisse zeigen, dass endotheliale Progenitorzellen eine wichtige Rolle bei der Instandhaltung der mikrovaskulären Homöostase unter physiologischen und pathologischen Bedingungen spielen und ihre Anzahl invers mit dem kardiovaskulären Risiko korreliert (Grisar et al. 2005). Sie sind Indikatoren für das Maß der Entzündung, den Grad des Gefäßschadens und reflektieren desweiteren das körpereigene reparative Potenzial (Ablin et al. 2009).

Dazu untersuchten wir in unserer Studie 50 Patienten mit axialer Spondylarthropathie, gesunde Individuen dienten als Kontrollgruppe. Die totale Anzahl an zirkulierenden EPCs wurde mittels einer FACS-Analyse spezifiziert. Die regenerative Aktivität der Zellen wurde per Colony-Forming-Unit-Assay analysiert. Vasomodulatorische Mediatoren wurden per ELISA quantifiziert. Außerdem wurde ein aktueller klinischer Untersuchungsbefund der Patienten erhoben und im Verlauf bei einem Großteil der Kohorte erneut bestimmt. Verschiedenste weitere Faktoren, wie etwa persönliche Merkmale, Parameter der klinischen Untersuchung, Krankheitsaktivität, Krankheits-Indizes, Begleiterkrankungen, Medikamenteneinnahme, genetische Eigenschaftem, wurden außerdem erhoben und auf Zusammenhänge untersucht. 


\section{Analyse der EPC-Proliferation (Colony-Forming-Unit-Assay)}

Unsere Daten zeigten eine verminderte Anzahl an CFU-ECs seitens der Patientengruppe (25 Kolonien) im Vergleich zur Kontrollgruppe (37 Kolonien). Dieser Unterschied ist mit einem $\mathrm{p}$-Wert von 0,02 statistisch signifikant.

Dementsprechend ist die axiale Spondylarthropathie mit einer verminderten Kolonienbildung der EPCs assoziiert, was für eine beeinträchtigte EPC-Proliferation und eine beeinträchtigte vaskuläre Gesundheit im Rahmen der Erkrankung spricht.

Insgesamt ist die Datenlage zum System der EPCs bei der axialen Spondylarthropathie limitiert. Eine weitere Studie untersuchte EPCs bei einer nah verwandten Erkrankung, der Psoriasisarthritis, im Jahre 2009 (Ablin et al. 2009). Hier konnte kein Zusammenhang zwischen EPCs und der Erkrankung aufgezeigt werden. Lediglich der Wert des VEGF korrelierte mit dem BASDAI. Vermutlich sind EPCs nicht essentiell in die Pathogenese der Psoriasisarthritis involviert.

Verschiedene weitere rheumatische Erkrankungen waren bereits intensiver Bestandteil der EPC-Forschung:

Grisar et al. (2005) untersuchten EPCs mittels FACS-Analyse und CFU-Assay bei der rheumatoiden Arthritis. Sie beschrieben bei der Erkrankung, die wie die axiale Spondylarthropathie mit einer erhöhten kardiovaskulären Morbidität und Mortalität einhergeht, deutlich verminderte EPC-Zahlen und beobachteten desweiteren einen Zusammenhang zwischen Krankheitsaktivität, TNF- $\alpha$-Leveln und Therapie mit TNF- $\alpha$-Blockern oder DMARDs. Sie betonten dabei die Wichtigkeit einer konsequenten Therapie, mit der auch das kardiovaskuläre Risiko gesenkt werden könne. Auch beim Lupus erythematodes beschrieben Patschan et al. (2013) mit einer beeinträchtigten Mobilisierung und Regenerationsfähigkeit der EPCs einen möglichen Erklärungsansatz für den mikrovaskulären Schaden im Rahmen der Erkrankung.

Die in unserer Studie nachgewiesene herabgesetzte EPC-Regenerationsfähigkeit könnte einen Erklärungsansatz für das erhöhte kardiovaskuläre Risiko im Rahmen der axSpA bieten. Optimalerweise wären mittels neuer Erkenntnisse hierzu sogar neue therapeutische oder diagnostische Optionen im weiteren Verlauf denkbar. In einer entprechenden Follow-upStudie wäre es ggf. interessant, nicht nur die EPCs zu untersuchen, sondern gleichzeitig auch das kardiovaskuläre Risiko zu bestimmen, beispielsweise mittels des Framingham Scores. 
Wie oben erwähnt, teilten wir unsere Patienten außerdem nach verschiedensten weiteren Kriterien ein, etwa der Krankheitsaktivität, dem Alter, dem Geschlecht und den Entzündungsparametern. Hier konnten wir, im Unterschied zu Verma et al. (2015), nur wenige Signifikanzen und mehrere Trends beobachten. Diese Beobachtungen sollten ggf. mit einer größeren Kohorte verifiziert werden.

\section{CFU-ECs und Geschlecht}

Wir beobachteten signifikant niedrigere Bildung von Kolonien bei den Männern ( $\mathrm{N}=20$ vs. 32 bei Frauen). Bereits Hoetzer et al. (2007) beschrieben eine höhere regenerative und proliferative Kapazität der EPCs bei Frauen mittleren Alters im Gegensatz zu Männern der gleichen Altersgruppe und sahen hier einen Erklärungsansatz für die deutlich häufiger auftretenden kardiovaskulären Ereignisse bei Männern. Diese Beobachtung scheint sich im Rahmen der axialen Spondylarthropathie zu bestätigen.

\section{CFU-ECs und Alter}

Weiterhin zeigte sich ein Trend zu verminderter Bildung der CFUs mit steigendem Alter. Ein weiterer Trend, der bereits mehrfach in der Literatur beschrieben ist und somit die Wertigkeit unserer Studie unterstützt.

\section{CFU-ECs und Krankheitsaktivität}

Wir bestimmten die Krankheitsaktivität der Patienten mittels zweier verschiedener Scores, dem BASDAI-Index und dem ASDAS-Score. Stets konnten wir beobachten, dass eine niedrige Krankheitsaktivität mit einem Trend zu niedrigen Kolonienzahlen einherging (und umgekehrt). Diese Beobachtung steht der bisherigen Studienlage entgegen und ist daher schwierig zu interpretieren.

In der Literatur findet man bei verschiedenen Erkrankungen, etwa der RA, dem Diabetes mellitus oder der COPD stets eine inverse Korrelation zwischen Krankheitaktivität und Zahl der zirkulierenden EPCs (Grisar et al. 2005). Auch Verma et al. beschrieben einen inversen Zusammenhang zwischen EPCs und Krankheitsaktivität (gemessen am BASDAI und an der Anzahl der EPCs gemessen durch die FACS-Analyse).

Einen geringen Ausschlag könnte hier gegeben haben, dass in unserer Studie deutlich mehr Männer einen niedrigen BASDAI aufwiesen. $72 \%$ der Männer, aber nur $28 \%$ der Frauen gaben einen BASDAI kleiner als vier an. Gleiches galt für den ASDAS, dessen Werte bei 
Männern tendenziell niedriger lagen als bei Frauen (ASDAS < 2,1 $68 \%$ männlich; ASDAS > 2,1 $52 \%$ männlich). Fraglich ist, ob dieser Erklärungsansatz unsere Beobachtung zum Zusammenhang zwischen Krankheitsaktivität und EPCs hinreichend erklären kann.

In weiteren Studien sollte der Zusammenhang zwischen Krankheitsaktivität und EPCs bei der axSpA noch genauer untersucht werden, möglichst unter Ausschluss eventueller Störfaktoren (wie etwa der Einnahme von Immunsuppressiva).

\section{CFU-ECs und Rauchen}

Das Rauchen ist stark mit endothelialer Dysfunktion assoziiert (Azevedo und Pecoits-Filho 2010). In der Literatur ist außerdem bereits beschrieben, dass Raucher mit einer axialen Spondylarthropathie einen früheren Krankheitsbeginn, höhere Krankheitsaktivität, vermehrte Entzündungszeichen und - schäden verzeichnen (Chung et al. 2012). Patienten mit Nikotinkonsum zeigten in unserer Studie lediglich einen (nicht signifikanten) Trend zu einer beeinträchtigten Fähigkeit Kolonien zu bilden. Man hätte hier einen potenzierenden Effekt zweier Faktoren (Nikotinkonsum sowie Grunderkrankung) mit einer deutlichen Reduktion der CFU-Zahlen erwarten können. Wir konnten dies jedoch nicht bestätigen. Diesen Zusammenhang in einer größeren Studie nochmals genauer zu untersuchen, könnte weiteren Aufschluss bringen.

\section{CFU-ECs und Medikamente}

In unserer Arbeit zeigt sich eine Tendenz zu einer höheren Anzahl an CFU-ECs bei Einnahme von Biologika (keine statistische Signifikanz). Der positive Effekt der Biologika auf Funktion und Anzahl der endothelialen Vorläuferzellen bei anderen Erkrankungen, etwa der rheumatoiden Arthritis, ist bereits beschrieben (Ablin et al. 2006) und konnte in unserer Studie als Trend auch bei der axialen Spondylarthropathie beobachtet werden. Bei allen anderen Medikamentengruppen sind keine nennenswerten Unterschiede zu erkennen (Statine, PPIs, NSAR). Insgesamt lagen bei unserer Patientenkohorte sehr variable Therapieschemata vor bzw. waren bereits durchgeführt worden. Daher waren die Untergruppen zu den einzelnen Therapieschemata ggf. zu klein, um statistische Signifikanzen herauszuarbeiten. So ist eventuell zu erklären, dass ein in der Literatur beschriebener Effekt von Statinen auf zirkulierende EPCs hier nicht beobachtet werden konnte (Urbich und Dimmeler 2005). Die Anwesenheit der axSpA zusätzlich scheint diese in der Literatur beschriebenen Beobachtungen nicht zu verstärken. Weitere von uns untersuchte Faktoren, wie etwa das CRP, HLA-B 27 und der BMI, zeigten keine Unterschiede zwischen Patienten und Kontrollgruppe. 


\section{Quantitative Beurteilung der zirkulierenden EPCs mittels FACS-Analyse}

Die FACS-Analyse dient der genauen Quantifizierung der EPCs anhand ihrer Oberflächenmoleküle (CD 133 \& FLK-1). In unserer Studie konnten wir keinen signifikanten Unterschied zwischen den durch die Durchflusszytometrie gemessenen EPCs im Vergleich zu der gesunden Kontrollgruppe aufzeigen. Unter Berücksichtigung des beschriebenen erhöhten kardiovaskulären Risikos in vorangegangenen Arbeiten wäre ein signifikanter Unterschied hier durchaus denkbar gewesen. So ist etwa auch die rheumatoide Arthritis durch ein erhöhtes kardiovaskuläres Risiko gekennzeichnet, das durch die bisher bekannten traditionellen Risikofaktoren allein nicht erklärt werden kann. Grisar et al. 2005 wiesen mittels FACS-Analyse nach, dass die Quantität der zirkulierenden EPCs im peripheren Blut, durch FACS gemessen, bei der Erkrankung erniedrigt ist. Sie gingen davon aus, dass die Anzahl der EPCs einer von verschiedenen Faktoren sein könnte, der zu dem erhöhten Risiko beiträgt. Auch die Krankheitsaktivität wirkte sich hier auf die Anzahl der EPCs im Sinne einer inversen Korrelation (Grisar et al. 2005) aus. Ein analoger Zusammenhang für die axSpA ergibt sich aus unserer Arbeit nicht. Weitere Arbeiten werden die Ursache hierfür eruieren müssen.

Auch für den systemischen Lupus erythematodes und die Sklerodermie ist ein beeinträchtigtes System der EPCs (defizitäre Regeneration wie Mobilisierung) beschrieben (Patschan et al. 2013; Brunasso und Massone 2016).

Im Gegensatz zu unseren Ergebnissen konnten Verma et al. (2015) in ihrer Studie zur axSpA in Verbindung mit EPCs signifikant niedrigere Konzentrationen von EPCs im peripheren Blut bei den Patienten im Vergleich zu der Kontrollgruppe nachweisen. Auch in unserer Studie wurde bei Patienten mit axialer Spondylarthropathie die Zahl der EPCs mittels FACSAnalyse untersucht. Allerdings wurden andere Oberflächenmarker zugrunde gelegt (CD34+/CD133+), was eine Vergleichsmöglichkeit erschwert.

Bei der Definition der EPCs (über das Isolationsverfahren) durch Verma et al. (2015) ist kritisch zu bedenken, dass vermulich eher unreife hämatopoietische Zellen anstatt der von uns gesuchten EPCs detektiert wurden. Bezüglich der Präzision hat die von uns verwandte Methode Vorteile. CD133+/FLK+-Zellen reflektieren mit einer größeren Wahrscheinlichkeit die gesuchten cEPCs, im Gegensatz zu CD34+/CD133+-Zellen.

Insgesamt machen die verschiedenen Identifikationstechniken der EPCs die Forschung in diesem Gebiet weiterhin schwierig und erschweren die Vergleichbarkeit der verschiedenen Studien untereinander. 
$\mathrm{Zu}$ berücksichtigen ist auch, dass die FACS-Analyse ein recht aufwendiges methodisches Verfahren ist und somit hoch anfällig für Fehler sein kann (Notwendigkeit verschiedener Geräte, mehrere Färbeverfahren, wesentlich größere Anzahl an Färbestoffen notwendig).

Die Patientengruppe der Studie von Verma et al. (2015) war aufgrund einer Vielzahl an Ein- und Ausschlusskriterien wesentlich weniger heterogen.

Eine entsprechende Follow-up-Studie sollte im Sinne der Validität eine wesentlich größere Patientenkohorte einschließen.

\section{EPCs und Knochen}

Obwohl originär nicht Bestandteil der Zielsetzung dieser Arbeit, soll hier ein kurzer Exkurs zum erst kürzlich aufgekommenen Thema des Zusammenhangs der Osteogenese mit EPCs erörtert werden. Rossini et al. (2016) untersuchten die Veränderungen bzw. die Beteiligung des Knochens bei verschiedenen entzündlichen Erkrankungen, unter anderem der RA und der SpA, außerdem die Auswirkungen von IL-17 und TNF- $\alpha$ in diesem Zusammenhang. Die RA und die SpA sind durch ein Missverhältnis zwischen der Knochenresorption durch Osteoklasten und dem Knochenaufbau durch Osteoblasten gekennzeichnet.

Bei der SpA wird neben dem Knochenabbau durch IL-17 insbesondere die Tätigkeit der Osteoblasten angeregt. Hierdurch kommt es zur vermehrten Knochenbildung. Im Gegensatz dazu ist die rheumatoide Arthritis durch eine Aktivierung der Osteoklasten und somit einen vermehrten Knochenabbau gekennzeichnet (Rossini et al. 2016). Bei der SpA werden vermehrt Syndesmophyten, Osteophyten und Enthesiophyten gebildet, die zur Fusion der Sakroiliakalgelenke oder zur spinalen Ankylose führen können (Shaw und Gravallese 2016). Das Gleichgewicht von Knochenbildung und - abbau ist gestört.

Eine 2014 veröffentlichte Studie von Park et al. zu verschiedenen, die zirkulierenden EPCs beeinflussenden Faktoren bei der rheumatoiden Arthritis offenbarte neue Aspekte der cEPCs. Höheres Alter, erniedrigte Spiegel des HDL und vor allem höhere Werte verschiedener Knochenerosions-Scores waren hier unabhängige negative Einflussfaktoren auf die EPC-Zahl.

Beeinträchtigte Zahlen an EPCs scheinen mit Knochenerosion /-abbau assoziiert zu sein. Eine Beeinträchtigung der EPCs scheint hiernach in Zusammenhang mit der Aufrechterhaltung von Gelenk-/Knochenschaden zumindest bei der RA zu stehen. Möglicherweise besteht sogar ein äthiologischer Zusammenhang. Bei Patienten mit einem verstärkten Knochenabbau fanden sich signifikant niedrigere Mengen zirkulierender EPCs. Dies könnte darauf hinweisen, dass 
EPCs an der intra- und periartikulären Balance zwischen Knochenauf- und -abbau beteiligt sind und adäquate EPC-Zahlen für die Aufrechterhaltung der strukturellen Integrität von Gelenken notwendig sind. Hierzu könnten weitere Studien neue Erklärungsansätze aufzeigen, ist doch auch die axSpA durch die Störung des Knochenstoffwechsels geprägt. Es erscheint somit möglich, dass ein beeinflusstes bzw. gestörtes System der EPCs Entzündungen im Gelenkbereich und den Prozess der artikulären Fusion/Steifheit unterstützen. In weiteren Arbeiten zur Klärung der Pathogenese sind diese Aspekte somit unbedingt zu berücksichtigen. Hier könnte die Bestimmung des mSASSS als Maß für die radiologisch sichtbare knöcherne Wirbelsäulenversteifung im Zusammenhang mit den EPC-Zahlen interessant sein.

\section{Verlaufsbeobachtung}

Cuadrado-Godia et al. (2015) konnten bei Patienten nach akutem Myokardinfarkt oder ischämischem Insult nachweisen, dass mittels der basalen EPC-Rate eine Vorhersage über die Wahrscheinlichkeit weiterer, in der Zukunft liegender vaskulärer Ereignisse getroffen werden kann. Auch in unserer Studie stellte sich die Frage, ob das EPC-System eine Vorhersage zur Entwicklung der Erkrankung oder verschiedener funktioneller Parameter erlaubt. Dazu wurden $68 \%$ der Patienten nach einer mittleren Zeit von 33 Monaten zu einer Verlaufsuntersuchung einbestellt. Aus den Werten der CFU-ECs, cEPCs, des VEGF, Angiopoetin 1/2, PDGF, TGF- $\beta$ im Vergleich zum ersten Vorstellungstermin resultierten keine signifikant unterschiedlichen Entwicklungen des BASDAI, des Ott-Maßes oder des Finger-FußbodenAbstandes im Verlauf. Somit ist zum aktuellen Zeitpunkt mittels der EPCs und deren Parameter eine Aussage über den Fortgang der Erkrankung leider nicht möglich. Auch die verschiedenen vasomodulatorischen Substanzen (Angiopoietin-1 and -2, VEGF, PDGF, TGF-b) scheinen keine Aussage über die Entwicklung von Krankheitsaktivität im Verlauf zu erlauben. Weitere Untersuchungen hierzu wären wünschenswert.

\section{Fehlerdiskussion}

Bei der Betrachtung unserer Ergebnisse sind einige bislang nicht genannten Punkte zu bedenken:

Wie bei allen Studien ist auch hier anzumerken, dass durch die begrenzte Probandenzahl statistische Fehler aufgetreten sein könnten. Deutlich weiter gefasste Folgestudien könnten hier weitere Gewissheit bringen. Solche könnten unter Umständen auch Signifikanzen der in unserer Studie beobachteten Trends aufzeigen. 
Bei unserer Kohorte handelte es sich um eine sehr heterogene Patientengruppe, wenn man die Einnahme von Medikamenten, Begleiterkrankungen, Alter, Krankheitsaktivität oder Erkrankungsdauer berücksichtigt. Im Unterschied zu der Studie von Verma et al. (2015) etwa war einzig gemeinsames Einschlusskriterium unserer Patienten die Diagnose der axialen Spondylarthropathie. Diese Heterogenität könnte sich verfälschend ausgewirkt haben, auch wenn keine Unterschiede bei der Betrachtung der einzelnen demographischen Faktoren auftraten.

Die Kontrollgruppe wurde aus den Beschäftigten der Abteilung und weiteren Doktoranden ausgewählt. Einschlusskriterien waren das Fehlen der axialen Spondylarthropathie sowie anderer schwerwiegender Erkrankungen. Inwiefern sich hier andere demographische Charakteristika auf das System der EPCs ausgewirkt haben, wie etwa Rauchen, Alter, Geschlecht oder die Einnahme von Medikamenten ist nicht bekannt und könnte in einer weiteren Studie berücksichtigt werden, um auch hier potentielle Störfaktoren auszuschließen.

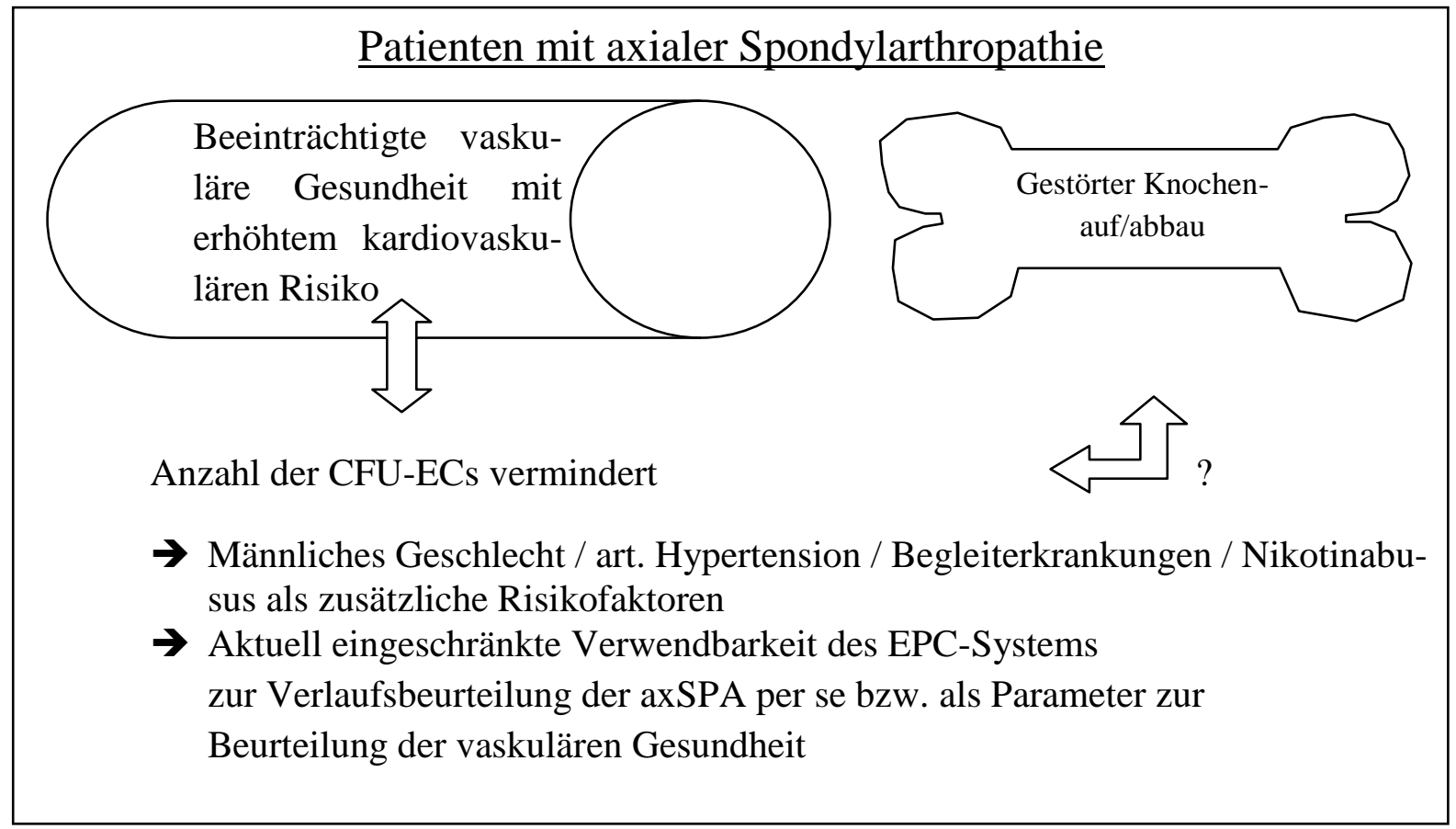

Abbildung 22: Schema zu den Ergebnissen dieser Arbeit 
Ziel dieser Arbeit war es, einen möglichen Zusammenhang zwischen der axialen Spondylarthropathie und endothelialen Progenitorzellen zu untersuchen. Es sollte insbesondere geklärt werden, inwiefern es bei der Erkrankung mit ihrem erhöhten kardiovaskulären Risiko zu einer Beeinträchtigung der Mobilisation oder funktionellen Potenz der EPCs kommt.

Dazu wurden bei insgesamt 92 Probanden (50 Patienten, 42 Kontrollpersonen) die total zirkulierende Anzahl an cEPCs mittels einer FACS-Analyse spezifiziert. Die regenerative Aktivität der EPCs wurde per Colony Forming Assay analysiert. Vasomodulatorische Mediatoren wurden per ELISA quantifiziert. Außerdem wurde ein aktueller klinischer Untersuchungsbefund der Patienten erhoben und im Verlauf bei einem Teil der Kohorte erneut bestimmt. Verschiedenste weitere Faktoren, wie etwa Krankheitsaktivität, Krankheitsindizes, Begleiterkrankungen, Medikamenteneinnahme und genetische prädisponierende Faktoren wurden zusätzlich erhoben und auf Zusammenhänge untersucht.

In unserer Arbeit konnten wir nachweisen, dass die axSpA mit einer verminderten Kolonienbildung der CFU-ECs, somit einer eingeschränkten EPC-Regenerationsfähigkeit und konsekutiv einer beeinträchtigten vaskulären Gesundheit, assoziiert ist. Weiterhin fanden sich bei niedriger Krankheitsaktivität dezimierte Zahlen der CFU-ECs. Die Gründe für eine niedrige regenerative Aktivität bei niedriger Krankheitsaktivität bleiben im Moment jedoch spekulativ. Männliche Patienten, Patienten mit arterieller Hypertension und solche mit bestehendem Nikotinabusus wiesen eine beeinträchtigte Zellregeneration auf. Die Veränderungen im System der EPCs könnten die entzündlich-rheumatischen Vorgänge im Bereich der Gelenke oder auch den Prozess der artikulären Versteifung fördern. Unterschiedliche Zahlen der zirkulierenden cEPCs (in Prozent) zwischen den verschiedenen Untergruppierungen konnten jedoch nicht nachgewiesen werden. Als Verlaufsparameter (über eine Zeitperiode von etwa 30 Monaten) für die Vorhersage der Entwicklung von Krankheitsaktivität oder funktionellen Einschränkungen der Erkrankten eignen sich zum jetzigen Zeitpunkt weder die Betrachtung der Anzahl der Kolonien noch die Anzahl der cEPCs. Auch zur Beurteilung des kardiovaskulären Risikos können EPCs aktuell nicht herangezogen werden. Weiteren Aufschluss hierüber können nur Folgestudien geben. 
Datum:

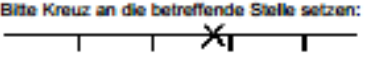

(1) Wie ausgeprägt war Ihre Müdigkeit und Erschöpfung in den vergangenen 7 Tagen insgesamt?

keine Madigkeit

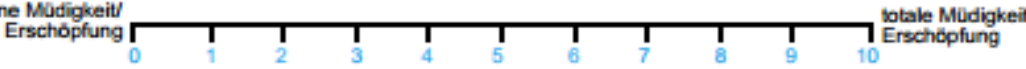

2. Wie ausgeprägt waren Ihre durch den Morbus Bechterew bedingten Nacken-, Rücken- oder Hüftschmerzen in den vergangenen 7 Tagen insgesamt?

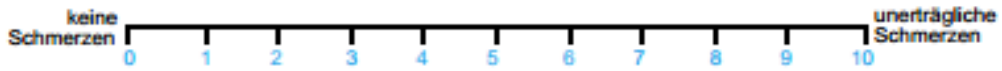

(3) Wie ausgeprägt waren Thre Schmerzen/ Schwellungen in anderen Gelenken in den vergangenen 7 Tagen insgesamt?

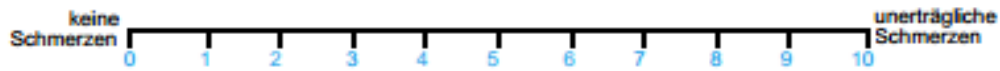

(4) Wie ausgeprägt waren Ihre Beschwerden in den Bereichen, die bei Berührung oder Druck empfindlich reagiert haben, in den vergangenen 7 Tagen insgesamt?

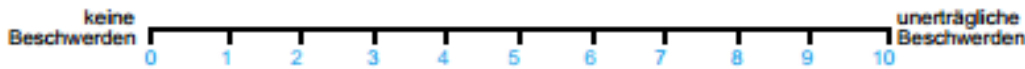

(5) Wie ausgeprägt war die Morgensteifigkeit nach dem Aufwachen in den vergangenen 7 Tagen insgesamt? Morgensteifigkeit $\Gamma_{0}^{\text {keine }}$

(6) Wie viele Stunden dauerte die Morgensteiflgkeit nach dem Aufwachen in den vergangenen 7 Tagen im Durchschnitt an?

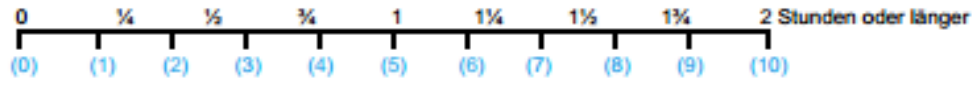


Name:

Datum:

Bite Kreuz en die betreftende Sxlle setzen: $\longrightarrow$

Können Sie

ohne Hilfe und Hilfsmittel (zB. Strumpfanzieher) Socken oder Strümpfe anziehen?

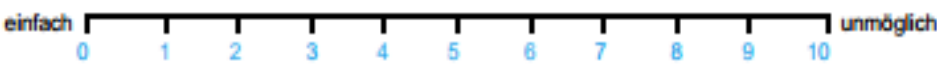

2 ohne Hilfe von der Hüfte aus nach vorn beugen, um einen Kugelschreiber vom Boden aufzuheben?

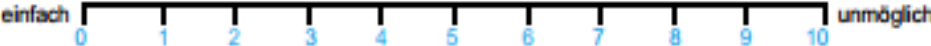

(3) ohne Hilfsmittel (z.B. Greifzange) etwas von einem hohen Regal herunternehmen?

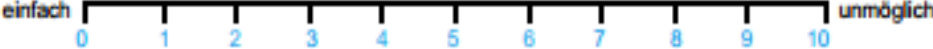

von einem Stuhl ohne Armlehne aufstehen, ohne dabei die Hănde oder eine andere Hilfe zu benutzen?

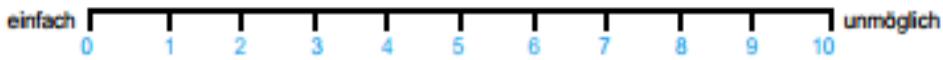

ohne Hilfe vom Boden aufstehen, wenn Sie auf dem Rücken liegen?

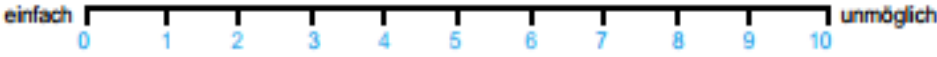

6) ohne Schmerzen 10 Minuten stehen, ohne sich anzulehnen?

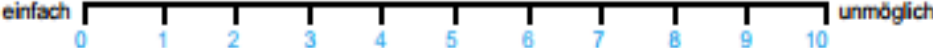

ohne Benutzung eines Gelānders oder von Gehhilfen 12-15 Treppenstufen steigen, 1 Schritt pro Stufe?

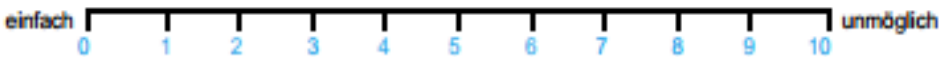

(8) uber die Schulter schauen, ohne den Körper zu drehen?

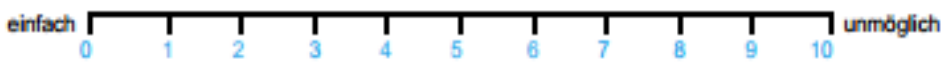

9 körperlich anstrengende Tätigkeiten verrichten (z.B. krankengymnastische Ôbungen, Gartenarbeit oder Sport)?

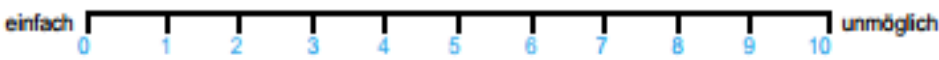

(1) zuhause oder bei der Arbeit den ganzen Tag aktiv sein?

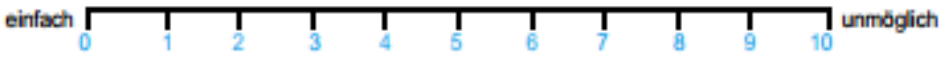


Name:

Datum:

Bite Kreuz an die betreffende Sxlle setzen:

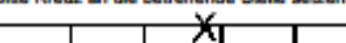

Welche Auswirkung hatte die Krankheit auf Thr Wohlbefinden während der vergangenen 7 Tage?

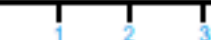

1

Welche Auswirkung hatte die Krankheit auf Thr Wohlbefinden wăhrend der vergangenen 6 Monate?

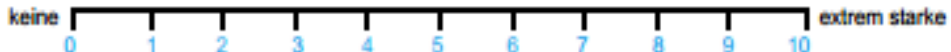


BASMI

Summenmaß für Beweslichkeitseinschränkungen

bei Spondylitis ankylosans (Morbus Bechterew)

Name :

Datum:

Lendenwirbelsãulen-Beugung (modifiziertes SchobermaB): In aufrechter Stellung des Patienten ausgehend vom Dornfortsatz des 5. Lendenwirbels (zwischen den reehts und links befindlichen Lumbalgrübehen) eine Marke $10 \mathrm{~cm}$ weiter oben und eine weitere $5 \mathrm{~cm}$ weiter unten anbringen, Verlängerung des Abstands dieser beiden Marken bei maximaler Beugung mit gestreckten Knien messen (in $\mathrm{cm}$ ).

Zugehörige Bewertung in der Tabelle ablesen und im Kasten rechts außen eintragen.

") Unter den veröflentichten modffzierten Schobermalen wird die von Macrae und Wright emplohlene Version verwendet.

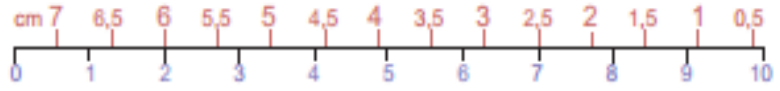

Wirbelsãulen-Seitneigung: Abstand zwischen der entlang des Oberschenkels so weit wie mōglich nach unten gestreckten Mittelfingerspitze und dem Fußboden messen, einmal in gerader Haltung und einmal in maximaler Seitneigung (siehe DVMB-Schriftenrethe Heft 13 Seite 9), ohne Rotation und ohne veranderte Schulterhaltung (z.B. Fersen, GesaB und Schultern an der Wand). Differenz links und Differenz rechts auf der roten Skala markieren. Mittelwert auf der blauen Skala ablesen (mindestens 0, hïchstens 10) und in den Kasten rechts übertragen.

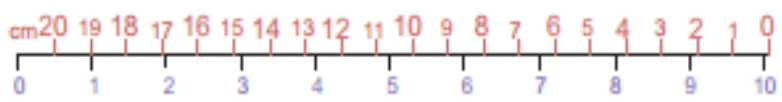

(3)

Tragus-Wand-Abstand: Patient aufrecht mit Fersen und Gesaß an der Wand, Knie gerade, Schultern zurilck. Kopf mit Blick geradeaus (Kinn eingezogen!) so weit wie möglich zurückziehen (siehe DVMB-Schriftenreihe Heft 13 Seite II). Abstand des Tragus (des Knorpels vor dem Gehörgang) von der Wand links und rechts messen und auf der roten Skala markieren. Mittelwert auf der blauen Skala ablesen (mindestens 0, höchstens 10) und in den Kasten rechts ubertragen.

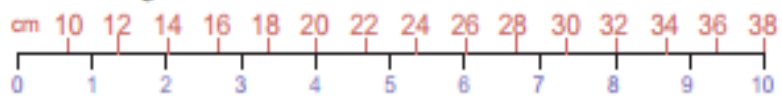

Maximaler Intermalleolarabstand: Den Patienten in Ruckenlage auf flacher Unterlage auffordern, die Beine mit gestreckten Knien und senkrecht nach oben gerichteten Fußspitzen entlang der Unterlage so weit wie mōglich zu spreizen. Abstand zwischen den inneren Fußknöcheln rasch messen (siehe DVMB-Schriftenreihe Heft 13 Seite 10) und auf der roten Skala markieren. Wert auf der blauen Skala ablesen (mindestens 0, hōchstens 10 ) und in den Kasten rechts ubertragen.

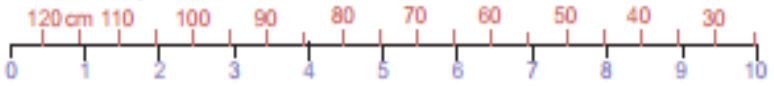

3WS-Rotationswinkel: Patient in Rückenlage, evtl. mit Kissen oder dgl. unter dem Kopf, damit das Gesicht gerade ausgerichtet ist (für Wiederholungsmessungen dokumentieren!). Schwerkraft-Goniometer zentral auf die Stim setzen (siehe DVMB-Schriftenreihe Heft 13 Seite 13). Kopf maximal drehen, ohne die Schultem zu bewegen und ohne Ausweichbewegung in Flexion oder Seitneigung. Rotationswinkel nach links und nach rechts auf der roten Skala markieren. Mittelwert auf der blauen Skala ablesen (mindestens 0, höchstens 10) und in den Kasten rechts ubertragen.

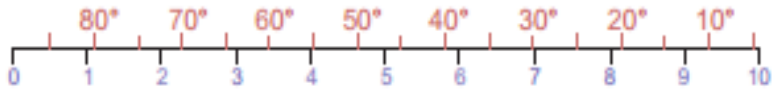

Anmerkung-

In der Literatur (Jenkinson et al, J Rheumatol 1994;21:1694-1698 und Jones et al, J Rheumatol 1996;22:1609) finden sich zwei verschiedene Definitionen des BASVI, die bei oleichen Messernebnissen zu unterschiedlicher

BASMI-Werten fuhren. Hier wird die 1995 veröffentlichte Definifion zugrunde gelegt, bei der jeder der fünf Messungen

ein Wert zwischen 0 und 10 zugeordnet wird. Während in den zitierten Arbeiten die Messwerte mit Hilfe von Tabellen

konvertiert werden, die nur ganzzahlige BASMiWerte bzw. geradzahlige Dezimalen zulassen, ermöglichen die hier

verwendeten Doppelskalen die Bidung analoger BASMHW Werte aus den analogen Messergebrissen.

\section{Deutsche Vereinigung Morbus Bechterew e.V.}

Ehrenamtlich gefuhrte Selbsthilfeorganisation

Metzgergasse 16, 97421 Schweinfurt, Tel. 09721 22033, Fax 0972122955

Homepage: www.bechterew.de - eMail: DVMB@bechterew.de 
Ablin JN, Goldstein Z, Aloush V, Matz H, Elkayam O, Caspi D, Swartzenberg S, George J, Wohl Y (2009): Normal levels and function of endothelial progenitor cells in patients with psoriatic arthritis. Rheumatol Int 29, 257-262

Aicher A, Heeschen C (2007): Nonbone marrow-derived endothelial progenitor cells: what is their exact location? Circ Res 101, e102

Amor B, Santos RS, Nahal R, Listrat V, Dougados M (1994): Predictive factors for the longterm outcome of spondyloarthropathies. J Rheumatol 21, 1883-1887

Asahara T, Murohara T, Sullivan A, Silver M, van der Zee R, Li T, Witzenbichler B, Schatteman G, Isner JM (1997): Isolation of putative progenitor endothelial cells for angiogenesis. Science $\underline{275}, 964-967$

Asahara T, Takahashi T, Masuda H, Kalka C, Chen D, Iwaguro H, Inai Y, Silver M, Isner JM (1999): VEGF contributes to postnatal neovascularization by mobilizing bone marrow-derived endothelial progenitor cells. EMBO J $\underline{18}, 3964-3972$

Azevedo VF, Pecoits-Filho R (2010): Atherosclerosis and endothelial dysfunction in patients with ankylosing spondylitis. Rheumatol Int $\underline{30}, 1411-1416$

Bakland G, Gran JT, Nossent JC (2011): Increased mortality in ankylosing spondylitis is related to disease activity. Ann Rheum Dis $\underline{70}, 1921-1925$

Balaji S, Han N, Moles C, Shaaban AF, Bollyky PL, Crombleholme TM, Keswani SG (2015): Angiopoietin-1 improves endothelial progenitor cell-dependent neovascularization in diabetic wounds. Surgery $\underline{158}, 846-856$

Ball EJ, Khan MA (2001): HLA-B27 polymorphism. Jt Bone Spine Rev Rhum $\underline{68}$, 378-382

Barkham N, Keen HI, Coates LC, O’Connor P, Hensor E, Fraser AD, Cawkwell LS, Bennett A, McGonagle D, Emery P (2009): Clinical and imaging efficacy of infliximab in HLA-B27-Positive patients with magnetic resonance imaging-determined early sacroiliitis. Arthritis Rheum $\underline{60}$, 946-954

Braun J, Sieper J (2007): Ankylosing spondylitis. Lancet Lond Engl 369, 1379-1390

Bremander A, Petersson IF, Bergman S, Englund M (2011): Population-based estimates of common comorbidities and cardiovascular disease in ankylosing spondylitis. Arthritis Care Res $\underline{63}, 550-556$

Brewerton DA, Hart FD, Nicholls A, Caffrey M, James DC, Sturrock RD (1973): Ankylosing spondylitis and HL-A 27. Lancet Lond Engl 1, 904-907

Brophy S, Calin A (2001): Ankylosing spondylitis: interaction between genes, joints, age at onset, and disease expression. J Rheumatol 28, 2283-2288

Brown MA (2009): Genetics and the Pathogenesis of Ankylosing Spondylitis. Curr Opin Rheumatol 21, 318-323 
Brunasso AMG, Massone C (2016): Update on the pathogenesis of Scleroderma: focus on circulating progenitor cells. F1000Research $\underline{5}$

Calin A, Marder A, Becks E, Burns T (1983): Genetic differences between B27 positive patients with ankylosing spondylitis and B27 positive healthy controls. Arthritis Rheum $\underline{26}, 1460-1464$

Calin A, Garrett S, Whitelock H, Kennedy LG, O’Hea J, Mallorie P, Jenkinson T (1994): A new approach to defining functional ability in ankylosing spondylitis: the development of the Bath Ankylosing Spondylitis Functional Index. J Rheumatol 21, 2281-2285

Chen J, Veras MMS, Liu C, Lin J (2013): Methotrexate for ankylosing spondylitis. Cochrane Database Syst Rev 2, CD004524

Chen T-G, Zhong Z-Y, Sun G-F, Zhou Y-X, Zhao Y (2011): Effects of tumour necrosis factor-alpha on activity and nitric oxide synthase of endothelial progenitor cells from peripheral blood. Cell Prolif $\underline{44}$, 352-359

Chung HY, Machado P, van der Heijde D, D’Agostino M-A, Dougados M (2012): Smokers in early axial spondyloarthritis have earlier disease onset, more disease activity, inflammation and damage, and poorer function and health-related quality of life: results from the DESIR cohort. Ann Rheum Dis $\underline{71}, 809-816$

Critser PJ, Yoder MC (2010): Endothelial colony-forming cell role in neoangiogenesis and tissue repair. Curr Opin Organ Transplant 15, 68-72

Cuadrado-Godia E, Regueiro A, Núñez J, Díaz-Ricard M, Novella S, Oliveras A, Valverde MA, Marrugat J, Ois A, Giralt-Steinhauer E, et al. (2015): Endothelial Progenitor Cells Predict Cardiovascular Events after Atherothrombotic Stroke and Acute Myocardial Infarction. A PROCELL Substudy. PLoS ONE $\underline{10}$

Dagfinrud H, Kvien TK, Hagen KB (2008): Physiotherapy interventions for ankylosing spondylitis. Cochrane Database Syst Rev CD002822

Deanfield JE, Halcox JP, Rabelink TJ (2007): Endothelial function and dysfunction: testing and clinical relevance. Circulation 115, 1285-1295

Divecha H, Sattar N, Rumley A, Cherry L, Lowe GDO, Sturrock R (2005): Cardiovascular risk parameters in men with ankylosing spondylitis in comparison with noninflammatory control subjects: relevance of systemic inflammation. Clin Sci Lond Engl 1979 109, 171-176

El Maghraoui A (2011): Extra-articular manifestations of ankylosing spondylitis: prevalence, characteristics and therapeutic implications. Eur J Intern Med 22, 554-560

Evrard SM, D'audigier C, Mauge L, Israël-Biet D, Guerin CL, Bieche I, Kovacic JC, Fischer A-M, Gaussem P, Smadja DM (2012): The profibrotic cytokine transforming growth factor- $\beta 1$ increases endothelial progenitor cell angiogenic properties. J Thromb Haemost $\underline{10}, 670-679$

Fang S, Salven P (2011): Stem cells in tumor angiogenesis. J Mol Cell Cardiol 50, 290-295 
Feldtkeller E, van der Heijde D: DVMB: Morbus Bechterew - Messwerte für den Krankheitsverlauf Klassifikations- und Diagnosekriterien. (Schriftenreihe der Deutschen Vereinigung Morbus Bechterew (DVMB) Heft 13); Schweinfurt 2005

Feldtkeller E, Khan MA, van der Heijde D, van der Linden S, Braun J (2003): Age at disease onset and diagnosis delay in HLA-B27 negative vs. positive patients with ankylosing spondylitis. Rheumatol Int $\underline{23}, 61-66$

Foresta C, Schipilliti M, De Toni L, Magagna S, Lancerotto L, Azzena B, Vindigni V, Mazzoleni F (2011): Blood levels, apoptosis, and homing of the endothelial progenitor cells after skin burns and escharectomy. J Trauma $\underline{70}$, 459-465

Garrett S, Jenkinson T, Kennedy LG, Whitelock H, Gaisford P, Calin A (1994): A new approach to defining disease status in ankylosing spondylitis: the Bath Ankylosing Spondylitis Disease Activity Index. J Rheumatol 21, 2286-2291

Gherghe AM, Dougados M, Combe B, Landewé R, Mihai C, Berenbaum F, Mariette X, Wolterbeek R, van der Heijde D (2015): Cardiovascular and selected comorbidities in early arthritis and early spondyloarthritis, a comparative study: results from the ESPOIR and DESIR cohorts. RMD Open $\underline{1}$, e000128

Golder V, Schachna L (2013): Ankylosing spondylitis: an update. Aust Fam Physician $\underline{42}$, 780-784

Gossec L, van der Heijde D, Melian A, Krupa DA, James MK, Cavanaugh PF, Reicin AS, Dougados M (2005): Efficacy of cyclo-oxygenase-2 inhibition by etoricoxib and naproxen on the axial manifestations of ankylosing spondylitis in the presence of peripheral arthritis. Ann Rheum Dis $\underline{64}, 1563-1567$

Grisar J, Aletaha D, Steiner CW, Kapral T, Steiner S, Seidinger D, Weigel G, Schwarzinger I, Wolozcszuk W, Steiner G, Smolen JS (2005): Depletion of Endothelial Progenitor Cells in the Peripheral Blood of Patients With Rheumatoid Arthritis. Circulation $\underline{111}$, 204-211

Groger A, Piatkowski A, Grieb G, Wolter TP, Fuchs PC, Pallua N (2010): The mobilisation of mononuclear cells and endothelial progenitor cells after burn injury in a porcine model. Burns J Int Soc Burn Inj $\underline{36}, 545-551$

Haroon N, Inman RD, Learch TJ, Weisman MH, Lee M, Rahbar MH, Ward MM, Reveille JD, Gensler LS (2013): The impact of tumor necrosis factor $\alpha$ inhibitors on radiographic progression in ankylosing spondylitis. Arthritis Rheum $\underline{65}, 2645-2654$

van der Heijde D, Landewé R, Feldtkeller E (2008): Proposal of a linear definition of the Bath Ankylosing Spondylitis Metrology Index (BASMI) and comparison with the 2-step and 10-step definitions. Ann Rheum Dis 67, 489-493

van der Heijde D, Lie E, Kvien TK, Sieper J, Van den Bosch F, Listing J, Braun J, Landewé R, Assessment of SpondyloArthritis international Society (ASAS) (2009): ASDAS, a highly discriminatory ASAS-endorsed disease activity score in patients with ankylosing spondylitis. Ann Rheum Dis $\underline{68}, 1811-1818$ 
Herbrig K, Haensel S, Oelschlaegel U, Pistrosch F, Foerster S, Passauer J (2006): Endothelial dysfunction in patients with rheumatoid arthritis is associated with a reduced number and impaired function of endothelial progenitor cells. Ann Rheum Dis $\underline{65}, 157-163$

Herold G: HEROLD Innere Medizin (2013). 2013

Herold M, Falkenbach A: Parameter zur Beurteilung von Krankheitsverlauf und Therapieerfolg; in: Falkenbach A: Morbus Bechterew: Beratung - Betreuung - Behandlung.; Springer-Verlag, Wien 2005, 83-104

Hill JM, Zalos G, Halcox JPJ, Schenke WH, Waclawiw MA, Quyyumi AA, Finkel T (2003): Circulating endothelial progenitor cells, vascular function, and cardiovascular risk. $\mathrm{N}$ Engl J Med 348, 593-600

Hirschi KK, Ingram DA, Yoder MC (2008): Assessing identity, phenotype, and fate of endothelial progenitor cells. Arterioscler Thromb Vasc Biol 28, 1584-1595

Hoetzer GL, MacEneaney OJ, Irmiger HM, Keith R, Van Guilder GP, Stauffer BL, DeSouza CA (2007): Gender differences in circulating endothelial progenitor cell colonyforming capacity and migratory activity in middle-aged adults. Am J Cardiol 99, 4648

Holdsworth R, Hurley CK, Marsh SGE, Lau M, Noreen HJ, Kempenich JH, Setterholm M, Maiers M (2009): The HLA dictionary 2008: a summary of HLA-A, -B, -C, DRB1/3/4/5, and -DQB1 alleles and their association with serologically defined HLAA, -B, -C, -DR, and -DQ antigens. Tissue Antigens $\underline{73}, 95-170$

van der Horst-Bruinsma IE, Nurmohamed MT (2012): Management and evaluation of extraarticular manifestations in spondyloarthritis. Ther Adv Musculoskelet Dis $\underline{4}$, 413-422

Hristov M, Fach C, Becker C, Heussen N, Liehn EA, Blindt R, Hanrath P, Weber C (2007): Reduced numbers of circulating endothelial progenitor cells in patients with coronary artery disease associated with long-term statin treatment. Atherosclerosis $\underline{192}, 413-$ 420

Huang P-H, Chen Y-H, Tsai H-Y, Chen J-S, Wu T-C, Lin F-Y, Sata M, Chen J-W, Lin S-J (2010): Intake of red wine increases the number and functional capacity of circulating endothelial progenitor cells by enhancing nitric oxide bioavailability. Arterioscler Thromb Vasc Biol 30, 869-877

Huang Y-P, Wang Y-H, Pan S-L (2013): Increased Risk of Ischemic Heart Disease in Young Patients with Newly Diagnosed Ankylosing Spondylitis - A Population-Based Longitudinal Follow-Up Study. PLoS ONE $\underline{8}$, e64155

Hur J, Yoon C-H, Kim H-S, Choi J-H, Kang H-J, Hwang K-K, Oh B-H, Lee M-M, Park Y-B (2004): Characterization of two types of endothelial progenitor cells and their different contributions to neovasculogenesis. Arterioscler Thromb Vasc Biol 24, 288-293

Ingram DA, Mead LE, Moore DB, Woodard W, Fenoglio A, Yoder MC (2005): Vessel wallderived endothelial cells rapidly proliferate because they contain a complete hierarchy of endothelial progenitor cells. Blood 105, 2783-2786 
Ito H, Rovira II, Bloom ML, Takeda K, Ferrans VJ, Quyyumi AA, Finkel T (1999): Endothelial progenitor cells as putative targets for angiostatin. Cancer Res $\underline{59}, 5875-5877$

Iwakura A, Shastry S, Luedemann C, Hamada H, Kawamoto A, Kishore R, Zhu Y, Qin G, Silver M, Thorne T, et al. (2006): Estradiol enhances recovery after myocardial infarction by augmenting incorporation of bone marrow-derived endothelial progenitor cells into sites of ischemia-induced neovascularization via endothelial nitric oxide synthasemediated activation of matrix metalloproteinase-9. Circulation $\underline{113}, 1605-1614$

Jie KE, Goossens MHJ, van Oostrom O, Lilien MR, Verhaar MC (2009): Circulating endothelial progenitor cell levels are higher during childhood than in adult life. Atherosclerosis 202, 345-347

Jones SD, Steiner A, Garrett SL, Calin A (1996): The Bath Ankylosing Spondylitis Patient Global Score (BAS-G). Br J Rheumatol 35, 66-71

Kalka C, Asahara T, Krone W, Isner JM (2000): [Angiogenesis and vasculogenesis. Therapeutic strategies for stimulation of postnatal neovascularization]. Herz $\underline{25}$, 611-622

Karberg K, Zochling J, Sieper J, Felsenberg D, Braun J (2005): Bone loss is detected more frequently in patients with ankylosing spondylitis with syndesmophytes. J Rheumatol $\underline{32}, 1290-1298$

Khakoo AY, Finkel T (2005): Endothelial progenitor cells. Annu Rev Med 56, 79-101

Korta K, Kupczyk P, Skóra J, Pupka A, Zejler P, Hołysz M, Gajda M, Nowakowska B, Barć P, Dorobisz AT, et al. (2013): [Stem and progenitor cells in biostructure of blood vessel walls]. Postępy Hig Med Dośw Online 67, 982-995

Kraag G, Stokes B, Groh J, Helewa A, Goldsmith C (1990): The effects of comprehensive home physiotherapy and supervision on patients with ankylosing spondylitis--a randomized controlled trial. J Rheumatol $\underline{17}, 228-233$

Laufs U, Urhausen A, Werner N, Scharhag J, Heitz A, Kissner G, Böhm M, Kindermann W, Nickenig G (2005): Running exercise of different duration and intensity: effect on endothelial progenitor cells in healthy subjects. Eur J Cardiovasc Prev Rehabil Off J Eur Soc Cardiol Work Groups Epidemiol Prev Card Rehabil Exerc Physiol 12, 407-414

Lin Y, Weisdorf DJ, Solovey A, Hebbel RP (2000): Origins of circulating endothelial cells and endothelial outgrowth from blood. J Clin Invest $\underline{105}, 71-77$

Llevadot J, Murasawa S, Kureishi Y, Uchida S, Masuda H, Kawamoto A, Walsh K, Isner JM, Asahara T (2001): HMG-CoA reductase inhibitor mobilizes bone marrow--derived endothelial progenitor cells. J Clin Invest 108, 399-405

Machado P, Landewé R, Lie E, Kvien TK, Braun J, Baker D, van der Heijde D, Assessment of SpondyloArthritis international Society (2011): Ankylosing Spondylitis Disease Activity Score (ASDAS): defining cut-off values for disease activity states and improvement scores. Ann Rheum Dis $\underline{70}$, 47-53

Manger B, Schulze-Koops H: Checkliste Rheumatologie. 4. Auflage; Thieme, Stuttgart 2012 
Martin TM, Smith JR, Rosenbaum JT (2002): Anterior uveitis: current concepts of pathogenesis and interactions with the spondyloarthropathies. Curr Opin Rheumatol 14, 337 341

Mayr M, Niederseer D, Niebauer J (2011): From bench to bedside: what physicians need to know about endothelial progenitor cells. Am J Med 124, 489-497

McGonagle D, Gibbon W, O’Connor P, Green M, Pease C, Emery P (1998): Characteristic magnetic resonance imaging entheseal changes of knee synovitis in spondylarthropathy. Arthritis Rheum 41, 694-700

Mehta NN, Azfar RS, Shin DB, Neimann AL, Troxel AB, Gelfand JM (2010): Patients with severe psoriasis are at increased risk of cardiovascular mortality: cohort study using the General Practice Research Database. Eur Heart J $\underline{31}$, 1000-1006

Moody R: Paleopathology. An introduction to the study of ancient evidences of disease.; University of Chicago Press, Chicago 1923, p128

Moyssakis I, Gialafos E, Vassiliou VA, Boki K, Votteas V, Sfikakis PP, Tzelepis GE (2009): Myocardial performance and aortic elasticity are impaired in patients with ankylosing spondylitis. Scand J Rheumatol $\underline{38}, 216-221$

Ostendorf B, Hettenkofer H, Kellner H, Schneider M: Klinische Untersuchung; in: Rheumatologie: Diagnostik - Klinik - Therapie., 6. Auflage; Georg Thieme Verlag, Heidelberg 2014, 38-49

Park Y-J, Kim J-Y, Park J, Choi J-J, Kim W-U, Cho C-S (2014): Bone erosion is associated with reduction of circulating endothelial progenitor cells and endothelial dysfunction in rheumatoid arthritis. Arthritis Rheumatol Hoboken NJ $\underline{66}, 1450-1460$

Patschan D, Krupincza K, Patschan S, Zhang Z, Hamby C, Goligorsky MS (2006): Dynamics of mobilization and homing of endothelial progenitor cells after acute renal ischemia: modulation by ischemic preconditioning. Am J Physiol Renal Physiol 291, F176-185

Patschan S, Patschan D, Potulski M, Henze E, Scholze J, Müller GA (2013): Endothelial progenitor cells in systemic lupus erythematosus. J Nephrol 26, 1065-1072

Patschan S, Nemirovsky K, Henze E, Scholze J, Müller GA, Patschan D (2014): Tocilizumab increases EPC regeneration in rheumatoid arthritis. Scand J Rheumatol $\underline{43}, 528-530$

Peichev M, Naiyer AJ, Pereira D, Zhu Z, Lane WJ, Williams M, Oz MC, Hicklin DJ, Witte L, Moore MA, Rafii S (2000): Expression of VEGFR-2 and AC133 by circulating human CD34(+) cells identifies a population of functional endothelial precursors. Blood $\underline{95}$, 952-958

Peters MJ, van der Horst-Bruinsma IE, Dijkmans BA, Nurmohamed MT (2004): Cardiovascular risk profile of patients with spondylarthropathies, particularly ankylosing spondylitis and psoriatic arthritis. Semin Arthritis Rheum 34, 585-592

Pfaff D, Fiedler U, Augustin HG (2006): Emerging roles of the Angiopoietin-Tie and the ephrin-Eph systems as regulators of cell trafficking. J Leukoc Biol 무, 719-726 
Piatkowski A, Grieb G, Simons D, Bernhagen J, van der Hulst RR (2013): Endothelial progenitor cells--potential new avenues to improve neoangiogenesis and reendothelialization. Int Rev Cell Mol Biol 306, 43-81

Poddubnyĭ DA, Gă̌dukova IZ, Rebrov AP (2009): [Heart rate variability in patients with ankylosing spondilitis (Bekhterev's disease)]. Ter Arkhiv ㅁ1, 56-62

Prater DN, Case J, Ingram DA, Yoder MC (2007): Working hypothesis to redefine endothelial progenitor cells. Leukemia $21,1141-1149$

Prati C, Claudepierre P, Pham T, Wendling D (2011): Mortality in spondylarthritis. Jt Bone Spine Rev Rhum $\underline{78}$, 466-470

Pschyrembel W: Pschyrembel® Klinisches Wörterbuch. 260. Auflage; de Gruyter, Berlin 2007

Puchner R: Rheumatologie aus der Praxis: Ein Kurzlehrbuch der entzündlichen Gelenkerkrankungen mit Fallbeispielen. Springer-Verlag 2012

Reed MD, Dharmage S, Boers A, Martin BJ, Buchanan RR, Schachna L (2008): Ankylosing spondylitis: an Australian experience. Intern Med J $\underline{38}, 321-327$

Rehman J, Li J, Orschell CM, March KL (2003): Peripheral blood „endothelial progenitor cells" are derived from monocyte/macrophages and secrete angiogenic growth factors. Circulation 107, 1164-1169

Robinson PC, Brown MA (2014): Genetics of ankylosing spondylitis. Mol Immunol 구, 2-11

Rojas-Vargas M, Muñoz-Gomariz E, Escudero A, Font P, Zarco P, Almodovar R, Gratacós J, Mulero J, Juanola X, Montilla C, et al. (2009): First signs and symptoms of spondyloarthritis--data from an inception cohort with a disease course of two years or less (REGISPONSER-Early). Rheumatol Oxf Engl 48, 404-409

Rosenbaum JT (1992): Acute anterior uveitis and spondyloarthropathies. Rheum Dis Clin North Am $\underline{18}, 143-151$

Rossini M, Viapiana O, Adami S, Idolazzi L, Fracassi E, Gatti D (2016): Focal bone involvement in inflammatory arthritis: the role of IL17. Rheumatol Int $\underline{36}, 469-482$

Rössner S (1978): Further studies on serum lipoproteins in connective tissue diseases. Atherosclerosis $\underline{31}, 93-99$

Rudwaleit M, Sieper J (2005): [Early diagnosis of spondyloarthritis with special attention to the axial forms]. Z Für Rheumatol $\underline{64}$, 524-530

Rudwaleit M, van der Heijde D, Khan MA, Braun J, Sieper J (2004): How to diagnose axial spondyloarthritis early. Ann Rheum Dis $\underline{63}$, 535-543

Rudwaleit M, Metter A, Listing J, Sieper J, Braun J (2006): Inflammatory back pain in ankylosing spondylitis: a reassessment of the clinical history for application as classification and diagnostic criteria. Arthritis Rheum 54, 569-578 
Rudwaleit M, Landewé R, van der Heijde D, Listing J, Brandt J, Braun J, Burgos-Vargas R, Collantes-Estevez E, Davis J, Dijkmans B, et al. (2009a): The development of Assessment of SpondyloArthritis international Society classification criteria for axial spondyloarthritis (part I): classification of paper patients by expert opinion including uncertainty appraisal. Ann Rheum Dis $\underline{68}, 770-776$

Rudwaleit M, van der Heijde D, Landewé R, Listing J, Akkoc N, Brandt J, Braun J, Chou CT, Collantes-Estevez E, Dougados M, et al. (2009b): The development of Assessment of SpondyloArthritis international Society classification criteria for axial spondyloarthritis (part II): validation and final selection. Ann Rheum Dis $\underline{68}, 777-783$

Rudwaleit M, van der Heijde D, Landewé R, Akkoc N, Brandt J, Chou CT, Dougados M, Huang F, Gu J, Kirazli Y, et al. (2011): The Assessment of SpondyloArthritis International Society classification criteria for peripheral spondyloarthritis and for spondyloarthritis in general. Ann Rheum Dis $\underline{70}$, 25-31

Sampaio-Barros PD, Bortoluzzo AB, Conde RA, Costallat LTL, Samara AM, Bértolo MB (2010): Undifferentiated spondyloarthritis: a longterm followup. J Rheumatol $\underline{37}$, 1195-1199

Sari I, Okan T, Akar S, Cece H, Altay C, Secil M, Birlik M, Onen F, Akkoc N (2006): Impaired endothelial function in patients with ankylosing spondylitis. Rheumatol Oxf Engl $\underline{45}, 283-286$

Schuh A, Liehn EA, Sasse A, Hristov M, Sobota R, Kelm M, Merx MW, Weber C (2008): Transplantation of endothelial progenitor cells improves neovascularization and left ventricular function after myocardial infarction in a rat model. Basic Res Cardiol 103 , 69-77

Shaw AT, Gravallese EM (2016): Mediators of inflammation and bone remodeling in rheumatic disease. Semin Cell Dev Biol $\underline{49}, 2-10$

Shoenfeld Y (2017): The Heart in Rheumatic, Autoimmune and Inflammatory Diseases: Pathophysiology, Clinical Aspects and Therapeutic Approaches, 1st edition. Isr Med Assoc J IMAJ 19, 395-396

Sieper J: Immunologie und Pathogenese; in: Falkenbach A: Morbus Bechterew: Beratung Betreuung - Behandlung.; Springer-Verlag 2005

Sieper J, Braun J: Clinician's Manual on Ankylosing Spondylitis | Joachim Sieper | Springer. 1. Auflage; Springer Healthcare, Berlin 2014

Sieper J, van der Heijde D, Landewé R, Brandt J, Burgos-Vagas R, Collantes-Estevez E, Dijkmans B, Dougados M, Khan MA, Leirisalo-Repo M, et al. (2009): New criteria for inflammatory back pain in patients with chronic back pain: a real patient exercise by experts from the Assessment of SpondyloArthritis international Society (ASAS). Ann Rheum Dis $\underline{68}, 784-788$

Sieveking DP, Buckle A, Celermajer DS, Ng MKC (2008): Strikingly different angiogenic properties of endothelial progenitor cell subpopulations: insights from a novel human angiogenesis assay. J Am Coll Cardiol 51, 660-668 
Slobodin G, Reyhan I, Avshovich N, Balbir-Gurman A, Boulman N, Elias M, Feld J, Mader R, Markovitz D, Rimar D, et al. (2011): Recently diagnosed axial spondyloarthritis: gender differences and factors related to delay in diagnosis. Clin Rheumatol $\underline{30}, 1075$ 1080

Slobodin G, Rosner I, Rimar D, Boulman N, Rozenbaum M, Odeh M (2012): Ankylosing spondylitis: field in progress. Isr Med Assoc J IMAJ 14, 763-767

Sobrino T, Hurtado O, Moro MA, Rodríguez-Yáñez M, Castellanos M, Brea D, Moldes O, Blanco M, Arenillas JF, Leira R, et al. (2007): The increase of circulating endothelial progenitor cells after acute ischemic stroke is associated with good outcome. Stroke J Cereb Circ 38, 2759-2764

Spoorenberg A, van der Heijde D, de Klerk E, Dougados M, de Vlam K, Mielants H, van der Tempel H, van der Linden S (1999): Relative value of erythrocyte sedimentation rate and C-reactive protein in assessment of disease activity in ankylosing spondylitis. J Rheumatol 26, 980-984

Steiner S, Niessner A, Ziegler S, Richter B, Seidinger D, Pleiner J, Penka M, Wolzt M, Huber $\mathrm{K}$, Wojta J, et al. (2005): Endurance training increases the number of endothelial progenitor cells in patients with cardiovascular risk and coronary artery disease. Atherosclerosis $\underline{181}, 305-310$

Szabo SM, Levy AR, Rao SR, Kirbach SE, Lacaille D, Cifaldi M, Maksymowych WP (2011): Increased risk of cardiovascular and cerebrovascular diseases in individuals with ankylosing spondylitis: A population-based study. Arthritis Rheum 63, 3294-3304

Taurog JD, Richardson JA, Croft JT, Simmons WA, Zhou M, Fernández-Sueiro JL, Balish E, Hammer RE (1994): The germfree state prevents development of gut and joint inflammatory disease in HLA-B27 transgenic rats. J Exp Med 180, 2359-2364

Taurog JD, Dorris ML, Satumtira N, Tran TM, Sharma R, Dressel R, van den Brandt J, Reichardt HM (2009): Spondylarthritis in HLA-B27/human beta2-microglobulintransgenic rats is not prevented by lack of CD8. Arthritis Rheum $\underline{60}, 1977-1984$

Timmermans F, Plum J, Yöder MC, Ingram DA, Vandekerckhove B, Case J (2009): Endothelial progenitor cells: identity defined? J Cell Mol Med 13, 87-102

Tura O, Crawford J, Barclay GR, Samuel K, Hadoke PWF, Roddie H, Davies J, Turner ML (2010): Granulocyte colony-stimulating factor (G-CSF) depresses angiogenesis in vivo and in vitro: implications for sourcing cells for vascular regeneration therapy. J Thromb Haemost JTH $\underline{8}, 1614-1623$

Urbich C, Dimmeler S (2004): Endothelial progenitor cells: characterization and role in vascular biology. Circ Res 95, 343-353

Urbich C, Dimmeler S (2005): Risk factors for coronary artery disease, circulating endothelial progenitor cells, and the role of HMG-CoA reductase inhibitors. Kidney Int 67, 16721676 
Vasa M, Fichtlscherer S, Aicher A, Adler K, Urbich C, Martin H, Zeiher AM, Dimmeler S (2001): Number and migratory activity of circulating endothelial progenitor cells inversely correlate with risk factors for coronary artery disease. Circ Res $\underline{89}$, E1-7

Verma I, Syngle A, Krishan P (2015): Endothelial progenitor cell biology in ankylosing spondylitis. Int J Rheum Dis $\underline{18}$, 336-340

Vosse D, de Vlam K (2009): Osteoporosis in rheumatoid arthritis and ankylosing spondylitis. Clin Exp Rheumatol 27, S62-67

Walter DH, Rittig K, Bahlmann FH, Kirchmair R, Silver M, Murayama T, Nishimura H, Losordo DW, Asahara T, Isner JM (2002): Statin therapy accelerates reendothelialization: a novel effect involving mobilization and incorporation of bone marrow-derived endothelial progenitor cells. Circulation 105, 3017-3024

Walther C, Adams V, Bothur I, Drechsler K, Fikenzer S, Sonnabend M, Bublitz B, Körner A, Erbs S, Busse M, Schuler G (2008): Increasing physical education in high school students: effects on concentration of circulating endothelial progenitor cells. Eur J Cardiovasc Prev Rehabil Off J Eur Soc Cardiol Work Groups Epidemiol Prev Card Rehabil Exerc Physiol 15, 416-422

Wanders A, Heijde D van der, Landewé R, Béhier J-M, Calin A, Olivieri I, Zeidler H, Dougados M (2005): Nonsteroidal antiinflammatory drugs reduce radiographic progression in patients with ankylosing spondylitis: a randomized clinical trial. Arthritis Rheum $\underline{52}$, 1756-1765

Werling NJ, Thorpe R, Zhao Y (2013): A systematic approach to the establishment and characterization of endothelial progenitor cells for gene therapy. Hum Gene Ther Methods 24, 171-184

Westerweel PE, Verhaar MC (2009): Endothelial progenitor cell dysfunction in rheumatic disease. Nat Rev Rheumatol ㅁ, 332-340

Westerweel PE, Luijten RKMAC, Hoefer IE, Koomans HA, Derksen RHWM, Verhaar MC (2007): Haematopoietic and endothelial progenitor cells are deficient in quiescent systemic lupus erythematosus. Ann Rheum Dis $\underline{66}, 865-870$

Wyler von Ballmoos M, Yang Z, Völzmann J, Baumgartner I, Kalka C, Di Santo S (2010): Endothelial Progenitor Cells Induce a Phenotype Shift in Differentiated Endothelial Cells towards PDGF/PDGFR $\beta$ Axis-Mediated Angiogenesis. PLoS ONE 5, e14107

Xu S, Zhao Y, Yu L, Shen X, Ding F, Fu G (2011): Rosiglitazone attenuates endothelial progenitor cell apoptosis induced by TNF- $\alpha$ via ERK/MAPK and NF- $\kappa B$ signal pathways. J Pharmacol Sci 117, 265-274

Yoder MC (2012): Human endothelial progenitor cells. Cold Spring Harb Perspect Med $\underline{2}$, a006692

Yoder MC (2013): Endothelial progenitor cell: a blood cell by many other names may serve similar functions. J Mol Med Berl Ger 91, 285-295 
Yoder MC, Mead LE, Prater D, Krier TR, Mroueh KN, Li F, Krasich R, Temm CJ, Prchal JT, Ingram DA (2007): Redefining endothelial progenitor cells via clonal analysis and hematopoietic stem/progenitor cell principals. Blood 109, 1801-1809

Yoon C-H, Hur J, Park K-W, Kim J-H, Lee C-S, Oh I-Y, Kim T-Y, Cho H-J, Kang H-J, Chae $\mathrm{I}-\mathrm{H}$, et al. (2005): Synergistic neovascularization by mixed transplantation of early endothelial progenitor cells and late outgrowth endothelial cells: the role of angiogenic cytokines and matrix metalloproteinases. Circulation 112, 1618-1627

Zaccone V, Flore R, Santoro L, De Matteis G, Giupponi B, Li Puma DD, Santoliquido A (2015): Focus on biological identity of endothelial progenitors cells. Eur Rev Med Pharmacol Sci $\underline{19}$, 4047-4063

Zhang B, Niu P, Li H, Jia S (2013): [Endothelial progenitor cells: the new target of antiatherosclerosis drugs]. Zhong Nan Da Xue Xue Bao Yi Xue Ban $\underline{38}$, 307-312

Zochling J, van der Heijde D, Burgos-Vargas R, Collantes E, Davis JC, Dijkmans B, Dougados M, Géher P, Inman RD, Khan MA, et al. (2006): ASAS/EULAR recommendations for the management of ankylosing spondylitis. Ann Rheum Dis $\underline{65}$, $442-452$

Zorab PA (1961): The historical and prehistorical background of ankylosing spondylitis. Proc R Soc Med 노, 415-420

Internetquellen:

http://www.asas-group.org/clinical-instruments/asdas_calculator/asdas.html; $\quad$ Zugriff am 04.10.2017 


\section{Lebenslauf}

Ich, Maria Elisabeth Vogt, geborene Struve, wurde am 29.05.1985 in Frankfurt an der Oder geboren. Seit 2014 bin ich mit Carsten Vogt verheiratet. Unsere Töchter kamen 2013 und 2015 zur Welt. Mein schulischer Werdegang begann 1991 in Düsseldorf. 2004 machte ich in Wuppertal das Abitur. Anschließend absolvierte ich ein freiwilliges soziales Jahr auf den Philippinen. Im April 2006 begann ich das Zahnmedizinstudium an der Westfälischen Wilhelms-Universität Münster. Im Oktober 2007 wechselte ich den Studiengang und begann das Humanmedizistudium an der Johannes Gutenberg-Universität in Mainz. Dieses beendete ich im Mai 2013 an der Georg-August-Universität in Göttingen. Aktuell arbeite ich seit September 2014 als Assistenzärztin in der Pädiatrie des christlichen Kinderhospitals Osnabrück. 